Aus dem Institut für Pathologie

(Prof. Dr. med. P. Ströbel)

der Medizinischen Fakultät der Universität Göttingen

\title{
Untersuchungen zu Veränderungen der extrazellulären Matrix beim Reinke-Ödem
}

\author{
INAUGURAL-DISSERTATION \\ zur Erlangung des Doktorgrades \\ für Zahnheilkunde \\ der Medizinischen Fakultät der \\ Georg-August-Universität zu Göttingen
}

vorgelegt von

Wolfgang Koenig

aus

Bamberg

Göttingen 2019 
Dekan:

Referent/in

Ko-Referent/in:

Drittreferent/in:
Prof. Dr. rer. nat. H. K. Kroemer

Prof. Dr. med. H. J. Radzun

PD Dr. Dr. Alexander Meyer

Prof. Dr. Rainer Mausberg

Datum der mündlichen Prüfung: 05.10.2020 
Hiermit erkläre ich, die Dissertation mit dem Titel "Untersuchungen zu Veränderungen der extrazellulären Matrix beim Reinke-Ödem“ eigenständig angefertigt und keine anderen als die von mir angegebenen Quellen und Hilfsmittel verwendet zu haben.

Göttingen, den

(Unterschrift) 


\section{Inhaltsverzeichnis}

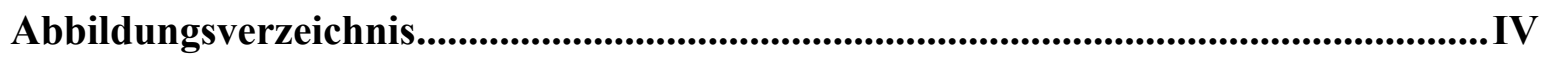

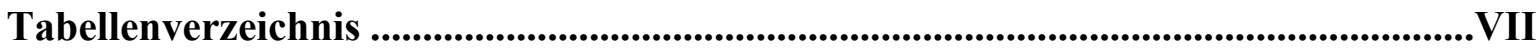

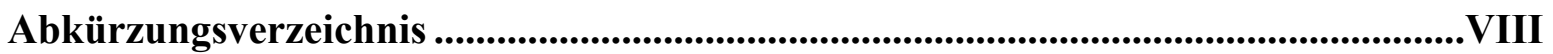

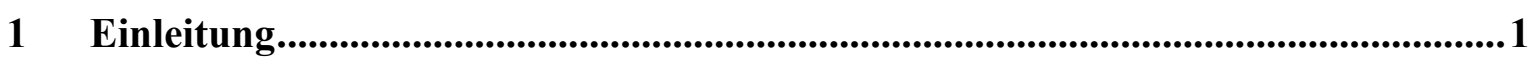

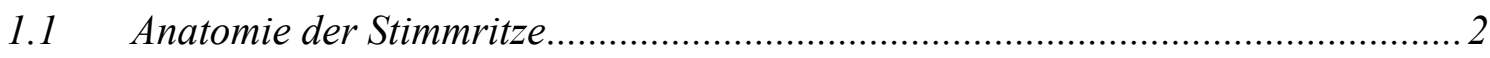

1.2 Histologie der Stimmlippenschleimhaut ............................................................. 3

1.3 Die extrazellulare Matrix der Lamina propria ................................................. 3

1.3.1 Kollagen in der Lamina propria ............................................................. 4

1.3.2 Die Aufgabe der Matrixmetalloproteinasen............................................... 6

1.3.3 Rolle der Hyaluronsäure in der Lamina propria ........................................ 6

1.3.4 Rolle der elastischen Fasern in der Lamina propria .................................. 7

$1.4 \quad$ Klinik und Ätiologie des Reinke-Ödems ............................................................. 7

1.4.1 Anamnestischer und makroskopischer Befund....................................... 7

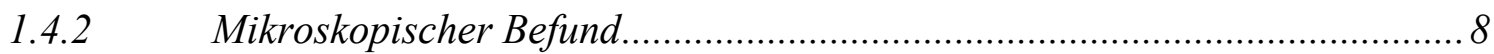

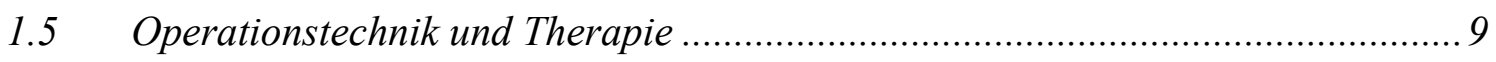

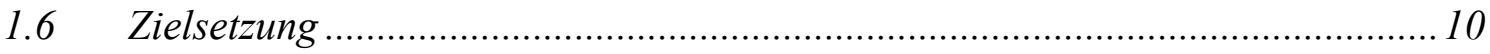

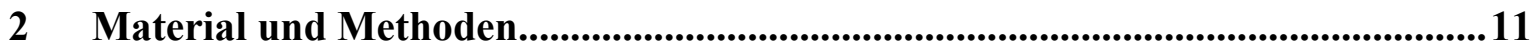

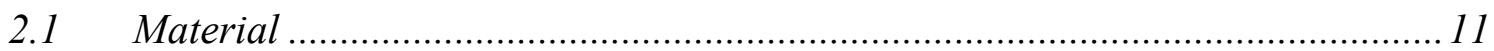

2.1.1 Zusammensetzung des Gewebekollektivs für die lichtmikroskopischen Untersuchungen ........................................................................................ 11

2.1.2 Zusammensetzung des Gewebekollektivs für die Nukleinsäureanalytik ...... 11

2.1.3 Verwendete Materialien ...................................................................... 12

2.1.4 Verwendete chemische Substanzen .......................................................... 13

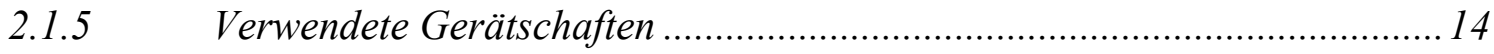

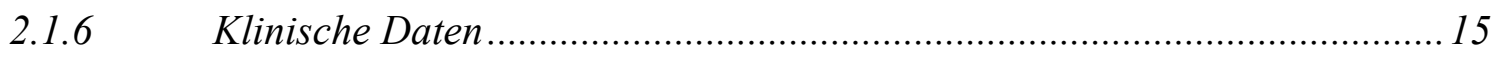

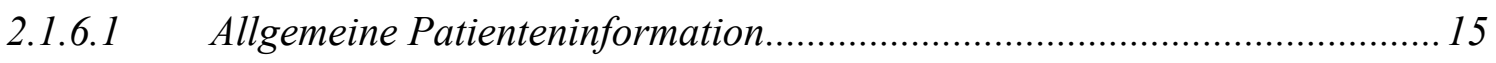

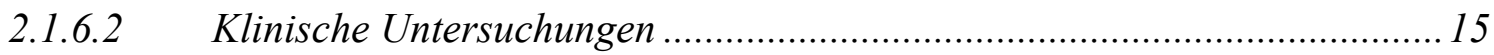

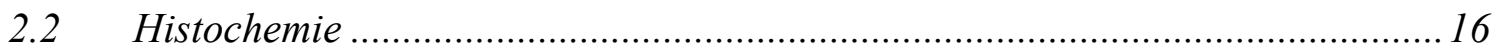




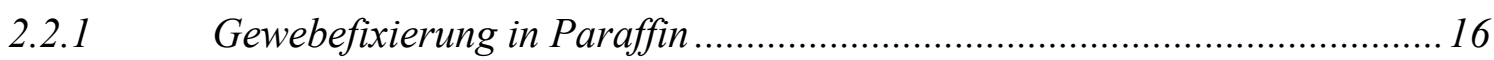

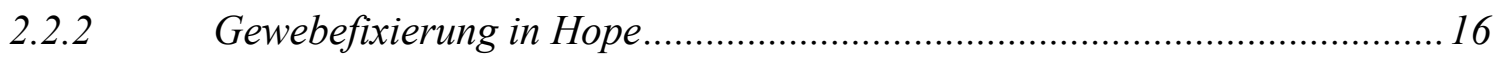

2.2.3 Herstellung von Gewebeschnittpräparaten .......................................... 17

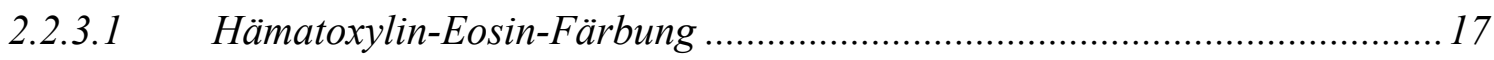

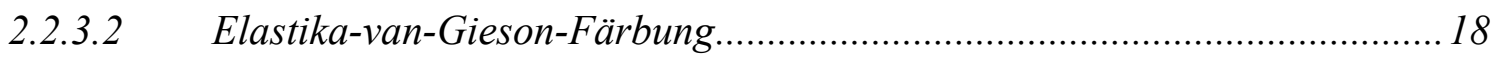

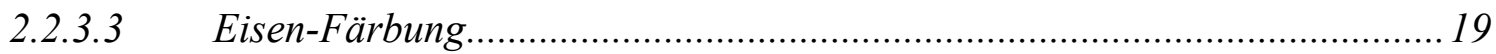

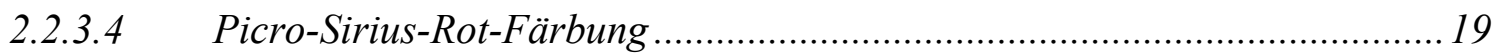

2.2.3.5 Alcianblau-Färbung und Hyaluronsäure-Verdau .....................................20

2.2.3.6 Immunhistochemie mit dem Antikörper CD34 zur Gefäßdarstellung.......... 21

2.3 Quantitative Bestimmung der Ribonukleinsäure-Expression .............................2 21

2.3.1 Entparaffinierung und Ribonukleinsäure-Isolierung ................................21

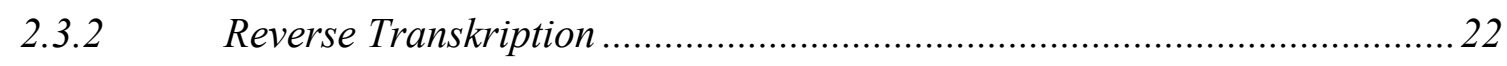

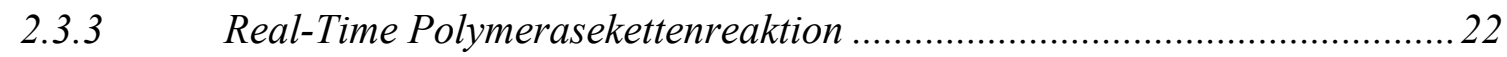

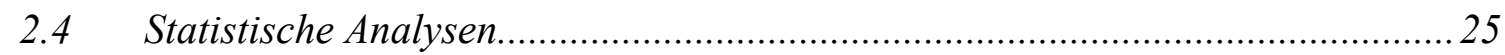

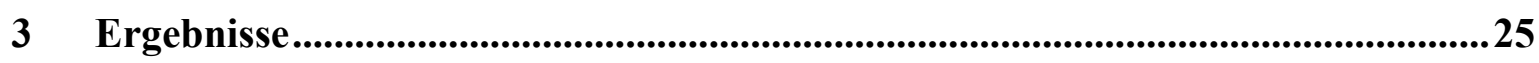

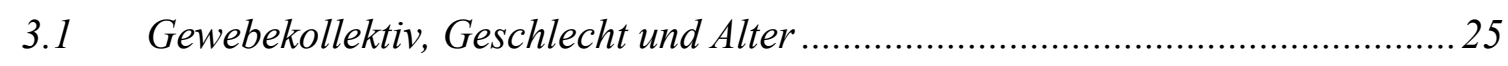

3.2 Klinischer und histologischer Befund der Stimmlippe, Rauchverhalten und Risikofaktoren bei RE-Patienten............................................................. 26

3.3 Untersuchungen der Hyaluronsäure in der Lamina propria .............................2 28

3.4 Untersuchungen der Kollagenfasern in der Lamina propria .............................. 30

3.5 Untersuchungen der elastischen Fasern in der Lamina propria..........................36

3.6 Untersuchungen der epithelialen Deckschicht der Lamina propria ................... 39

3.7 Untersuchungen der vaskulären Struktur ....................................................... 41

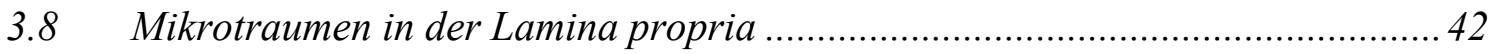

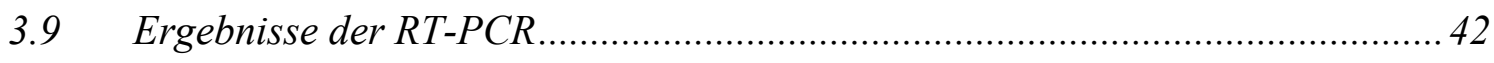

3.9.1 Hyaluronsynthasen HAS-1, HAS-2 und HAS-3.................................. 43

3.9.2 Hyaluronidasen Hyal-1 und Hyal-2 .................................................. 43

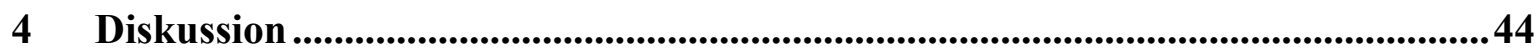

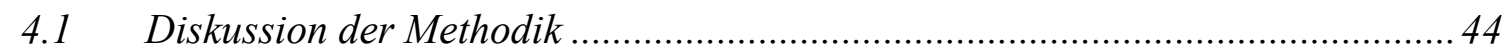

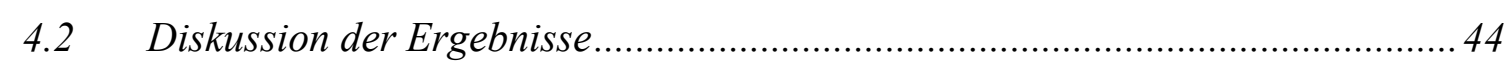

4.2.1 Der Hyaluronsäurehaushalt beim Reinke-Ödem ........................................ 44 
4.2.2 Kollagenfaserqualität und -quantität beim Reinke-Ödem ........................... 47

4.2.3 Veränderung der elastischen Fasern beim Reinke-Ödem............................. 48

4.2.4 Veränderungen an der Epithelschicht und Basalmembran beim

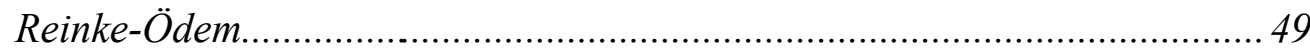

4.2.5 Vaskuläre Strukturen im Stimmlippengewebe ...............................................50

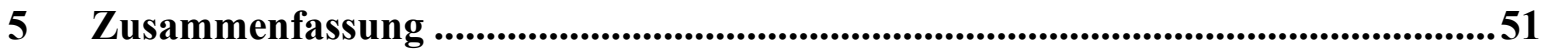

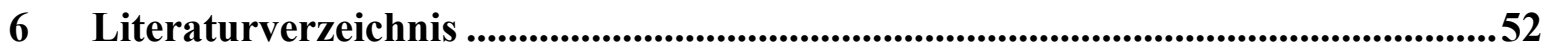




\section{Abbildungsverzeichnis}

Abbildung 1: Kehlkopfetagen (links) und Querschnitt der Glottis (rechts) 2

Abbildung 2: Schematische Darstellung eines coronalen Schnittes durch eine

Stimmlippe mit ihrer mikroanatomischen Struktur 3

Abbildung 3: Schematische Darstellung des Kollagennetzwerks in der LP eines Neugeborenen

Abbildung 4: Schematische Darstellung der adulten SL mit der Anordnung der Kollagenfasern in den einzelnen Schichten der LP 5

Abbildung 5: Übersichtsaufnahme eines RE-Gewebeschnitts in HE-Färbung mit großflächiger Faserdestruktion in 10x Vergrößerung 8

Abbildung 6: Destruktion der architektonischen Struktur der Kollagenfasern 9

Abbildung 7: Direkte Laryngoskopie mit Vergrößerung durch das Operationsmikroskop und abgestütztes Operationslaryngoskop 10

Abbildung 8: Schema normale SL (eigene Zeichnung) .................................................. 16

Abbildung 9: Schema Ödem Grad I (eigene Zeichnung) ................................................ 16

Abbildung 10: Schema Ödem Grad II (eigene Zeichnung) ............................................ 16

Abbildung 11: Schema Ödem Grad III (eigene Zeichnung) ............................................ 16

Abbildung 12: Verteilung des klinischen Befundes bei Patienten mit einem Reinke-Ödem

Abbildung 13: Histologisches Ödemausmaß für die obere und mittlere LP bei den Reinke-Ödem Patienten

Abbildung 14: Reinke-Ödem mit 10x Vergrößerung in HE-Färbung .....

Abbildung 15: Rauchverhalten der RE-Patienten.

Abbildung 16: Reinke-Ödem in 10x Vergrößerung und Alcianblau-Färbung mit und ohne Verdau.

Abbildung 17: Stimmlippenpolyp in 10x Vergrößerung und Alcianblau-Färbung mit und ohne Verdau.

Abbildung 18: Verteilung der HA in der LP im Medianwert

Abbildung 19: Geschlechtsspezifische Verteilung der HA in der LP bei Patienten mit RE 30

Abbildung 20: Altersabhängige Verteilung der HA in der mittleren LP 30

Abbildung 21: Kollagenfaserdichte in der oberen LP bei RE- und N-RE-Patienten 31 
Abbildung 22: Kollagenfaserdichte in der mittleren LP bei RE- und

N-RE-Patienten

Abbildung 23: Vernetzung der Kollagenfasern in der oberen LP bei RE- und

N-RE-Patienten

Abbildung 24: Vernetzung der Kollagenfasern in der mittleren LP bei RE- und

N-RE-Patienten

Abbildung 25: Verteilung der Kollagenfasern Typ I in der oberen LP bei REund N-RE-Patienten

Abbildung 26: Verteilung der Kollagenfasern Typ I in der mittleren LP bei REund N-RE-Patienten

Abbildung 27: Verteilung der Kollagenfasern Typ III in der oberen LP bei REund N-RE-Patienten

Abbildung 28: Verteilung der Kollagenfasern Typ III in der mittleren LP bei REund N-RE-Patienten

Abbildung 29: Übersichtsaufnahme der Kollagenfasern eines RE

und einer Leukoplakie in 10x Vergrößerung und Sirius-Red-Färbung

Abbildung 30: Kollagentyp I und Kollagen Typ III beim RE links

und bei der Leukoplakie in 10x Vergrößerung und Sirius-Red-Färbung

Abbildung 31: Faserdichte der elastischen Fasern in der oberen LP bei REund N-RE-Patienten

Abbildung 32: Faserdichte der elastischen Fasern in der mittleren LP bei RE und N-RE-Patienten

Abbildung 33: Faserdestruktion der elastischen Fasern in der oberen LP bei REund N-RE-Patienten

Abbildung 34: Faserdestruktion der elastischen Fasern in der mittleren LP bei REund N-RE-Patienten

Abbildung 35: Elastische Fasern bei einem RE und einer Leukoplakie,

EvG-Färbung 39

Abbildung 36: Zellhyperplasie der Epithelzellen bei RE- und N-RE-Patienten ............... 39

Abbildung 37: Dicke der Basalmembran bei RE-und N-RE-Patienten .

Abbildung 38: Darstellung der Basalmembrand und Epithelzelldeckschicht beim RE und einer SL-Hyperplasie 40

Abbildung 39: Deckschicht aus Keratin im Vergleich RE- und N-RE-Patienten 41

Abbildung 40: Leukoplakie mit Deckschicht aus Keratin und einer Zellhyperplasie 41 
Abbildung 41: Durchmesser und Verteilung der Gefäße bei REund N-RE-Patienten im Median

Abbildung 42: RE mit großen Gefäßlumen und Leukoplakie mit kleineren Gefäßlumen 42

Abbildung 43: RT-PCR der Hyaluronsynthasen 43

Abbildung 44: RT-PCR der Hyaluronidasen 43 


\section{Tabellenverzeichnis}

Tabelle 1: Pathologische Diagnosen des Patientenkollektives ......................................... 12

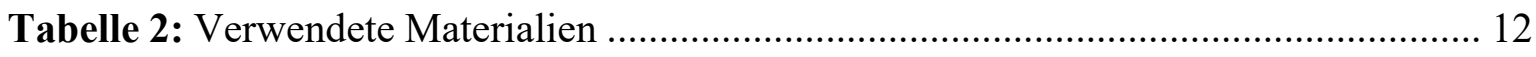

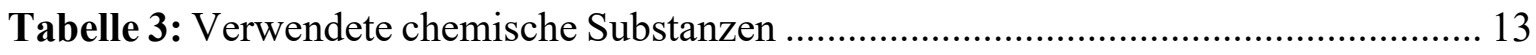

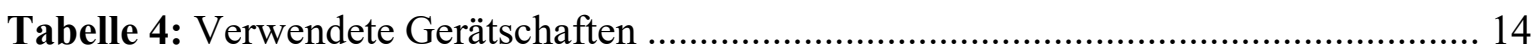

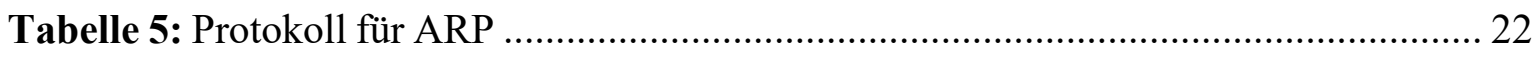

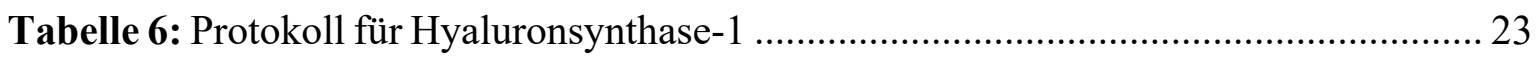

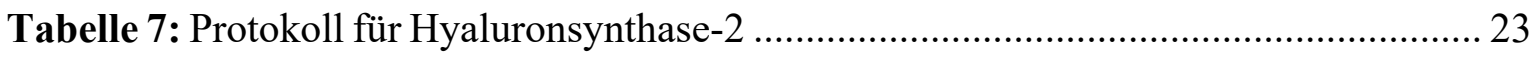

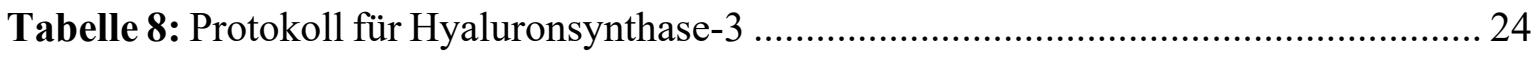

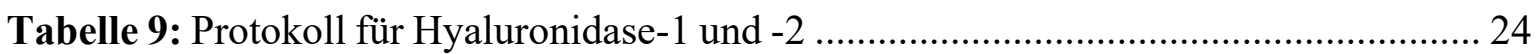

Tabelle 10: Verteilung der N-RE-Veränderungen im Vergleichskollektiv ........................ 25

Tabelle 11: Auswertung der Kollagenfaserqualität und -quantität in der oberen und mittleren LP von RE-Patienten und N-RE-Patienten ....

Tabelle 12: Ergebnisse der elastischen Fasern Auswertung in der oberen und mittleren LP bei RE- und N-RE-Patienten 


\section{Abkürzungsverzeichnis}

$\mathrm{DA}=$ Dalton

$\mathrm{EvG}=$ Elastika-van-Gieson

$\mathrm{EZM}=$ Extrazelluläre Matrix

$\mathrm{HA}=$ Hyaluronsäure

HAS $=$ Hyaluronsäuresynthase

$\mathrm{HE}=$ Hämatoxylin-Eosin

Hyal $=$ Hyaloronidasen

$\mathrm{LP}=$ Lamina propria

MMP $=$ Matrixmetalloproteinase

N-RE $=$ Nicht-Reinke (Vergleichskollektiv)

$\mathrm{nm}=$ Nanometer

$\mathrm{RE}=$ Reinke-Ödem

RT-PCR = Real-Time Transkriptase-Polymerase-Kettenreaktion

$\mathrm{SL}=$ Stimmlippen 


\section{$1 \quad$ Einleitung}

Das Reinke-Ödem (RE) zählt zu den häufigsten benignen Kehlkopferkrankungen (Lehmann et al. 1989, Kleinsasser 1974). Leitsymptom ist eine Stimmstörung, welche mit einer Rauigkeit und Heiserkeit der Stimme einhergeht. Die Erkrankung kommt überwiegend bei Frauen jenseits des 40. Lebensjahres vor (Raabe und Pascher 1999; Tillman et al. 1995) und zeigt eine Assoziation zum Nikotinkonsum, hoher Stimmbelastung sowie laryngopharyngalem Reflux (Dikkers und Nikkles 1995, Sato et al. 1999, Marcotullio et al. 2002, Sake et al. 2008).

Die Pathogenese des RE ist bis heute nicht eindeutig geklärt. Bereits Ende des 19. Jahrhunderts setzte sich der Rostocker Anatom Friedrich Berthold Reinke (1862-1919) genauer mit dem Erscheinungsbild des Stimmbandödems auseinander. Er erforschte die morphologischen und histologischen Strukturen der Stimmlippen (SL). Aufbauend auf den Untersuchungen des Wiener Laryngologen Markus Hajek (1861-1941) über das Larynxödem, vertiefte Reinke als Erstbeschreiber seine Arbeit durch pathologische und anatomische Forschung am menschlichen Stimmband mit seinem Werk Untersuchungen über das menschliche Stimmband (Reinke 1895). Das Fundament über die Anatomie des Stimmbandes beschrieb der HNO-Arzt Fränkel (Fränkel 1889). Reinke beschrieb das Stimmband als zweigeteilte Struktur: Die lateral gelegene Basis als erste Struktur sowie den Stimmbandfortsatz, der medial gelegen ist und sich histologisch von der Basis unterscheidet, als zweite Struktur (Reinke 1895).

Um die Ausdehnung des Stimmbandödems zu beschreiben, verwendete Reinke menschliche Kehlköpfe von Hingerichteten, welche frisch in Müllerscher Lösung fixiert wurden. Um ein künstliches Ödem zu erzeugen, wurde Leim oder Luft zwischen Epithel und das elastische Band injiziert. Das Ödem zeigte sich durch die Linea arcuata inferior und Linea arcuata superior scharf begrenzt und war streng auf die subepitheliale Lamina propria (LP) beschränkt. Die Grenzlinien stellten somit den Übergang von Platten- in Flimmerepithel sowie die Verwachsung des Perimysiums des M. vocalis mit der Schleimhaut dar, wobei diese Linien eine fast undurchdringliche Barriere bildeten (Reinke 1895). In den folgenden Jahren beschrieb Reinke bereits Strukturen der extrazellulären Matrix (EZM) in Form von teils geflechtartig angeordneten, teils parallel verlaufenden elastischen Fasern in den SL, wobei die Fasern senkrecht zum Druck und in gleichbleibender Richtung des Zuges ausgerichtet erschienen (Reinke 1897). 
Hajek konnte etwa 30 Jahre später die Ergebnisse von Reinke durch eigene Untersuchungen bestätigen und bezeichnete den Ödem-Raum als „Reinkeschen Raum“ (Hajek 1925). Eine detaillierte Beschreibung der anatomischen Strukturen sowie der Ausdehnung des Reinkeschen Raumes gelang Anton Mayet in den 50/60er Jahren (Mayet 1955 und 1961). Mayet sprach von einer Lamellenstruktur des Bindegewebes im Stimmband. Des Weiteren beschrieb er eine Ödemausbreitung im Recessus Laryngis, der frei von der Lamellenstruktur ist (Mayet 1961). Mittlerweile sind weitere lichtmikroskopische und elektronenmikroskopische Untersuchungen von den SL vorhanden. So konnten z. B. durch Tillmann und Rudert die oben genannten Ergebnisse von Reinke und Mayet bestätigt werden. Es gelang ferner, die ödematösen Strukturen der SL sowie das bedeckende Epithel einschließlich der Basalmembran genauer zu analysieren und erste Zusammenhänge mit dem klinischen Bild herzustellen (Tillmann und Rudert 1982).

\subsection{Anatomie der Stimmritze}

Der menschliche Kehlkopf wird gebildet durch ein Gerüst aus Knorpelgewebe, Muskeln, Schleimhaut, Bändern und Membranen. Die Einteilung des Larynx erfolgt in drei Etagen von kranial nach kaudal: supraglottischer, glottischer und subglottischer Raum. Die Rima glottis (Stimmritze) wird durch die Plicae vocalis (Stimmlippen = SL) und die Processi vocali gebildet. Die Stimmbänder sind an den Stellknorpeln befestigt, welche die funktionelle Bewegung der SL beeinflussen. Der Ventriculus laryngis ist eine Einfaltung zwischen den Plicae vocalis und den SL. Die gesamten Strukturen des Larynx sind komplex mit Bändern und Muskeln verbunden und dienen den diversen Bewegungsmustern des Kehlkopfes (Boenninghaus und Lenarz 2007, Schiebler und Korf 2007, Schünke et al. 2005, Abbildung 1).
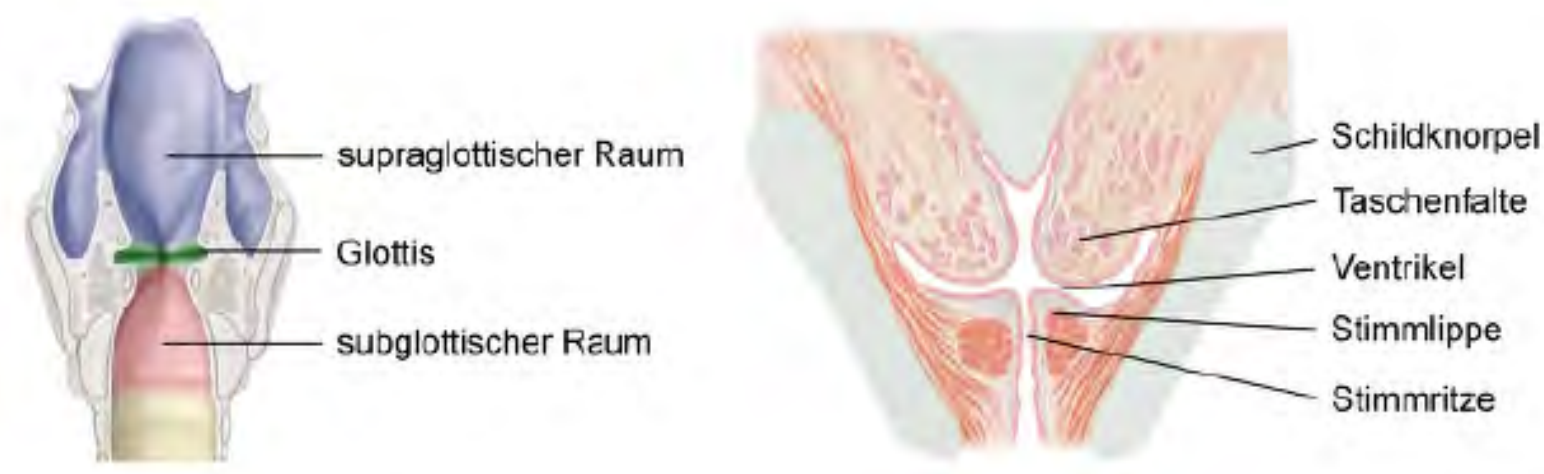


\section{$1.2 \quad$ Histologie der Stimmlippenschleimhaut}

Der histologische Aufbau der SL ist wie folgt:

Auf die Bedeckung durch ein mehrschichtiges unverhorntes Epithel mit einer Basalmembran folgen die Lamina propia (LP), die quergestreifte Muskulatur und das Knorpelgewebe. Von Plattenepithel überzogen ist der membranöse Teil der SL, die vordere und hintere Kommisur werden von Flimmerepithel bedeckt. Die LP ist in drei Schichten aufgebaut: oberflächliche, mittlere und tiefe Schicht. Das Stimmband wird durch die mittlere und tiefe Schicht gebildet (Abbildung 2).

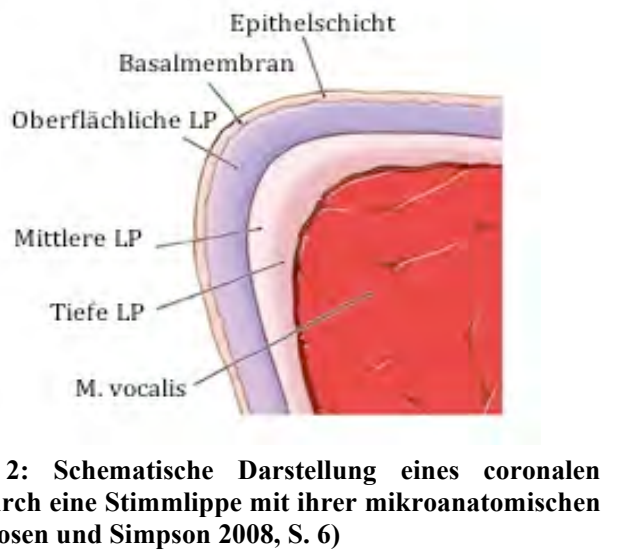

Schnittes durch eine Stimmlippe mit ihrer mikroanatomischen Struktur (Rosen und Simpson 2008, S. 6)

1981 entwickelte Hirano die funktionelle Einteilung der SL mittels des Body-CoverModells: Epithel und obere LP bilden das Cover, das Stimmband entspricht der Übergangsschicht (Transition), welche aus elastischen und kollagenen Fasern besteht, und der M. vocalis bildet den Body (Nawaka und Hosemann 2005, Rosen und Simpson 2008, Hirano 1981). Die LP durchläuft einen Entwicklungs- bzw. Reifeprozess. Im Stadium eines Fetus oder Neugeborenen weist die LP noch keine klassische Schichtung in drei Teile auf (Sato et al. 2001, Abbildung 3). Die Entwicklung der LP in das klassische Dreischichtmodell beginnt ca. mit dem 10. Lebensjahr und ist etwa mit dem 17. komplett abgeschlossen (Sato et al. 2001). Die mittlere Schicht der LP macht $51 \%$ der gesamten Schicht aus, $13 \%$ bilden den oberen Anteil und $36 \%$ die tiefe Schicht der LP (Prades et al. 2010).

\subsection{Die extrazellulare Matrix der Lamina propria}

Die EZM setzt sich aus den Bestandteilen zwischen den einzelnen Zellen zusammen, sie füllt den sogenannten Interzellularraum aus. Sie wird durch Sekretion und Synthese von Faserproteinen und Proteoglykanen durch die Zellen gebildet und ist gewebespezifisch. 
Hauptaufgabe der EZM ist die Verbindung und Fixierung der Zellen im Gewebeverband, ferner kommt es zu Wechselwirkungen zwischen den Zellen und der EZM (Hamacher et al. 2004, Bosman und Stamenkoviv 2003, Hubmacher und Apte 2013). Der Abbau der Moleküle erfolgt intra- oder extrazellulär durch verschiedene Proteasen wie Serin/Threonin-, Cystein-, Aspartat- und Metalloproteinasen (Woessner 1998). Die Verteilung der EZM in der LP ist teils organisiert und teils ungeordnet (Gray et al. 2000). Die EZM der LP besteht aus zwei großen Gruppen der Matrixproteine: den fibrösen Proteinen wie z. B. Kollagen und Elastin, sowie den interstitialen Proteinen wie Fibromodulin, Decorin und Hyaluronsäure (HA). Diese Proteine sind spezifisch hinsichtlich ihrer Qualität und Quantität in der LP verteilt und bestimmen somit die biomechanischen Eigenschaften (Gray et al. 1999).

\subsubsection{Kollagen in der Lamina propria}

Kollagene gehören zu den Faserproteinbestandteilen der EZM in der LP und werden von Fibroblasten gebildet. Bindegewebe bestehen zu einem großen Anteil aus Kollagen. Aufgebaut sind die Kollagenfasern in Tripelhelixstrukturen, sich wiederholend aus dem Abspann von Glycin-X-Y ( $\alpha$-Kette). An die Stelle von X und Y treten oft die Aminosäuren Prolin und Hydroxilysin. Es entstehen diverse Kollagentypen durch unterschiedliche Längen der tripelhelikalen Struktur, Interruptionen in der Tripelhelix und das Vorhandensein von globulären Abschnitten. Es gibt fibrilläre Kollagene, dazu zählen Typ I, II, III, V und XI sowie die nicht-fibrillären Kollagene Typ IV, VI, VII, VIII, IX, X, XII, XIII, XIV, XV, XVII und XVIII. Vorläufermoleküle werden als Prokollagene bezeichnet (Bornstein 1974, Deutzman et al. 2007).

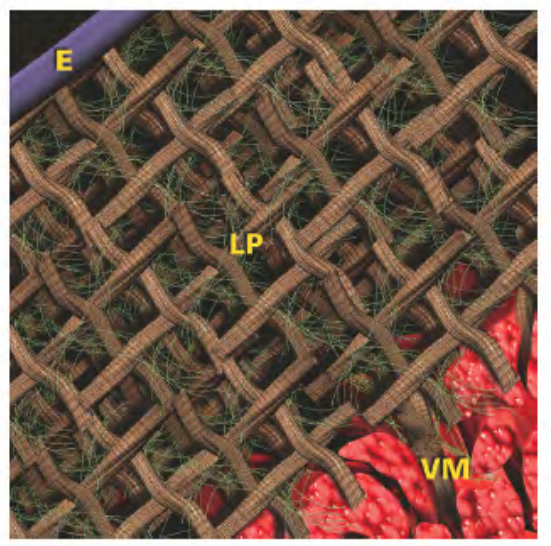

Abbildung 3: Schematische Darstellung des

Kollagennetzwerks in der LP eines

Neugeborenen (Buhler et al. 2008, S. 373)

$\mathbf{E}=$ Epithel, $\quad$ LP=Lamina $\quad$ propia,

$\mathrm{VM}=$ Musculus vocalis 
Für die Physiologie der SL spielen die Kollagenfasern eine große Rolle. Sie verleihen den SL elastische Fähigkeiten sowie Zug- bzw. Dehnungsfestigkeit (Gray 2000). Es werden zwei bandartige Kollagenschichtstrukturen beschrieben: Ein schmales Kollagenband, welches direkt unter dem Epithel verläuft, sowie ein dickeres Kollagenband in der tiefen Schicht der LP (Melo et al. 2003). Die Anordnung der einzelnen Fasern wird in Form eines Korbgeflechts beschrieben (Melo et al. 2003 und Prades et al. 2010, Abbildung 4). In der fetalen SL wird nur eine geflechtartige Schichtstruktur der Kollagenfasern beobachtet (Buhler et al. 2008, Prades et al. 2010). Bei älteren Menschen geht das Kollagennetzwerk teilweise aufgrund des Alterungsprozesses verloren (Melo et al. 2003).

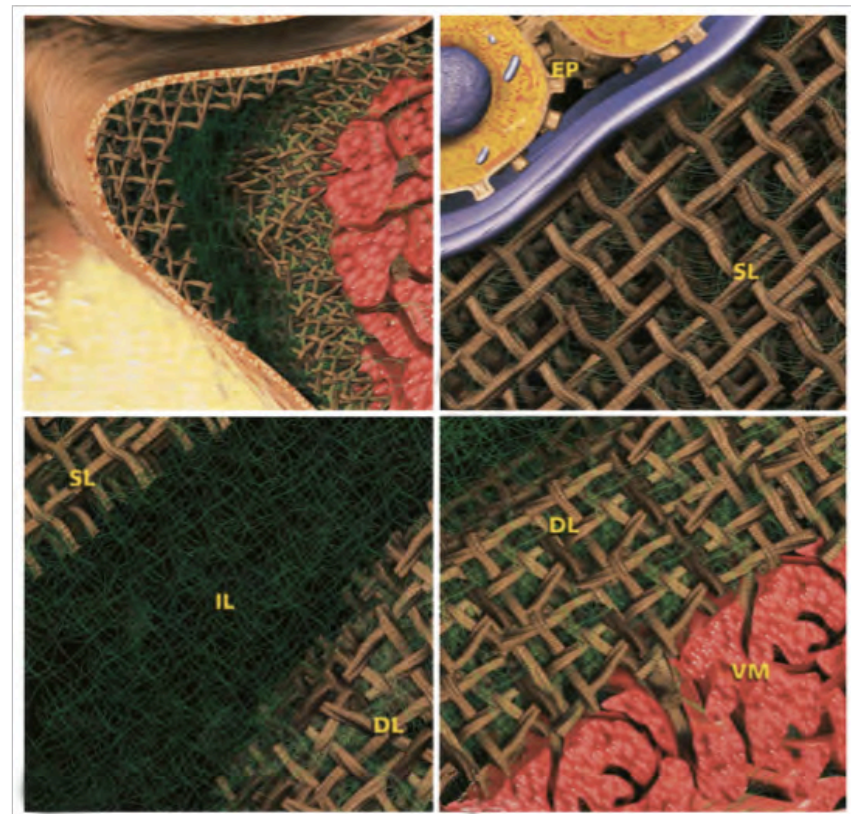

Abbildung 4: Schematische Darstellung der adulten SL mit der Anordnung der Kollagenfasern in den einzelnen Schichten der LP (Melo et al. 2003, S. 2190) $\mathbf{E P}=$ Epithel, $S L=$ superfiziale Lamina, $I L=$ intermediat (mittlere) Lamina, $\mathrm{DL}=$ deep (tiefe) Lamina, $\mathrm{VM}=$ Musculus vocalis

Kollagen der Qualitäten von Typ 1 und Typ 3 sind prädominierend in der menschlichen SL (Hahn et al. 2006b). Der Kollagen-Typ I bildet hauptsächlich die dicken, gebündelten Fasern in der Umgebung des M. vocalis, und der Kollagentyp III bildet das feine Netzwerk in der mittleren Schicht der LP (Melo et al. 2003, Tateya et al. 2006, Prades et al. 2010). Zusätzlich wird dem subepithelialen Abschnitt an Fasern auch die Kollagenqualität Typ I zugesprochen (Tateya et al. 2006). Kollagenfasern der tiefen Schicht umschlingen die Fasern des M. vocalis und dringen auch in die muskuläre Faserstruktur ein. Die mittlere Schicht der LP ist weniger dicht mit Kollagenfasern besiedelt als die tiefe Schicht (Prades et al. 2010). 


\subsubsection{Die Aufgabe der Matrixmetalloproteinasen}

Die Biochemie der EZM wird unter anderem durch den Ab- und Umbau durch Matrixmetalloproteinasen (MMP's) geregelt. Dazu gehören Vorgänge wie Gewebeprogression oder Wundheilung (Lemaître und D'Armiento 2006). MMP's werden auch mit Tumor- und Metastasenbildung, rheumatischer Arthritis und kardiovaskulären Erkrankungen in Verbindung gebracht. Sie sind membranständig oder frei und zerlegen die Bestandteile der EZM in ihre einzelnen Moleküle. Die MMP's liegen in inaktiven Vorstufen vor und aktivieren sich selbst durch positive Rückkopplung oder andere proteinspaltende Enzyme (Snoek-van Beurden und Von den Hoff 2005, Visse und Nagase 2003). Eingeteilt werden die MMP's nach ihrer Fähigkeit Moleküle zu spalten sowie nach ihrem Aufbau. Die einzelnen MMP's jeder Hauptgruppe haben überschneidende Eigenschaften in ihrer Fähigkeit Moleküle zu spalten (Lemaître und D’Armiento 2006).

\subsubsection{Rolle der Hyaluronsäure in der Lamina propria}

Ein weiterer Bestandteil der EZM der LP ist die HA. Diese spielt eine wichtige Rolle im biochemischen und mechanischen Gewebemanagement (Ward et al. 2002). Die HA beeinflusst vor allem die Viskosität und Elastizität der LP, was wiederum Einfluss auf die Stimmgebung und Stimmfrequenz hat. Weiterhin ist sie bedeutend für den Prozess der Wundheilung, den Wasserhaushalt im Gewebe, die osmotische Regulation und dient als Füllstoff im Gewebe der LP (Butler et al. 2001, Gray et al. 1999). Die HA gehört zu der Familie der Glykosaminoglycane und ist ein Disacharid bestehend aus D-Glucuronsäure und D-N-Acetylglucosamin (Necas et al. 2008). Die Hyaluronsäuresynthasen (HAS), HAS-1, $-2,-3$ in den Fibroblasten produzieren polymere Strukturen aus den beiden Bausteinen, welche wiederum an Proteine gebunden werden und somit Proteoglykane bilden (Meyer und Palmer 1934, Lee und Spicer 2000). HAS-1 und -2 produzieren hochmolekulargewichtige HA von $4 \times 10^{6}$ Dalton (DA) und HAS-3 wiederum niedrigmolekular-gewichtige HA von $1 \times 10^{4}$ DA (Ward et al. 2002). Niedrigmolekulare HA ist ein Auslöser für Signalkaskaden und stimuliert die Zellproliferation und Inflammation (Ohkawara et al. 2000, McKee et al. 1997). Die hochmolekulare HA dagegen hat eher eine anti-inflamatorische Funktion (Neumannn et al. 1999). Die Degradation der HA erfolgt über die Hyaluronidasen (Hyal), die $\mathrm{zu}$ den Endohexosaminidasen gehören und im gesamten Körper verteilt sind (Kreil 1995). Die zwei wichtigsten Hyal im menschlichen Körper sind die Hyal-1 und Hyal-2. Die Hyal-1 hat die Fähigkeit die Moleküle in kurze Tetrasacharide zu spalten. Hyal-2 dagegen die hochmolekulare HA in ein ca. 50 Untereinheiten-Sacharidmolekül-Produkt abzubauen. 
Hyal-2 besitzt ein breiteres pH-Optimum Spektrum (Stern und Jedrzejas 2006). Die HA ist durchweg in der LP zu finden, die höchste Konzentration ist in der mittleren Schicht (Butler et al. 2001). Geschlechtsspezifisch haben Männer in den oberen Anteilen der LP mehr HA als Frauen, während Frauen in den mittleren und tiefen Anteilen der LP mehr HA ausweisen (Butler et al. 2001). Eine Schwankung der HA-Konzentration in der LP führt zu Veränderungen in den oben beschriebenen Gewebeeigenschaften (Gray et al. 1999). Die Menge an HA nimmt mit dem Alterungsprozess ab, ebenso die Expression der HASynthasen (Ohno et al. 2009).

\subsubsection{Rolle der elastischen Fasern in der Lamina propria}

Elastischen Fasern setzen sich aus dem Polymer Elastin und Mikrofibrillen zusammen. Die Mikrofibrillen werden durch Fibrillin und Fibulin gebildet, welche der Quervernetzung dienen. Tropoelastin durchläuft diverse Vorstufen und wird durch das Abspalten von Sequenzen schließlich zu Elastin. Es bestehen drei Arten von elastischen Fasern, welche sich durch das Verhältnis von Elastin und Mikrofibrillen unterscheiden: Oxytalan, ohne Elastin, Elaunin, mit Elastin im Verhältnis halb zu halb und reife elastische Fasern mit einem hohen Anteil an Elastin (Debelle und Tamburro 1999, Kielty et al. 2002, Deutzmann 2007). Der generelle Turnover der elastischen Fasern beim Erwachsenen ist gering. Der Metabolismus ist dennoch abhängig von Alterungsprozess und Funktionsstörung. Geschlechtsspezifisch zeigen sich keine Unterschiede (Hammond et al. 1998).

Die Konzentration an elastischen Fasern in der LP variiert je nach Schicht: Sie ist in der obersten Schicht am geringsten, wobei diese einen geringen Elastin-Anteil besitzen. In der mittleren Schicht ist der Gehalt an elastischen Fasern eher moderat, es liegen mehr reife elastische Fasern vor, welche dann in der tiefen Schicht ihre höchste Konzentration zeigen (Hammond et al. 1997; Roberts et al. 2011). Die elastischen Fasern geben der LP Elastizität und sorgen für eine elastische Funktion während der Vibration (Kahane 1987).

\subsection{Klinik und Ätiologie des Reinke-Ödems}

\subsubsection{Anamnestischer und makroskopischer Befund}

Als eine der häufigsten benignen Kehlkopferkrankung (Lehmann et al. 1989 und Kleinsasser 1974) fällt das RE durch eine Stimmstörung mit Rauigkeit und Heiserkeit der Stimme mit abgesenkter mittlerer Sprechstimmlage auf. Hauptsächlich ist das weibliche Geschlecht betroffen (Raabe und Pascher 1999) und die Patienten sind in der Regel älter als 40 Jahre (Tillmann et al. 1995). Der initial auslösende Faktor des RE ist nicht bekannt, jedoch werden 
der Prozess des Alterns und Nikotinkonsum mit dem RE in Verbindung gebracht (Dikkers und Nikkels 1995, Sato et al. 1999, Marcotullio et al. 2002). Zu den weiteren Risikofaktoren zählen eine hohe Stimmbelastung, laryngopharyngaler Reflux und eine Schilddrüsenunterfunktion, welche die Entstehung eines RE begünstigen (Sake et al. 2008). Andere Co-Faktoren wie Allergien, Infektionskrankheiten (Raabe und Pascher 1999, Cohen et al. 2009) und hormonelle Veränderungen werden diskutiert, konnten aber nicht bewiesen werden (Voelter et al 2008).

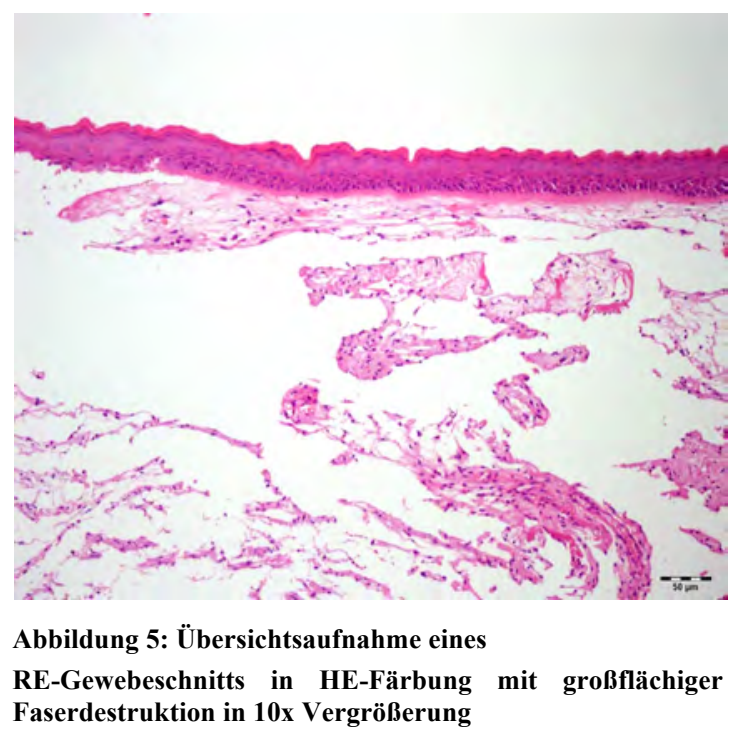

Laryngoskopisch sieht man eine meistens breitbasige oder kissenartige, ödematöse Veränderung der SL-Schleimhaut. Gelegentlich kann es aufgrund von lappen- und wulstartigen Ausstülpungen in das Kehlkopflumen zum Fremdkörpergefühl, Schluckbeschwerden und Dyspnoe kommen. Teilweise kann das Epithel sich chronisch entzünden oder leukoplakisch verhornen, hervorgerufen durch die mechanische Reizung der kontralateralen SL (Tillmann und Rudert 1982). Die Schwellung entsteht durch Ansammlung gelartiger Flüssigkeit im subepithelialen Bereich (Pastuzek et al. 2003), aufgrund der aufgelockerten und brüchigen epithelialen Deckschicht (Hammer 2007).

\subsubsection{Mikroskopischer Befund}

Histologisch wird eine Veränderung des Kollagen-Netzwerkes beschrieben (Abbildung 5). Die normalerweise geflechtartigen Anordnungen der Kollagenfasern zeigen bei dem RE eine nicht regelhafte Anordnung in der LP (Sake et al. 2008, Abbildung 6). Ebenso wird auch ein vermehrtes Auftreten von ektatischen Gefäßen mit dünnen und brüchigen Wänden beschrieben, welche dazu neigen Anastomosen zu bilden (Jovanovic et al. 2007). 
Zusätzlich zeigt sich noch eine gesteigerte Produktion bzw. ein vermehrtes Vorhandensein an EZM als Folge des Wundheilungsprozess und eine Auflockerung der Epithelschicht, welche auch am Wundheilungsprozess beteiligt ist (Volić et al. 2004). Schließlich wird eine verzerrte, teils aber auch verbreiterte Basalmembranschicht als Reaktion auf die Traumata in der LP beobachtet (Volić et al. 2004, Knöbber 1994).

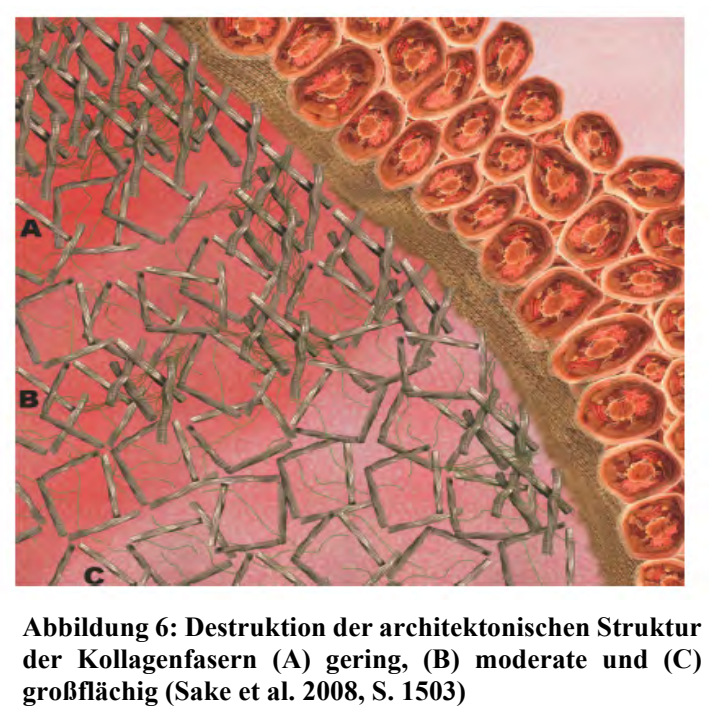

Eine maligne Entartung des RE ist nicht bekannt (Raabe und Pascher 1999, Marcotullio et al. 2002). Die Therapie der Wahl ist heutzutage die chirurgische Entfernung des RE mit der Methode nach Kleinsasser, um einen adäquate Verbesserung der Stimmqualität zu erzielen (Raabe und Pascher 1999).

\subsection{Operationstechnik und Therapie}

Die Abtragung des veränderten Gewebes erfolgte in direkter Laryngoskopie, welche ein standardisiertes Verfahren zur Entfernung gutartiger SL-Erkrankungen ist (Abbildung 7). Der Vorteil der laryngoskopischen Operation gegenüber konservativen Therapieansätzen ist eine funktionelle Verbesserung, sowie die Gewinnung von Gewebematerial für eine histopathologische Befundung.

Die Durchführung der Operation erfolgt mit starren Laryngoskopen in Intubationsnarkose am relaxierten Patienten mit überstreckter Kopflage. Phonochirurgische Eingriffe können so beidhändig in sicherem Blick- und Überwachungsfeld durchgeführt werden (Berbohm et al. 2009). Die Operationstechnik nach Kleinsasser hat sich als erfolgreich bewährt. Hierbei wird das RE gespalten, die ödematöse Flüssigkeit abgesaugt und die überschüssige Schleimhaut mittels $\mathrm{CO}_{2}$-Laser entfernt (Kleinsasser 1991). Vor allem bei unklarem klinischen Befund 
zeigt sich die direkte Methode von Vorteil zu sein, da eine bessere Differenzierung bzw. Abgrenzung des pathologisch veränderten Gewebes möglich ist (Seidner 2000). Um eine deutliche Verbesserung der Stimmqualität zu erhalten, ist es bedeutsam, dass der Operateur minimalinvasiv vorgeht und die tiefe Schicht der LP schont, um so ein Trauma am M. vocalis zu vermeiden. Ein Nachteil dieser Operationstechnik ist, dass während der Operation keine funktionelle Analyse der Stimme sowie der SL-Beweglichkeit möglich ist (Schade und Hess 2001).

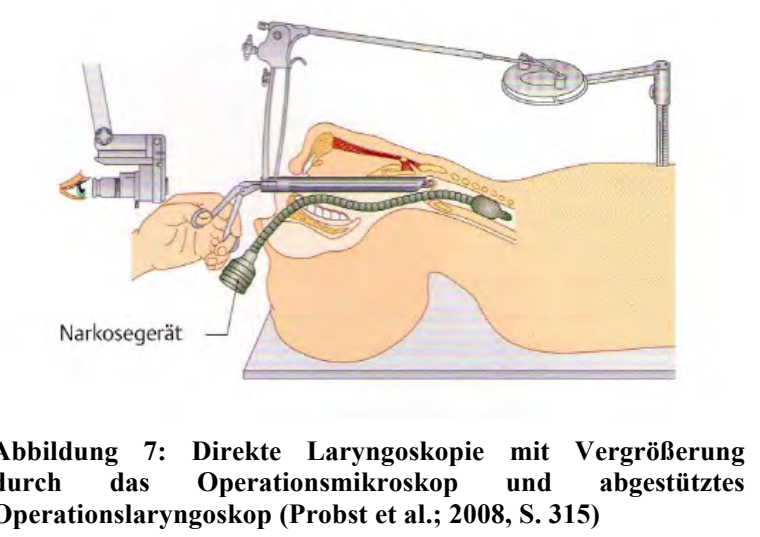

\subsection{Zielsetzung}

Auch wenn die anatomischen und histopathologischen Veränderungen des RE bereits in zahlreichen Publikationen beschrieben worden sind und einige Risikofaktoren postuliert wurden, ist die eigentliche Pathogenese des RE nicht eindeutig geklärt (Thibeault 2005). Im Gegensatz zu anderen pathologischen SL-Veränderungen scheinen beim RE besondere Faktoren eine Rolle zu spielen: Epidemiologische bzw. geschlechtsspezifische Faktoren, wie z. B. das vermehrte Auftreten bei weiblichen Personen (Raabe und Pascher 1995) ab der vierten Lebensdekade (Tillmann et al. 1995). Neben dem Alterungsprozess spielt der Nikotinkonsum eine wesentliche Rolle (Dikkers und Nikkles 1995, Sato et al. 1999), oft in Verbindung mit einer beruflichen Stimmexposition oder auch gelegentliche mit ösophagalen Reflux (Sake et al. 2008). Da das bedeckende Epithel in zahlreichen Voruntersuchungen nicht relevant verändert $\mathrm{zu}$ sein schien und die beschriebenen Risikofaktoren auch auf die subepithelialen Schichten und die EZM wirken (z. B. Mikrotraumen bei starker Stimmbelastung, altersbedingte Degeneration, Nikotin und ein postulierter hormoneller Effekt), soll in dieser Arbeit ein besonderer Fokus auf die möglichen Veränderungen der EZM (v. a. der HA-Haushalt sowie Veränderungen der Faserstrukturen) gelegt werden. Ziel ist es, Veränderungen der EZM sowie des Epithels und der Basalmembran im RE zu bestimmen und mit anderen gutartigen SL-Erkrankungen zu vergleichen. 


\section{Material und Methoden}

\subsection{Material}

\subsubsection{Zusammensetzung des Gewebekollektivs für die lichtmikroskopischen Untersuchungen}

Das zu untersuchende Gewebe wurde vom Institut für Pathologie der Universitätsmedizin Göttingen zur Verfügung gestellt. Es handelt sich dabei ausschließlich um Gewebeproben, welche aufgrund diagnostischer und/oder therapeutischer Indikation gewonnen wurden und bei welchen die histopathologische Diagnostik abgeschlossen war. Die Patienten wurden ferner vor dieser Studie über die weitere wissenschaftliche Gewebeuntersuchung aufgeklärt und haben per Unterschrift die Einwilligung erteilt. Die Studie wurde von der Ethikkommission der Universitätsmedizin Göttingen genehmigt (Ethik-Votum-Nummer: $15 / 4 / 11)$.

Jeweils 50 Patienten-Proben, sowohl weiblich als auch männlich, mit der pathologischen Diagnose „Reinke-Ödem“ und 55 weitere Patienten-Proben als Vergleichskollektiv, auch weiblich und männlich, mit vom „Reinke-Ödem“ abweichenden pathologischen Veränderungen (Nicht-Reinke-Veränderungen N-RE) an dem SL aus dem Zeitraum 2006 2012 wurden in diese Studie eingeschlossen. Bei den Patienten wurde eine mikrolaryngoskopischen Abtragung in Intubationsnarkose in der Klinik für Hals-NasenOhrenheilkunde der Universitätsklinik Göttingen durchgeführt. Dabei wurde minimalinvasiv vorgegangen und es wurden nur die obere und mittlere Schicht der LP entfernt. Für die Untersuchungen in dieser Arbeit wurden ausschließlich Proben verwendet, in denen sowohl die obere als auch die mittlere Schicht der LP vorhanden war. Die untere Schicht der LP war nicht erfasst und somit nicht beurteilbar. Weitere relevante Daten über die Patienten stammten aus der Aktendokumentation bzw. aus digitalisierten Laryngoskopien der Abteilung für Phoniatrie bzw. Hals-Nasen- Ohrenheilkunde der Universitätsklinik Göttingen.

\subsubsection{Zusammensetzung des Gewebekollektivs für die Nukleinsäureanalytik}

Die chirurgische Abtragung des Gewebekollektivs erfolgte durch die Klinik für HalsNasen-Ohrenheilkunde der Universitätsklinik Göttingen im Zeitraum von 2011 - 2014. Unmittelbar danach wurde das Gewebe in die Abteilung für Pathologie zur Diagnostik überstellt und mittels Hope-Verfahren aufbereitet. 
Das Kollektiv setzt sich einmal aus 20 ausschließlich weiblichen Patienten mit einem klinisch und pathologisch diagnostizierten RE zusammen. Das Vergleichskollektiv besteht aus 46 N-RE-Patienten (Tabelle 1). Davon sind 21 weiblich und 25 männlich. Die pathologischen Diagnosen setzen sich wie folgt zusammen:

Tabelle 1: Pathologische Diagnosen des Patientenkollektives

\begin{tabular}{|l|c|}
\hline \multicolumn{1}{|c|}{ Pathologie } & Anzahl \\
\hline SL-Polyp & 11 \\
\hline Leukoplakie & 7 \\
\hline Fibrose & 7 \\
\hline Laryngocele & 4 \\
\hline Papillom & 3 \\
\hline Hyperplasie & 2 \\
\hline Carcinom in situ & 2 \\
\hline Plattenepithelcarzinom & 2 \\
\hline SL-Knötchen & 1 \\
\hline SL-Zyste & 1 \\
\hline Pseudozyste & 20 \\
\hline Granulom & 1 \\
\hline Ohne pathologischen Befund & 4 \\
\hline Reinke-Ödem & \\
\hline
\end{tabular}

\subsubsection{Verwendete Materialien}

Tabelle 2: Verwendete Materialien

\begin{tabular}{|l|l|}
\hline Material & Hersteller \\
\hline Ausgießförmchen & Leica Microsystems, Wetzlar, Deutschland \\
\hline Deckplättchen & $\begin{array}{l}\text { Menzel-Gläser, Braunschweig, Deutsch- } \\
\text { land }\end{array}$ \\
\hline Einbettkasetten & $\begin{array}{l}\text { Kabe-Labortechnik, Nümbrecht-Elsenroth, } \\
\text { Deutschland }\end{array}$ \\
\hline Marker SecureLine II & Sigma, St. Louis, USA \\
\hline $\begin{array}{l}\text { Klebefolie I-Cycler IQ Optical Quality } \\
\text { Sealing tape }\end{array}$ & $\begin{array}{l}\text { BioRad Laboratories, München, Deutsch- } \\
\text { land }\end{array}$ \\
\hline Objektträger & Knittel-Gläser, Braunschweig, Deutschland \\
\hline Objektträger SuperFrost Plus & Menzel-Gläser, Braunschweig Deutschland \\
\hline Pipettenspitzen $10 \mu 1,100 \mu l$ und 1000 $\mu 1$ & Sarstedt, Nümbrecht, Deutschland \\
\hline Pipettenspitzen $2,5 \mu 1$ & $\begin{array}{l}\text { Biozym Diagnostik, Hess. Oldendorf, } \\
\text { Deutschland }\end{array}$ \\
\hline Eppendorfcup & Eppendorf, Hamburg, Deutschland \\
\hline
\end{tabular}




\subsubsection{Verwendete chemische Substanzen}

Tabelle 3: Verwendete chemische Substanzen

\begin{tabular}{|c|c|}
\hline Substanz & Hersteller \\
\hline Xylol & Mallinckrodt Baker, Deventer, Holland \\
\hline Paraffin & Süsse, Gudensberg, Deutschland \\
\hline Aqua bidest & Roth, Karlsruhe, Deutschland \\
\hline Aqua dest & $\begin{array}{l}\text { Universitätsmedizin, Göttingen, Deutsch- } \\
\text { land }\end{array}$ \\
\hline Bovine Testicular Hyaluronidase & Sigma, St. Louis, USA \\
\hline Tris-buffered saline (TBS) pH 7,4 & Dako, California, USA \\
\hline Paraffin & Süsse, Gudensberg, Deutschland \\
\hline Alkohol 100\%, 96\%, $70 \%$ & Chemie-Vertrieb, Hannover, Deutschland \\
\hline SyberGreen & $\begin{array}{l}\text { BioRad Laboratories, München, Deutsch- } \\
\text { land }\end{array}$ \\
\hline Hämatoxylin $\left(\mathrm{C}_{16} \mathrm{H}_{14} \mathrm{O}_{6} \cdot \mathrm{x} \mathrm{H}_{2} \mathrm{O}\right)$ & Merck, Darmstadt, Deutschland \\
\hline Kaliumaluminiumsulfat $\left(\mathrm{KAl}\left(\mathrm{SO}_{4}\right)_{2}\right)$ & Merck, Darmstadt, Deutschland \\
\hline Natriumjodad (NaI) & Merck, Darmstadt, Deutschland \\
\hline Chloralhydrat $\left(\mathrm{C}_{2} \mathrm{H}_{3} \mathrm{Cl}_{3} \mathrm{O}_{2}\right)$ & Merck, Darmstadt, Deutschland \\
\hline Citronensäure $\left(\mathrm{C}_{6} \mathrm{H}_{8} \mathrm{O}_{7}\right)$ & Merck, Darmstadt, Deutschland \\
\hline $\operatorname{Eosin}\left(\mathrm{C}_{20} \mathrm{H}_{6} \mathrm{Br}_{4} \mathrm{Na}_{2} \mathrm{O}_{5}\right)$ & Merck, Darmstadt, Deutschland \\
\hline Essigsäure $\left(\mathrm{C}_{2} \mathrm{H}_{4} \mathrm{O}_{2}\right)$ & Merck, Darmstadt, Deutschland \\
\hline Kaliumhexacyanidoferrat III $\left(\mathrm{C}_{6} \mathrm{FeK}_{3} \mathrm{~N}_{6}\right)$ & Merck, Darmstadt, Deutschland \\
\hline Kernechtrot $\left(\mathrm{C}_{14} \mathrm{H}_{8} \mathrm{NNaO}_{7} \mathrm{~S}\right)$ & Merck, Darmstadt, Deutschland \\
\hline $\begin{array}{l}\text { Resorcin-Fuchsin }\left(\mathrm{C}_{6} \mathrm{H}_{6} \mathrm{O}_{2}-\mathrm{C}_{20} \mathrm{H}_{19} \mathrm{~N}_{3} \quad \mathrm{x}\right. \\
\mathrm{HCl})\end{array}$ & Chroma, Münster, Deutschland \\
\hline Alcian-Blau $\left(\mathrm{C}_{56} \mathrm{H}_{68} \mathrm{Cl}_{4} \mathrm{CuN}_{16} \mathrm{~S}_{4}\right)$ & Serva, Heidelberg, Deutschland \\
\hline Direct Red $80\left(\mathrm{C}_{45} \mathrm{H}_{26} \mathrm{~N}_{10} \mathrm{Na}_{6} \mathrm{O}_{21} \mathrm{~S}_{6}\right)$ & Sigma, St. Louis, USA \\
\hline Pikrinsäure $\left(\mathrm{C}_{6} \mathrm{H}_{3} \mathrm{~N}_{3} \mathrm{O}_{7}\right)$ & Sigma, St. Louis, USA \\
\hline Fast Green FCF $\left(\mathrm{C}_{37} \mathrm{H}_{34} \mathrm{~N}_{2} \mathrm{Na}_{2} \mathrm{O}_{10} \mathrm{~S}_{3}\right)$ & Roth, Karlsruhe, Deutschland \\
\hline Formalin $(4 \%)$ & Süsse, Gudensberg, Deutschland \\
\hline Cytoseal XYL & Thermo Scientific, Waltham, USA \\
\hline Salzsäure-Alkohol & Merck, Darmstadt, Deutschland \\
\hline Salzsäure $(\mathrm{HCl})$ & Merck, Darmstadt, Deutschland \\
\hline
\end{tabular}




\begin{tabular}{|c|c|}
\hline Substanz & Hersteller \\
\hline $\begin{array}{l}\text { Trishydroxymethylaminomethan } \\
\left(\mathrm{C}_{4} \mathrm{H}_{11} \mathrm{NO}_{3}\right)\end{array}$ & Carl Roth, Karlsruhe, Deutschland \\
\hline Natriumchlorid $(\mathrm{NaCl})$ & Merck, Darmstadt, Deutschland \\
\hline Hope I/II & $\begin{array}{l}\text { DCS Innovative Diagnostik, Hamburg, } \\
\text { Deutschland }\end{array}$ \\
\hline Low Melting Paraffin & $\begin{array}{l}\text { DCS Innovative Diagnostik, Hamburg, } \\
\text { Deutschland }\end{array}$ \\
\hline BSA-Blocker ( $2 \%)$ & $\begin{array}{l}\text { CANDOR Biosince GmbH, Wangen, } \\
\text { Deutschland }\end{array}$ \\
\hline $\begin{array}{l}\text { Antikörper CD-34 (Clone QBEND 10) Neo } \\
\text { Markers }\end{array}$ & Zytomed Systems, Berlin, Deutschland \\
\hline $\begin{array}{l}\text { Detektionskit (Sekundärantikörper, Label, } \\
\text { Fast Red) }\end{array}$ & Dako, Hamburg, Deutschland \\
\hline RNeasy ${ }^{\circledR}$ Mini-Kit (50) & Qiagen, Hilden, Deutschland \\
\hline Omniscript RT Kit (50) & Qiagen, Hilden, Deutschland \\
\hline 2-Mercaptoethanol $98 \%$ & Sigma, St. Louis, USA \\
\hline
\end{tabular}

\subsubsection{Verwendete Gerätschaften}

Tabelle 4: Verwendete Gerätschaften

\begin{tabular}{|c|c|}
\hline Gerät & Hersteller \\
\hline Schlittenmikrotom & Reichert \& Jung, Heidelberg, Deutschland \\
\hline Wasserbad & GFL, Burgwedel, Deutschland \\
\hline Brutschrank $\left(+39,+52^{\circ} \mathrm{C}\right)$ & Heraeus, Düsseldorf, Deutschland \\
\hline Eismaschine & Scotsmann Ice Systems, Mailand, Italien \\
\hline Kühlschrank & Siemens, München, Deutschland \\
\hline Eisschrank $\left(-20^{\circ} \mathrm{C}\right)$ & Liebherr, Bieberach, Deutschland \\
\hline Eisschrank $\left(-80^{\circ} \mathrm{C}\right)$ & GFL, Burgwedel, Deutschland \\
\hline Mikroskop ID 03 & Zeiss, Jena, Deutschland \\
\hline $\begin{array}{l}\text { Kolbenhub-Pipetten }(0,1-2,5 \mu 1,0,5-10 \mu 1 \text {, } \\
10-100 \mu 1,100-1000 \mu 1)\end{array}$ & Eppendorf, Hamburg, Deutschland \\
\hline Thermomixer 5436 & Eppendorf, Hamburg, Deutschland \\
\hline Zentrifuge 5424 & Eppendorf, Hamburg, Deutschland \\
\hline Vortex Genie 2 & Bänder und Hobein, Zürich, Schweiz \\
\hline NanoDrop 2000 & Thermo Scientific, Waltham, USA \\
\hline
\end{tabular}




\begin{tabular}{|l|l|}
\hline Gerät & Hersteller \\
\hline Thermocycler (TPersonal) & Biometra, Göttingen, Deutschland \\
\hline iCycler iQ & BIO-RAD, Hercules Kalifornien, USA \\
\hline $\begin{array}{l}\text { Objektträger-Scanner Olympus BX- } \\
\text { REMCB }\end{array}$ & Olympus Europa, Hamburg, Deutschland \\
\hline
\end{tabular}

\subsubsection{Klinische Daten}

\subsubsection{Allgemeine Patienteninformation}

Der Patienten-Name sowie die Vorgangsnummer wurden durch eine willkürlich ausgesuchte dreistellige Ziffer anonymisiert. Erfasst werden folgende Daten: Geschlecht, Alter der Patienten bei chirurgischer Abtragung im Universitätsklinikum Göttingen, Nikotinkonsum, ösophagaler Reflux und eine hohe Stimmexposition.

\subsubsection{Klinische Untersuchungen}

Alle Patienten wurden mittels indirekter Laryngoskopie untersucht und die Befunde dokumentiert. Die Untersuchungsdaten wurden auf einem DVD-Speichermedium archiviert und ausgewertet. Die Lokalisation und Ausdehnung der RE-Veränderung an den SL wurden mittels eines Schaubildes festgehalten (Abbildung 8). Kleine Ödeme machten weniger als die Hälfte der SL-Breite aus: klinische Klassifikation Grad I (Abbildung 9). Mittelgradige Ödeme bewegten sich in Bereichen mehr als die Hälfte der SL-Breite und weniger als eine SL-Breite: klinische Klassifikation Grad II (Abbildung 10). Hochgradige Ödem gingen über die gesamte SL-Breite hinaus: klinische Klassifikation Grad III (Abbildung 11). Bei fehlender digitaler Archivierung der Laryngoskopie wurde das klinische Ausmaß mittels OP-Bericht erarbeitet. 


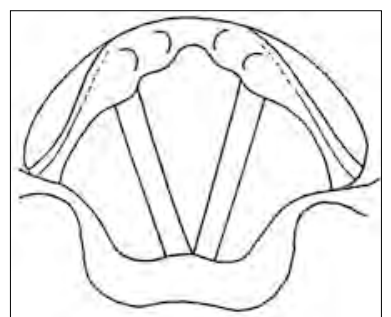

Abbildung 8: normale SL

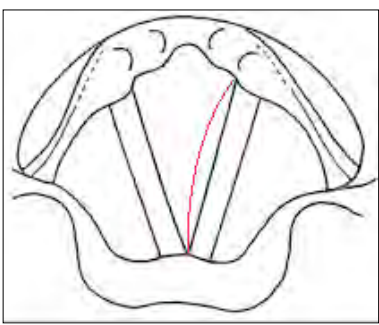

Abbildung 10: Ödem Grad II

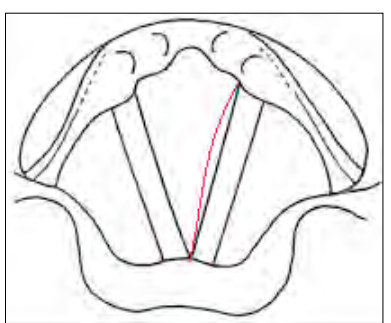

Abbildung 9: Ödem Grad I

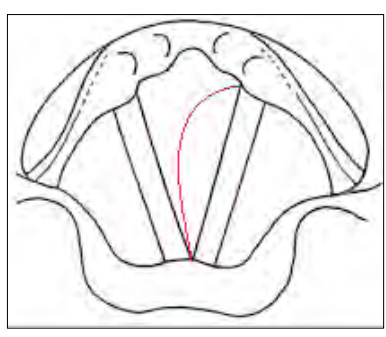

Abbildung 11: Ödem Grad III

\subsection{Histochemie}

\subsubsection{Gewebefixierung in Paraffin}

Um das Gewebe vor Autolyse und dem Verwesungsprozess zu schützen, wurde dieses in 4\%-Formalin Lösung für ca. acht Stunden fixiert. Danach wurde es mit Leitungswasser gespült und im Einbettautomaten Excelsior ES über die aufsteigende Alkoholreihe $(70 \% \rightarrow$ $96 \% \rightarrow 96 \% \rightarrow 100 \% \rightarrow 100 \% \rightarrow 100 \%$ ) entwässert. Schließlich wurde mit Xylol der Alkohol, dem Gewebe entzogen, und es folgte die Lagerung in $56,0^{\circ} \mathrm{C}$ warmem Paraffin (max. 24 h). Letztendlich wurde das Gewebe in ein Paraffinblock eingebettet und die Einbettkassette mit einer Nummer dokumentiert (Tabelle 2, 3, 4).

\subsubsection{Gewebefixierung in Hope}

Das frische Gewebe wurde über Nacht in Hope I Lösung auf Eis im Kühlschrank bei $4,0^{\circ} \mathrm{C}$ gelagert. Am folgenden Tag wurde das Gewebe für $2 \mathrm{~h}$ in Hope-II-Lösung auf Eis gelagert. Danach folgte ein dreimaliges Bad in Aceton für jeweils $2 \mathrm{~h}$ auf Eis. Im Anschluss wurde das Gewebe über Nacht in Low Melting Paraffin im Wärmeschrank bei $52,0{ }^{\circ} \mathrm{C}$ gelagert, und am nächsten Tag erfolgte die Einbettung in einen Paraffinblock (Tabelle 2, 3, 4). 


\subsubsection{Herstellung von Gewebeschnittpräparaten}

2,0 $\mu \mathrm{m}$ dünne Paraffinschnitte wurden, von den gekühlten Paraffinblöcken, mit einem Schlittenmikrotom angefertigt. Der Gewebeschnitt wurde zur Entspannung in ein Wasserbad gelegt und auf einen Objektträger aufgezogen. Anschließend wurde der Objektträger bei 39,0 ${ }^{\circ} \mathrm{C}$ im Brutschrank getrocknet. Mit Xylol erfolgte die Entparaffinierung aller Schnittpräparate, das Xylol wird mit der absteigenden Alkoholreihe $(100 \% \rightarrow 100 \% \rightarrow$ $100 \% \rightarrow 96 \% \rightarrow 96 \% \rightarrow 70 \%$ ) ausgewaschen und dem Gewebe wieder $\mathrm{H}_{2} 0$ zugeführt. Anschließend erfolgten die spezifischen Färbungen. Nach jeder Färbung wurden die Gewebeschnitte mit Aqua dest gespült, mit der aufsteigenden Alkoholreihe entwässert und schließlich mit Deckglas und Eindeckmedium fertiggestellt (Tabelle 2, 3, 4).

\subsubsection{Hämatoxylin-Eosin-Färbung}

Die Hämatoxylin-Eosin (HE)-Färbung wurde als Übersichtsfärbung ausgewählt, sowie zur Beurteilung der epithelialen Strukturen und der Basalmembran. Nachdem die Gewebeschnitte die absteigende Alkoholreihe durchlaufen hatten, folgte ein 10-minütiges Bad in der Hämalaunlösung. Die blau Färbung der Zellkerne wurde mit Leitungswasser umgesetzt, und es folgte die Färbung der zytoplasmatischen Strukturen durch 30-sekündige Inkubation in Eosin-Lösung.

Der Ansatz für Hämalaun besteht aus: 1,0 g Hämatoxylin, 50,0 g Kaliumaluminiumsulfat, 150,0 mg Natriumjodat, 50,0 g Chloralhydrat, 1,0 g Citronensäure gelöst in 1 Liter Aqua bidest.

Der Ansatz Eosin besteht aus: 20,0 g Eosin gelöst in 1 Liter Aqua bidest sowie 4 Tropfen Essigsäure (Tabelle 2, 3, 4).

Die so entstandenen HE-Präparate der SL wurden hinsichtlich folgender Parameter durch zwei unabhängige Betrachter beurteilt:

1. Vorhandensein von Dysplasien mit dem Score 0 für nicht vorhanden und dem Score 1 für vorhanden.

2. Schweregrad des Reinke-Ödems mit dem Score der histologischen Einteilung des RE: Score 0 für kein RE, Score 1 für aufgelockerte Gewebestrukturen, Score 2 für Lakunen bis 50,0 $\mu \mathrm{m}$ im Durchmesser sowie Score 3 für Lakunen $>50,0 \mu \mathrm{m}$ im Durchmesser.

3. Veränderung des Epithels mit dem Score der Hyperplasie der Epithelzelllagen. Score 0 für $5-7$ Zelllagen, Score 1 für $8-15$ Zelllagen und Score 2 für $>15$ Zelllagen. 
4. Vorhandensein einer Keratinschicht auf der Epithelschicht mit dem Score 0 für nicht vorhanden und dem Score 1 für vorhanden.

5. Vorhandensein von entzündlichen Veränderungen mit dem Score 0 für nicht vorhanden und dem Score 1 für vorhanden.

6. Veränderungen der Basalmembrandicke mit dem Score 0 für 1,0-2,0 $\mu \mathrm{m}$, dem Score 1 für 2,1 - 10,0 $\mu \mathrm{m}$ und dem Score 2 für $>10,0 \mu \mathrm{m}$

\subsubsection{Elastika-van-Gieson-Färbung}

Zur Beurteilung der elastischen Fasern wurde die Elastika-van-Gieson (EvG)-Färbung verwendet. Nachdem die Gewebeschnitte von dem Paraffin befreit wurden, folgte ein 30 min Bad in Resorcinfuchsinlösung (Lösung A). Die Schnitte werden 10 sek in HClAlkohol gespült und 5 min unter Leitungswasser gebläut. Danach wurden sie 5 min in Eisenhämatoxylin (Lösung B) getaucht und erneut unter Leitungswasser gebläut. Letztendlich wurden die Proben für 3 min in Picrofuchsin gelegt und durchliefen dann die aufsteigende Alkoholreihe.

Lösung A besteht aus: 10,0 g Hämatoxylin, $100 \mathrm{ml}$ Ethanol (100 \%) sowie $900 \mathrm{ml}$ Ethanol $(96 \%)$

Lösung B besteht aus: $950 \mathrm{ml}$ Aqua bidest, $40 \mathrm{ml}$ Eisen-III-chlorid Lösung (29 \%) sowie $10 \mathrm{ml} \mathrm{HCl}(25 \%)$ (Tabelle 2, 3, 4).

Folgende Parameter wurden mit dieser Methodik semiquantitativ und doppelblind untersucht:

1. Veränderungen an der Anordnung der elastischen Fasern mit dem Score 0 für: knäuelartige Anordnung, Score 1 für: strukturlose Anordnung und Score 2 für: bandförmige Anordnung.

2. Veränderungen an der Dichte der elastischen Fasern mit dem Score 0 für: geringe Faserdichte, Score 1 für: wenig Faserdichte, Score 2 für: physiologische Faserdichte und Score 3 für: vermehrte Faserdichte.

3. Zerstörungsgrad der elastischen Fasern mit dem Score 0 für: keine Destruktion, Score 1 für: geringe Destruktion, Score 2 für: mäßige Destruktion und dem Score für: vermehrte Destruktion. 


\subsubsection{Eisen-Färbung}

Die Eisen (FE)-Färbung diente dem Nachweis von älteren Einblutungen in das Gewebe. Die Schnitte wurden 20 min an einem dunklen Ort in FE-Lösung (Ansatz 1) inkubiert, danach mit destilliertem Wasser gespült und 5 min in Kernechtrot (Ansatz 2) gebadet. Es folgte die aufsteigende Alkoholreihe.

Ansatz 1 besteht aus: 10,0 g Kaliumhexacyanoferat III gelöst in $500 \mathrm{ml}$ Aqua bidest.

Ansatz 2 besteht aus: 50,0 g Aluminiumsulfat und 1,0 g Kernechtrot gelöst in 11 Aqua bidest (Tabelle 2, 3, 4).

Folgende Kriterien wurden semiquantitativ und unabhängig von zwei Betrachtern bestimmt: 1. Vorhandensein von Eisen mit dem Score 0 für: Kein Eisen nachweisbar, Score 1 für: 1- 2 Stellen mit Eisen sowie Score 2 für: $>2$ Stellen mit Eisen.

\subsubsection{Picro-Sirius-Rot-Färbung}

Zur besseren Beurteilung der Kollagenfasern im Gewebe der SL wurde die Sirus-RotFärbung angewandt. Mittels doppeltbrechendem chromatischem Licht lassen sich dann Kollagen Typ I (rot/gelb) und Typ III (grün/blau) voneinander unterscheiden.

Nachdem die Schnitte entparaffiniert waren, wurden diese für $60 \mathrm{~min}$ in die Sirus-Red Lösung gelegt, danach in HCL $(0,01 \mathrm{~N})$ ausgewaschen und 2 min in Fast-Green und Essigsäure (1 \%) gebadet. Danach folgt das Auswaschen in Leitungswasser und die aufsteigende Alkoholreihe.

Ansatz Sirius-Red besteht aus: 0,1 g Direct Red 80 gelöst in $100 \mathrm{ml}$ Pikrinsäure (1\%) auf pH 2 eingestellt mittels $\mathrm{NaOH}$.

Ansatz Fast Green besteht aus 0,1 g Fast Green (0,1\%) gelöst in $100 \mathrm{ml}$ Essigsäure (1\%) (Tabelle 2, 3, 4).

Semiquantitativ und unabhängig von zwei Betrachtern wurden folgende Strukturen beurteilt:

1. Veränderungen an der Anordnung der Kollagenfasern mit dem Score 0 für: strukturlose Anordnung, dem Score 1 für netzartige Anordnung sowie Score 2 für: wellenförmige / parallele Anordnung. 
2. Veränderungen an der Vernetzung der Kollagenfasern mit dem Score 0 für: keine Faservernetzung, dem Score 1 für: geringe Faservernetzung, dem Score 2 für: mäßige Faservernetzung sowie dem Score 3 für: vermehrte Faservernetzung.

3. Veränderungen an der Dichte der Kollagenfasern mit dem Score 0 für: geringe Faserdichte, dem Score 1 für: wenig Faserdichte, dem Score 2 für: physiologische Faserdichte sowie Score 3 für: vermehrte Faserdichte.

4. Veränderungen an den Kollagenfasern Typ I mit dem Score 0 für: Vorhandensein von wenig Kollagen Typ I, mit dem Score 1 für: mäßiges Vorhandensein von Kollagen Typ I sowie dem Score 2 für: vermehrtes Vorhandensein von Kollagen Typ I.

5. Veränderungen an den Kollagenfasern Typ III mit dem Score 0 für: Vorhandensein von wenig Kollagen Typ III, mit dem Score 1 für: mäßiges Vorhandensein von Kollagen Typ III sowie dem Score 2 für: vermehrtes Vorhandensein von Kollagen Typ III.

\subsubsection{Alcianblau-Färbung und Hyaluronsäure-Verdau}

Alcianblau färbt spezifisch Glykosaminoglykane, besonders HA, an. Als erstes folgte ein Bad in Alcianblau-Lösung für 20 min. Die Schnitte wurden gespült in destilliertem Wasser und $6 \mathrm{~min}$ in Kernechtrot inkubiert. Ausgewertet wurden 2 Serienschnitte vor und nach Verdau mit Hyal. Der Verdau erfolgte an einem der beiden Gewebeschnitte vor der Färbung mit Alcianblau. Hierzu wurden die entparaffinierten Gewebeschnitte in einem Bad aus Hyal (Ansatz 2), gelöst in TBS, bei $37^{\circ} \mathrm{C}$ im Brutschrank für 2 Stunden inkubiert. Danach wurden diese mit Alcianblau (Ansatz 1) gefärbt.

Ansatz 1 besteht aus: 0,5 g Alcianblau pH 2,5 (0,1 \%) gelöst in $500 \mathrm{ml}$ Essigsäure (3\%). Ansatz 2 besteht aus: 50,0 g Bovine Testicular Hyaluronidase gelöst in $100 \mathrm{ml}$ TBS pH 7,4 (Tabelle 2, 3, 4).

Die Auswertung erfolgte digital. Hierzu wurden alle Gewebeschnitte mit einem Objektträger-Scanner (Olympus BX-REMCB) digitalisiert. Mit Hilfe von Olympus DotSlide 2.1 und Gimp 2.6.11 wurde das Dateiformat bearbeitet. Die Auswertung erfolgte mit Adobe Photoshop CS5, indem für die obere Schicht der LP 10 Kästchen mit der Größe von $225 \mathrm{Pixel}^{2}$, insgesamt $2250 \mathrm{Pixel}^{2}$ (100\%), ausgeschnitten wurden. Für die mittlere Schicht wurden 10 Kästchen mit der Größe von $841 \mathrm{Pixel}^{2}$, insgesamt $8410 \mathrm{Pixel}^{2}$ (100 \%) ausgewählt. Die Durchführung erfolgte am unverdauten und verdauten Gewebeschnitt 
möglichst an der gleichen Stelle. Die jeweils 10 isolierten Quadrate wurden quantitativ auf ihre Blaufärbung mit dem Programm Axiovision 3.1 von Zeiss untersucht. Mittels einer Farbpipette wurde dort das blau erscheinende Gewebe markiert und als Gesamtfläche ausgedrückt. Das erfolgte auch mit dem kongruenten Bild, welches vorher mit dem HAVerdau behandelt wurde (Tabelle 2, 3, 4).

\subsubsection{Immunhistochemie mit dem Antikörper CD34 zur Gefäßdarstellung}

Die Gewebeschnitte wurden entparafiniert, wie oben beschrieben. Nachdem die Präparate mit destilliertem Wasser gespült worden waren, folgte die fünfminütige Inkubation zur Blockung mit BSA (2 \%) und für 30 min mit dem Primärantikörper CD 34 (1/400) zur Darstellung von Gefäßstrukturen. Danach wurden die Schnitte für 3 min mit TBS (Ansatz 1) gewaschen, und es folgte die Inkubation für $20 \mathrm{~min}$ mit dem Sekundärantikörper (Detektions-Kit). Zur Sichtbarmachung wurden die Präparate in alkalischer Phosphatase (Detektions-Kit) für $20 \mathrm{~min}$ inkubiert und mit Fast Red (Detektions-Kit) zweimal für 10 min sowie mit Hämalaun nach Mayer für 45 sek gefärbt. Anschließend erfolgte die dauerhafte Eindeckung. Ansatz 1 besteht aus: 12,1 $\mathrm{g}$ Tris, $\mathrm{NaCl} 17,53 \mathrm{~g}$ auf $\mathrm{pH} 7,4$ eingestellt mittels $\mathrm{HCl}$ ( $37 \%$ ) (Tabelle 2, 3, 4).

\subsection{Quantitative Bestimmung der Ribonukleinsäure- Expression}

\subsubsection{Entparaffinierung und Ribonukleinsäure-Isolierung}

Die Ribonukleinsäure (RNA)-Isolierung erfolgte mittels RNeasy® Mini-Kit (50) der Firma Qiagen nach Protokoll des Herstellers. Als erstes wurden von jedem Paraffinblock 10 Schnitte mit einer Stärke von 10,0 $\mu \mathrm{m}$ mit einem Schlittenmikrotom hergestellt und in ein beschriftetes Eppendorf-Cup gegeben. Mehrmals wurde $60,0{ }^{\circ} \mathrm{C}$ warmes Isopropanol zur Entparaffinierung hinzugefügt. Anschließend wurden $600 \mu 1$ vom Lysis-Puffer RLTPuffer/ $\beta$-Mercapto dazugegeben, die Proben gut gemixt und über Nacht bei $-20,0{ }^{\circ} \mathrm{C}$ eingefroren. Nachdem das Gewebe aufgetaut und mit „Shreddersäulen“, aus dem jeweiligen Kit, zerkleinert wurde, erfolgten mehrmalige Abzentrifugationen bei $10.000 \mathrm{rpm}$ und Waschvorgänge mit $700 \mu \mathrm{l}$ RW1-Pufferlösung und zweimal mit $500 \mu 1$ RPE-Pufferlösung. Die so gebundene RNA wurde mit $20 \mu$ l Rnase-freiem Wasser aus dem Filter gelöst bei $13.000 \mathrm{rpm}$ zentrifugiert und bei $-80,0{ }^{\circ} \mathrm{C}$ gelagert (Tabelle 2, 3, 4). 


\subsubsection{Reverse Transkription}

Die Umschreibung der RNA erfolgte mittels Omniscript ${ }^{\circledR}$ RT Kit (50) der Firma Qiagen gemäß den Herstellerangaben. Die genomische DNA Elimination wurde bei $42,0{ }^{\circ} \mathrm{C}$ für 2 min im Thermocycler durchgeführt. Die Reaktion wurde unterbrochen, indem die Proben sofort auf Eis gestellt wurden. Danach folgte die reverse Transkription gemäß den Angaben für 15 min bei $42,0^{\circ} \mathrm{C}$ und 3 min bei $95,0{ }^{\circ} \mathrm{C}$. Anschließend wurden die Proben bei $4,0{ }^{\circ} \mathrm{C}$ gehalten und mit $\mathrm{H}_{2} \mathrm{O}$ auf eine gesamte Konzentration von 500,0 ng aufgefüllt. Die c-DNA wurde bis zum Gebrauch bei $-20^{\circ} \mathrm{C}$ gelagert (Tabelle 2, 3, 4).

\subsubsection{Real-Time Polymerasekettenreaktion}

Mittels Real-Time Transkriptase-Polymerase-Kettenreaktion (RT-PCR) wurden die HASyntheasen HAS-1, -2, -3 und die Hyaluronidasen Hyal-1 und -2 untersucht. Die Auftragung erfolgte in 8er-Streifen, jeweils für 16 Patienten pro Ansatz in einfacher Bestimmung und einer Negativ-Kontrolle, in welcher die Menge an cDNA durch $\mathrm{H}_{2} \mathrm{O}$ ersetzt wurde. Zusätzlich wurde für jede PCR das „Housekeeping-Gen“ (ARP) pro Patient bestimmt. SYBR $^{\circledR}$ Green 1 wurde als Fluoreszenzfarbstoff verwendet (Tabelle 2, 3, 4, 5).

Ansatz pro Cup in einem 8er Streifen: $10 \mu 1$ Syber Green, 0,15 $\mu 1$ Primer forward, 0,15 $\mu 1$ Primer reverse, 4,70 $\mu 1$ RNAse freies $\mathrm{H}_{2} 0$ und 5,00 $\mu$ l cDNA (Tabelle 2, 3, 4, 6, 7, 8, 9 ).

Tabelle 5: Protokoll für ARP

\begin{tabular}{|l|l|l|l|}
\hline \multicolumn{2}{|l|}{ Protokoll für ARP pro CUP im 8er Streifen: } \\
\hline 1. Zyklus $95,0^{\circ} \mathrm{C}$ & $15 \mathrm{~min}$ & Auftrennung der DNA & $1 \mathrm{x}$ \\
\hline 2. Zyklus: & & Denaturierung & \\
$95,0^{\circ} \mathrm{C}$ & $30 \mathrm{sek}$ & & $40 \mathrm{x}$ \\
$59,0{ }^{\circ} \mathrm{C}$ & $30 \mathrm{sek}$ & & \\
$72,0{ }^{\circ} \mathrm{C}$ & $30 \mathrm{sek}$ & Anlagerung der Primer und Elongation & $50 \mathrm{x}$ \\
\hline 3. Zyklus $70,0{ }^{\circ} \mathrm{C}$ & $10 \mathrm{sek}$ & & Halten \\
\hline 4. Zyklus $4,0{ }^{\circ} \mathrm{C}$ & & 5 - CGACCTGGAAGTCCAACTAC -3 \\
\hline Primer forward (ARP): & 5 - ATCTGCTGCATCTGCTTG -3 \\
\hline \multicolumn{2}{|l|}{ Primer reverse (ARP): } & & \\
\hline
\end{tabular}


Tabelle 6: Protokoll für Hyaluronsynthase-1

\begin{tabular}{|c|c|c|c|}
\hline \multicolumn{4}{|c|}{ Protokoll für Hyaluronsynthase-1: } \\
\hline 1. Zyklus $95,0^{\circ} \mathrm{C}$ & $15 \mathrm{~min}$ & Auftrennung der DNA & $1 \mathrm{x}$ \\
\hline 2. Zyklus: & & Denaturierung & \\
\hline $95,0^{\circ} \mathrm{C}$ & 30 sek & & \\
\hline $58,0^{\circ} \mathrm{C}$ & $1 \mathrm{~min}$ & & $40 x$ \\
\hline $72,0^{\circ} \mathrm{C}$ & 30 sek & & \\
\hline 3. Zyklus $60,0^{\circ} \mathrm{C}$ & $10 \mathrm{sek}$ & Anlagerung der Primer und Elongation & $80 \mathrm{x}$ \\
\hline 4. Zyklus $4,0^{\circ} \mathrm{C}$ & & & Halten \\
\hline \multicolumn{2}{|c|}{ Primer forward (HAS-1): } & \multicolumn{2}{|c|}{ 5'- GGAATAACCTCTTGCAGCAGTTTC -3' } \\
\hline \multicolumn{2}{|c|}{ Primer reverse (HAS-1): } & \multicolumn{2}{|l|}{ 5'- GCCGGTCATCCCCAAAAG -3' } \\
\hline
\end{tabular}

Tabelle 7: Protokoll für Hyaluronsynthase-2

\begin{tabular}{|c|c|c|c|}
\hline \multicolumn{4}{|c|}{ Protokoll für Hyaluronsynthase-2: } \\
\hline 1. Zyklus $95,0{ }^{\circ} \mathrm{C}$ & $15 \mathrm{~min}$ & Auftrennung der DNA & $1 \mathrm{x}$ \\
\hline 2. Zyklus: & & Denaturierung & \\
\hline $95,0^{\circ} \mathrm{C}$ & 30 sek & & \\
\hline $54,0^{\circ} \mathrm{C}$ & $1 \mathrm{~min}$ & & $40 \mathrm{x}$ \\
\hline $72,0^{\circ} \mathrm{C}$ & 30 sek & & \\
\hline 3. Zyklus $60,0^{\circ} \mathrm{C}$ & $10 \mathrm{sek}$ & Anlagerung der Primer und Elongation & $80 \mathrm{x}$ \\
\hline 4. Zyklus $4,0^{\circ} \mathrm{C}$ & & & Halten \\
\hline \multicolumn{2}{|c|}{ Primer forward (HAS-2): } & \multicolumn{2}{|l|}{ 5' - TCGCAACACGTAACGCAAT -3' } \\
\hline \multicolumn{2}{|c|}{ Primer reverse (HAS-2): } & \multicolumn{2}{|c|}{ 5' - АСТTCTCTTTTTCCACCCCATTT -3' } \\
\hline
\end{tabular}


Tabelle 8: Protokoll für Hyaluronsynthase-3

\begin{tabular}{|c|c|c|c|}
\hline \multicolumn{4}{|c|}{ Protokoll für Hyaluronsynthase-3: } \\
\hline 1. Zyklus $95,0^{\circ} \mathrm{C}$ & $15 \mathrm{~min}$ & Auftrennung der DNA & $1 \mathrm{x}$ \\
\hline 2. Zyklus: & & Denaturierung & \\
\hline $95,0^{\circ} \mathrm{C}$ & 30 sek & & \\
\hline $56,0^{\circ} \mathrm{C}$ & $1 \mathrm{~min}$ & & $40 x$ \\
\hline $72,0^{\circ} \mathrm{C}$ & 30 sek & & \\
\hline 3. Zyklus $60,0^{\circ} \mathrm{C}$ & $10 \mathrm{sek}$ & Anlagerung der Primer und Elongation & $80 x$ \\
\hline 4. Zyklus $4,0^{\circ} \mathrm{C}$ & & & Halten \\
\hline \multicolumn{2}{|c|}{ Primer forward (HAS-3): } & \multicolumn{2}{|c|}{ 5' - AACAAGTACGACTCATGGATTTCCT -3’ } \\
\hline \multicolumn{2}{|c|}{ Primer reverse (HAS-3): } & \multicolumn{2}{|l|}{ 5'- GCCCGCTCCACGTTGA -3' } \\
\hline
\end{tabular}

Tabelle 9: Protokoll für Hyaluronidase-1 und -2

\begin{tabular}{|c|c|c|c|}
\hline \multicolumn{4}{|c|}{ Protokoll für Hyaluronidase-1 und -2} \\
\hline 1. Zyklus $95,0^{\circ} \mathrm{C}$ & $15 \mathrm{~min}$ & Auftrennung der DNA & $1 \mathrm{x}$ \\
\hline 2. Zyklus: & & Denaturierung & \\
\hline $95,0^{\circ} \mathrm{C}$ & 30 sek & & \\
\hline $60,0^{\circ} \mathrm{C}$ & $1 \mathrm{~min}$ & & $40 \mathrm{x}$ \\
\hline $72,0^{\circ} \mathrm{C}$ & 30 sek & & \\
\hline 3. Zyklus $60,0^{\circ} \mathrm{C}$ & 10 sek & Anlagerung der Primer, Elongation & $80 \mathrm{x}$ \\
\hline 4. Zyklus $4,0^{\circ} \mathrm{C}$ & & & Halten \\
\hline \multicolumn{2}{|c|}{ Primer forward (Hyal-1): } & \multicolumn{2}{|c|}{ 5'-GATGTCAGTGTCTTCGATGTGGTA-3' } \\
\hline \multicolumn{2}{|c|}{ Primer reverse (Hyal-1): } & \multicolumn{2}{|c|}{ 5'-GGGAGCTATAGAAAATTGTCATGTCA-3' } \\
\hline \multicolumn{2}{|c|}{ Primer forward (Hyal-2): } & \multicolumn{2}{|c|}{ 5'-CTAATGAGGGTTTTGTGAACCAGAATAT-3' } \\
\hline \multicolumn{2}{|c|}{ Primer reverse (Hyal-2): } & \multicolumn{2}{|c|}{ 5'-GCAGAATCGAAGCGTGGATAC-3' } \\
\hline
\end{tabular}

So konnte der ct-Wert (=Schwellenwert-Zyklus) des Zielgens bestimmt werden, an dem die DNA Amplifikation exponentiell beginnt. Bei diesem Wert steigt erstmals die Fluoreszenz des Farbstoffes SYBR ${ }^{\circledR}$ Green signifikant über die Hintergrundfluoreszenz. Ermittelt wurde die Genexpression durch folgende Formel: $\mathrm{y}=2^{-\Delta \mathrm{Ct}}, \Delta \mathrm{Ct}$ berechnete sich aus dem Schwellenwert des gesuchten Gens minus dem Schwellenwert des Standard- bzw. Housekeeping-Gen (ARP). 


\subsection{Statistische Analysen}

Die statistische Auswertung der Ergebnisse erfolgte unter Mitwirkung von Frau Dr. Imme Haubitz mit Hilfe des Computerprogramms MEDAS (C. Grund, Margetshöchheim).

Die Dependenz von zwei klassifizierten Variablen wurde mit dem Chi-Quadrat-Test nach der Maximum-Likelihood-Methode verifiziert. Bei niedrigen Erwartungswerten wurde mittels 4-Felder-Tafel der genaue Chi-Quadrat-Test nach Fischer und Yates errechnet sowie nach Mehta und Patel bei größeren Tafeln. Um zwei Gruppen zueinander zu vergleichen, wurde der U-Test nach Mann und Whitney verwendet, da keine Gaußsche Normalverteilung der Werte angenommen werden kann. Als Signifikanzniveau wurde eine Irrtumswahrscheinlichkeit von fünf Prozent $(p<0,05)$ vorgegeben.

\section{$3 \quad$ Ergebnisse}

\subsection{Gewebekollektiv, Geschlecht und Alter}

Die Proben für die lichtmikroskopische Untersuchung stammten aus dem Zeitraum 2006 2012 aus der UMG. Für die Untersuchungen in der EZM der LP wurden max. 57 Proben, von 50 Patienten ( $\mathrm{n}=41$ weiblich und $\mathrm{n}=9$ männlich) mit einem klinisch und histologisch nachgewiesenen RE begutachtet. Zusätzlich wurde ein Vergleichskollektiv aus max. 60 Proben von 55 Patienten ( $\mathrm{n}=23$ weiblich und $\mathrm{n}=32$ männlich) mit anderen pathologischen Veränderungen (Nicht-Reinke-Ödem) an der SL untersucht (vgl. Tabelle 10).

Tabelle 10: Verteilung der N-RE -Veränderungen im Vergleichskollektiv

\begin{tabular}{|l|c|c|}
\hline \multicolumn{1}{|c|}{ Pathologie } & Probenanzahl & Patientenzahl \\
\hline Hyperplasie & 25 & 20 \\
\hline Leukoplakie & 22 & 21 \\
\hline SL-Polyp & 5 & 5 \\
\hline Retentionszyste & 3 & 4 \\
\hline Fibrose & 2 & 2 \\
\hline Papillom & 1 & 1 \\
\hline Chron. Ulcus & 1 & 1 \\
\hline Ca in situ & 1 & 1 \\
\hline Reinke-Ödem & 57 & 50 \\
\hline
\end{tabular}


Die Geschlechterverteilung zwischen den beiden Kollektiven ist statistisch signifikant ( $\mathrm{pc}=0,000017$ ) für die RE-Patienten das weibliche und für das Vergleichskollektiv das männliche Geschlecht. Im Mittelwert sind die Reinke-Patienten 55,7 Jahre und das Vergleichskollektiv 59,5 Jahre alt. Der Altersunterschied von 3,8 Jahren ist statistisch nicht signifikant $\left(\mathrm{p}_{\mathrm{u}}=0,076\right)$.

\subsection{Klinischer und histologischer Befund der Stimmlippe, Rauchverhalten und Risikofaktoren bei RE-Patienten}

Bei den RE-Patienten traten im klinischen laryngoskopischen Befund hauptsächlich hochgradige Ödembefunde auf (Abbildung 12).

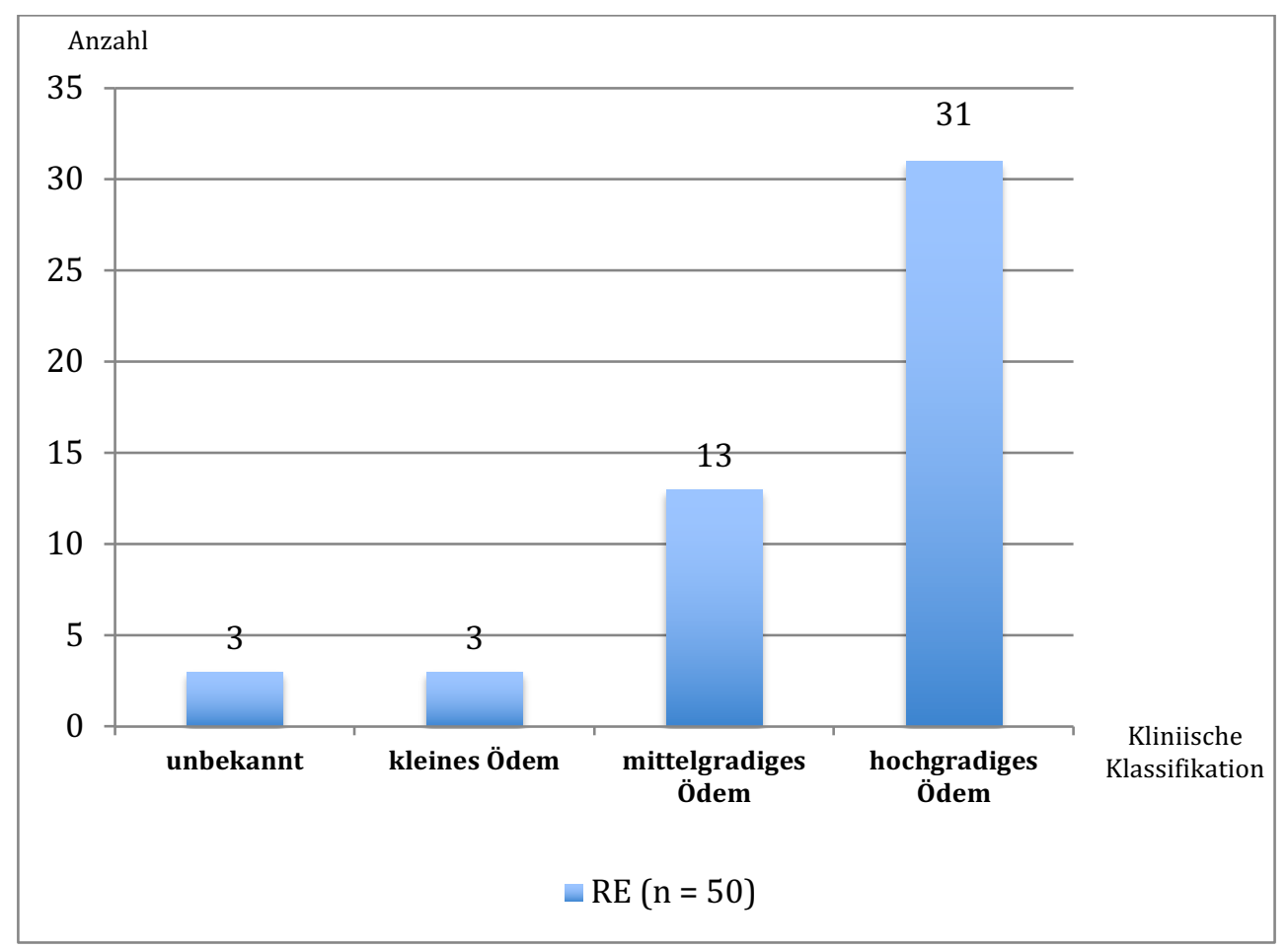

Abbildung 12: Verteilung des klinischen Befundes bei Patienten mit einem Reinke-Ödem 
Das histologische Ödemausmaß war in der oberen LP gering. Dort sind hauptsächlich aufgelockerte Gewebestrukturen $\mathrm{zu}$ finden. In der mittleren LP dagegen war das Ödemausmaß deutlich erkennbar (Abbildung 13). Hier sah man großflächige Lakunen, die das Gewebe verdrängten (Abbildung 14). Es gibt keine statistischen Signifikanzen zwischen der klinischen Klassifikation des RE und der histologischen Klassifikation des RE sowohl für die obere LP $(p=0,72)$ als auch für die mittlere LP $(p=0,10)$.

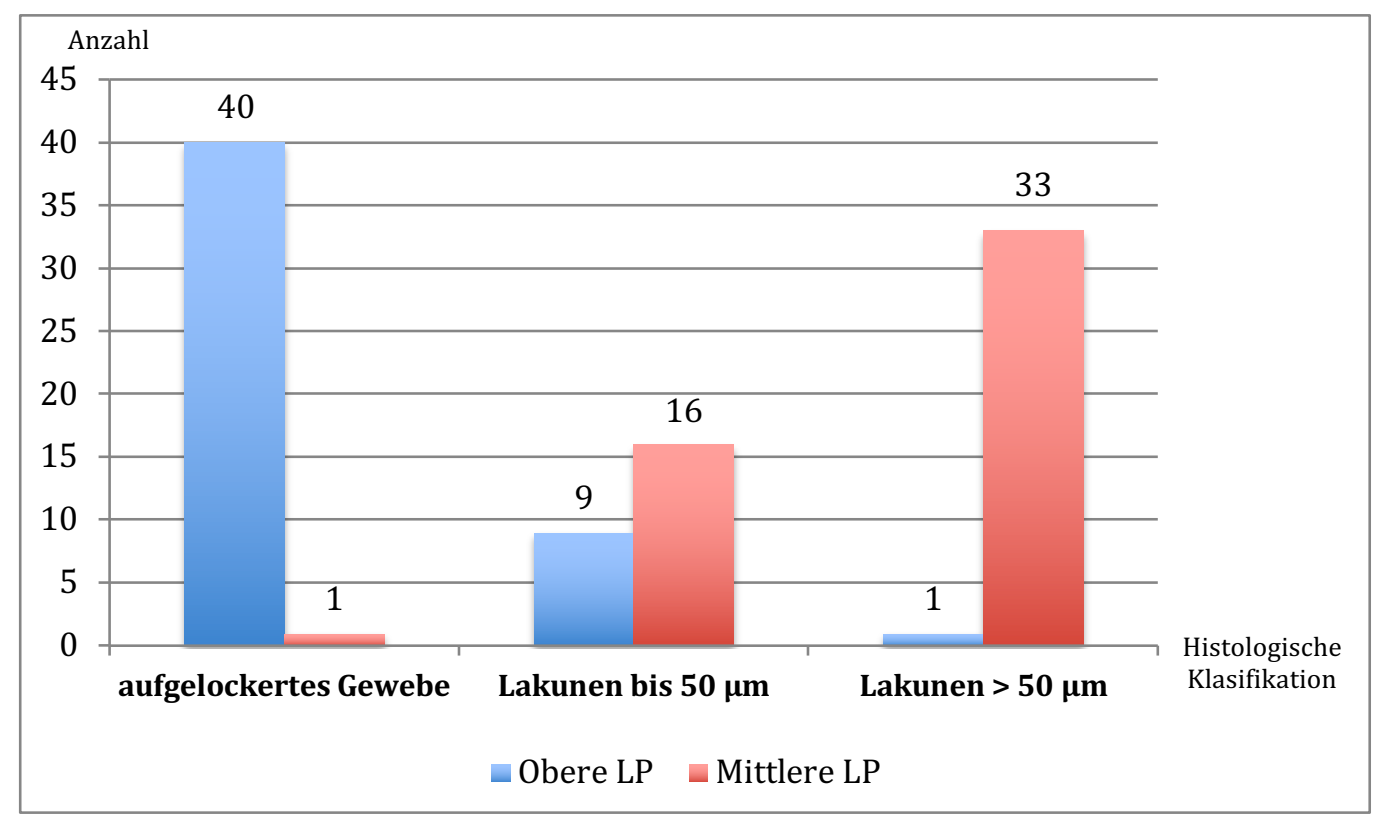

Abbildung 13: Histologisches Ödemausmaß für die obere und mittlere LP bei den Reinke-Ödem Patienten

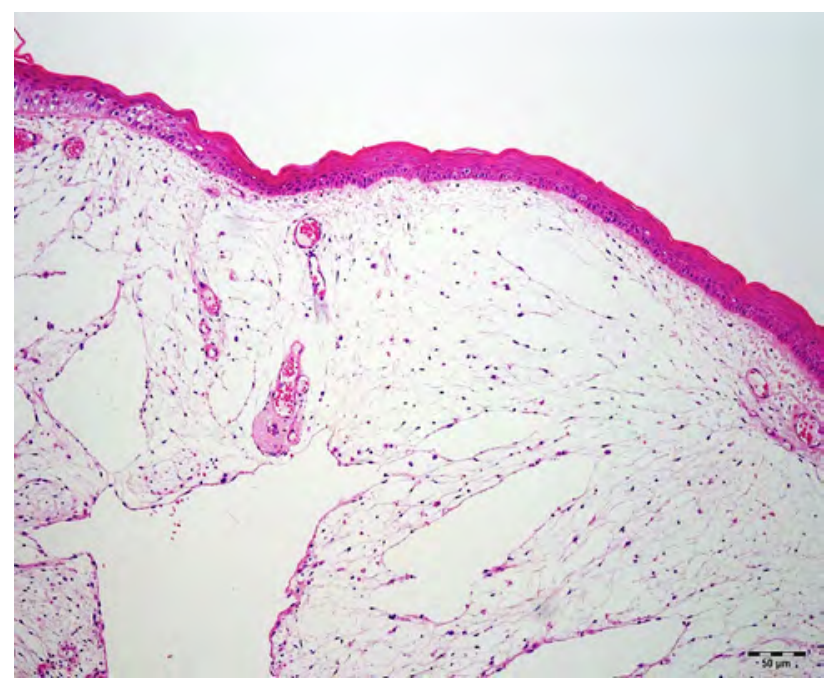

Abbildung 14: Reinke-Ödem mit leichter Gewebeauflockerung in der oberen LP und großen Lakunen in der mittleren LP, 10x Vergrößerung in HE-Färbung 
Die meisten RE-Patienten rauchen zwischen 10 und 20 Zigaretten am Tag (Abbildung 15).

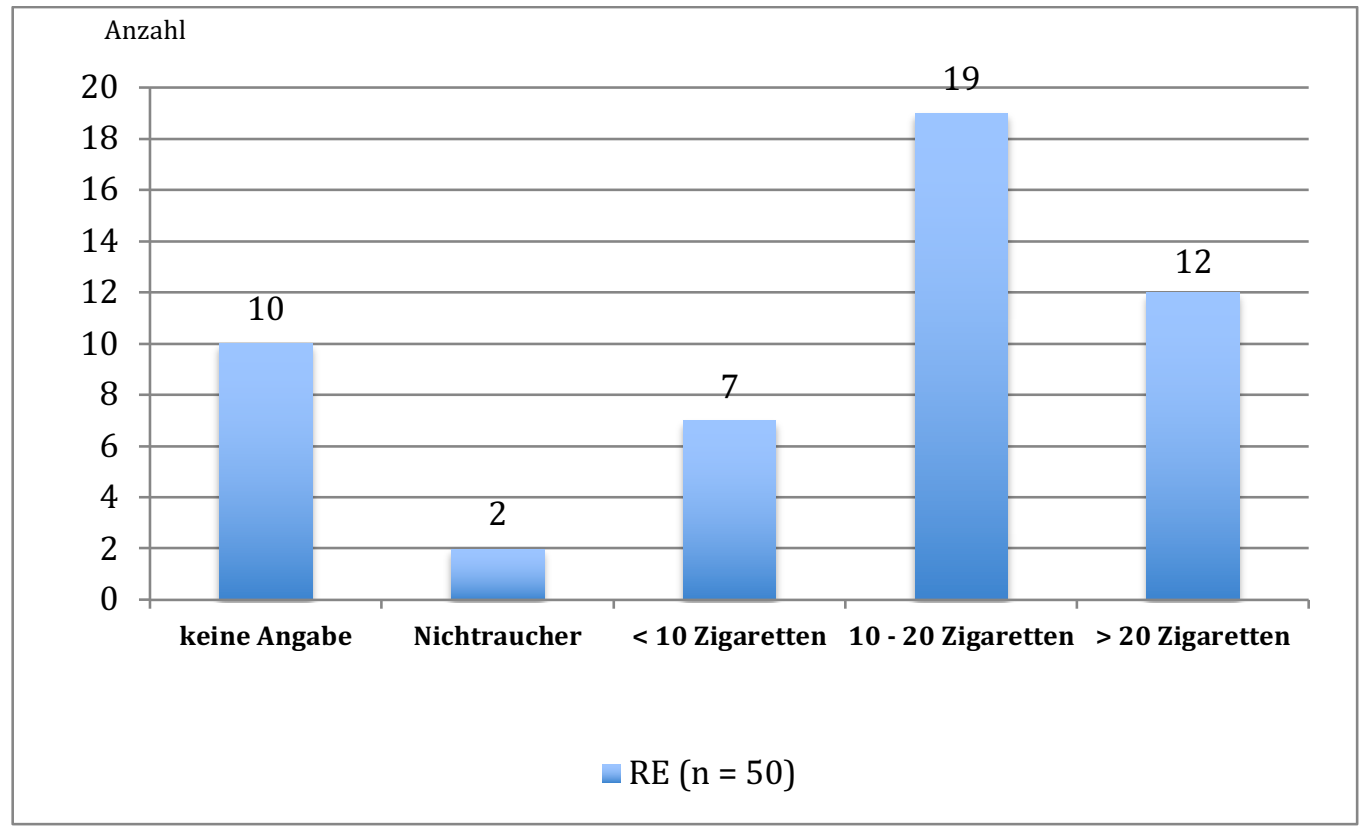

Abbildung 15: Rauchverhalten der RE-Patienten in Zigaretten pro Tag

Eine hohe Stimmbelastung zeigte sich nur bei 8 von 50 RE-Patienten. Ein ösophageler Reflux wurde nur bei 10 von 50 Patienten nachgewiesen.

\subsection{Untersuchungen der Hyaluronsäure in der Lamina propria}

Es wurden 50 Patientenproben mit einem klinisch und histologisch nachgewiesenen RE untersucht. Das Vergleichskollektiv bestand aus 55 Patienten. Bei Patienten mit einem RE war mehr HA in der oberen und mittleren LP vorhanden als in den Kontrollproben (Abbildung 16, 17, 18). Bei Patienten mit einem RE zeigte die obere Schicht der LP eine Konzentration im Median von 36,96 \% HA und die mittlere Schicht der LP 45,74 \% (Abbildung 18). Im Vergleichskollektiv zeigten sich im Median in der oberen Schicht der LP mit 3,27\% und in der mittleren Schicht der LP mit 3,02\% insgesamt geringere Konzentrationen an HA (Abbildung 18). Es zeigte sich eine statistische Signifikanz zwischen den Patienten mit einem RE und dem Vergleichskollektiv für beide Schichten $(\mathrm{p}=0,000005)$. Es gibt keine Abhängigkeit zwischen dem Alter der Patienten und der Menge an HA in der LP (Abbildung 20).

Männer mit einem RE zeigten in der oberen LP im Median (1091 Pixel²) mehr HA als Frauen (799 Pixel $^{2}$ ). Dagegen zeigten in der mittleren LP im Median Frauen (4634,5 Pixel $^{2}$ ) mehr HA als Männer (3423 Pixel²) (Abbildung 19). 

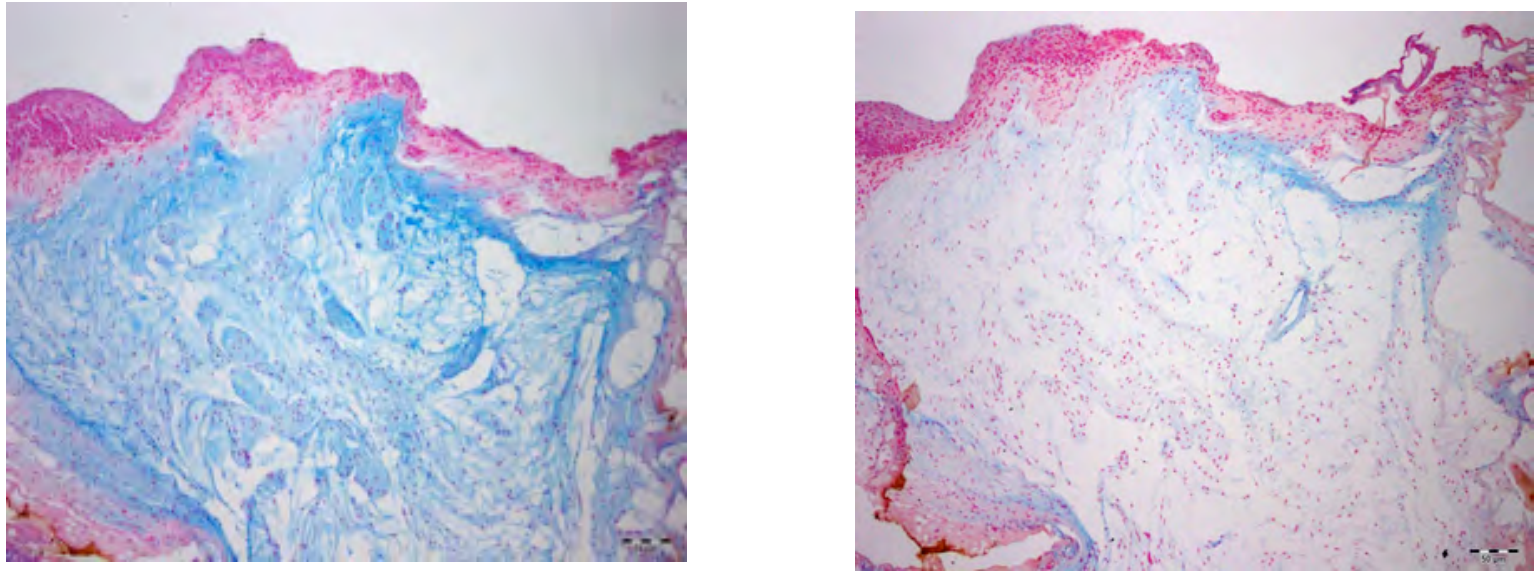

Abbildung 16: Reinke-Ödem ohne Hyaluronidase (links), Reinke-Ödem mit Hyaluronidase behandelt (rechts), in 10x Vergrößerung und Alcianblau-Färbung
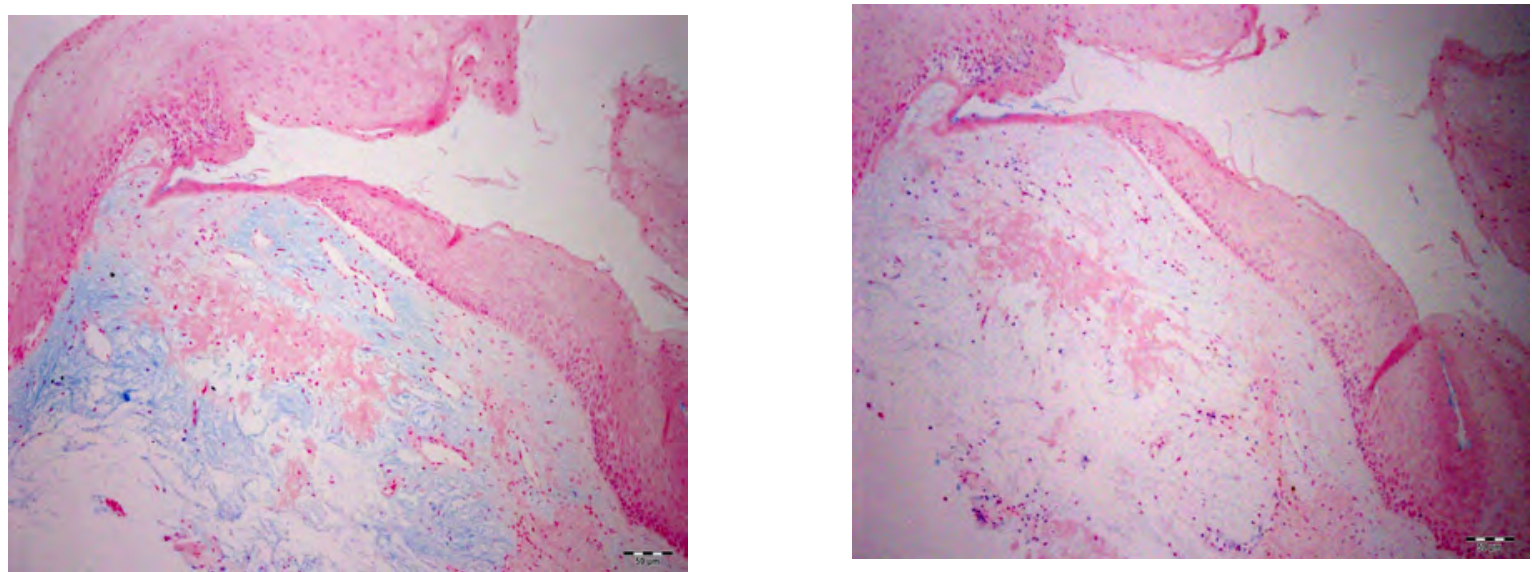

Abbildung 17: Stimmlippenpolyp ohne Hyaluronidase (links), Stimmlippenpolyp mit Hyaluronidase behandelt (rechts), in 10x Vergrößerung und Alcianblau-Färbung

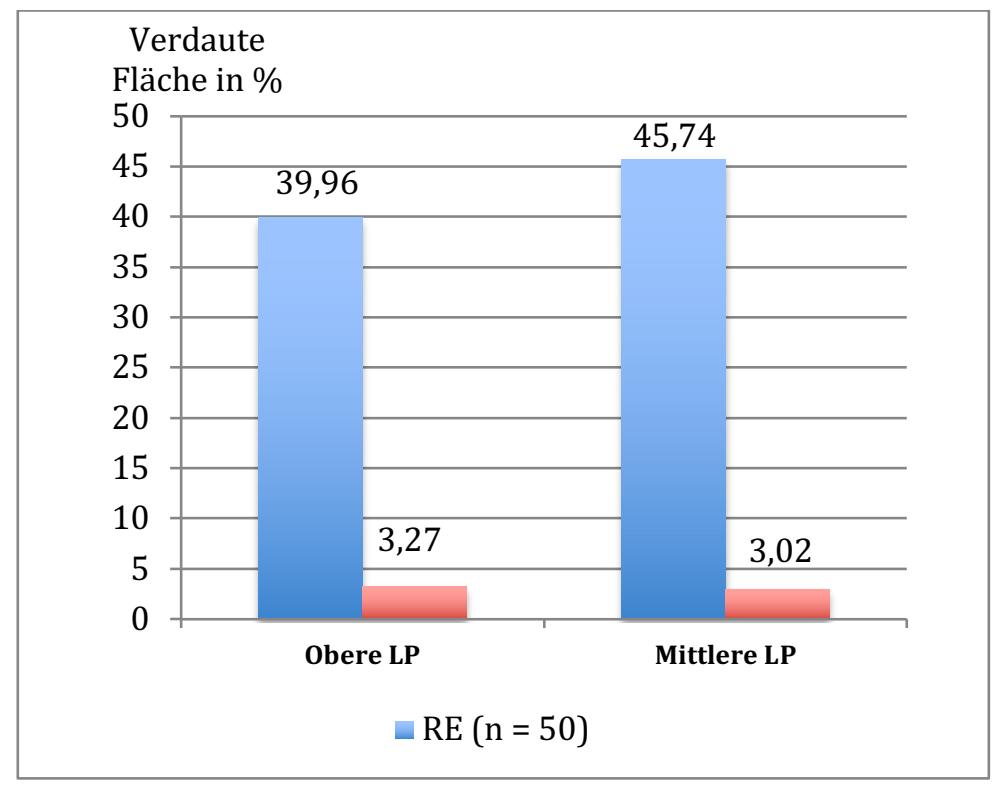

Abbildung 18: Verteilung der HA in der LP im Medianwert 


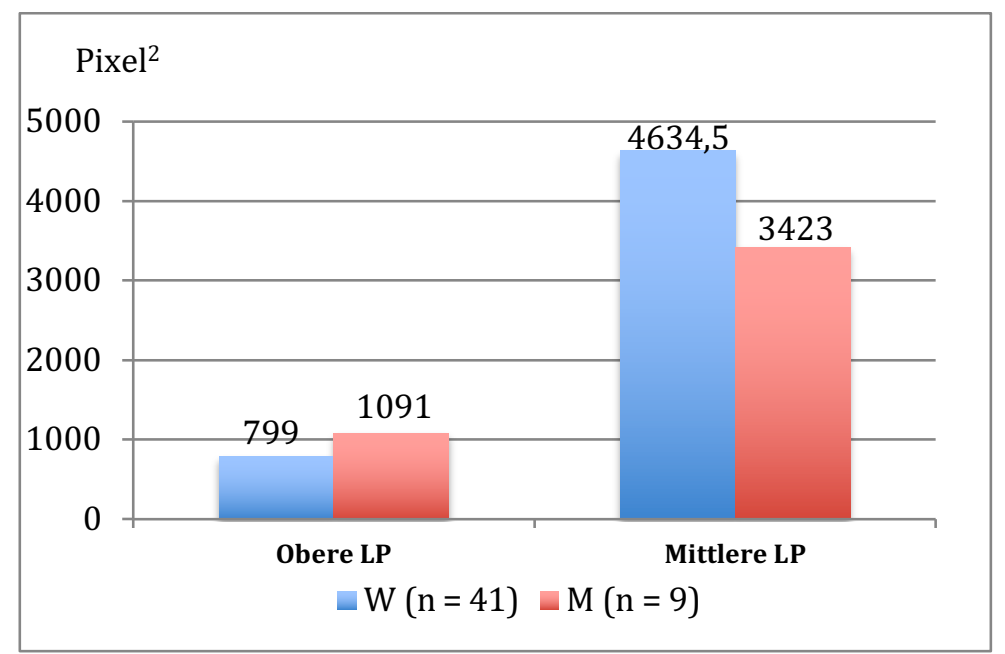

Abbildung 19: Geschlechtsspezifische Verteilung der HA in der LP bei Patienten mit RE

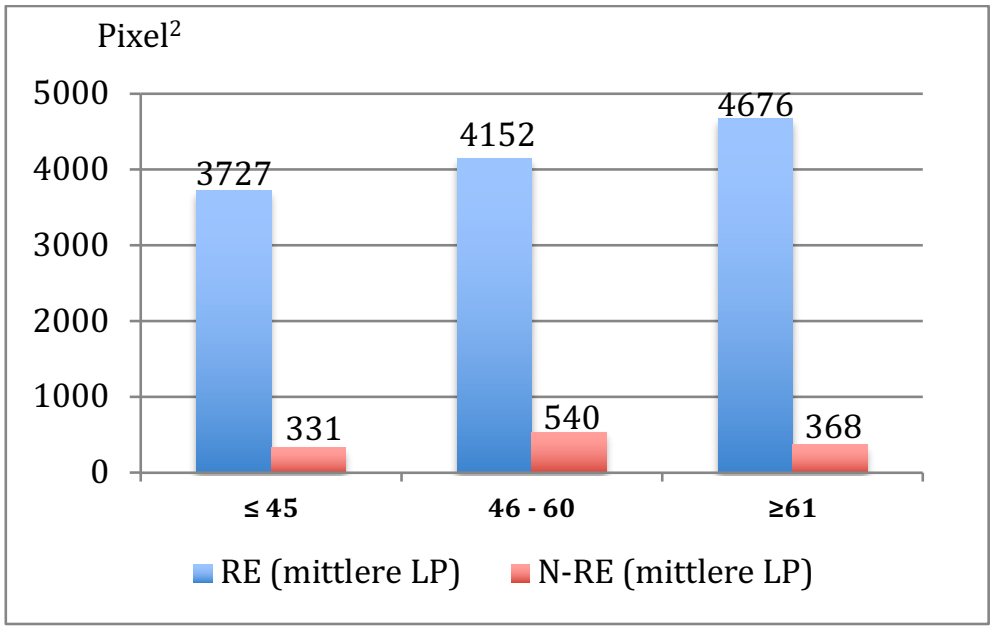

Abbildung 20: Altersabhängige Verteilung der HA in der mittleren LP

\subsection{Untersuchungen der Kollagenfasern in der Lamina propria}

Für die Begutachtung der Kollagenfaserqualität und -quantität wurden 57 Proben von 50

Patienten mit einem klinisch und histologisch nachgewiesenen RE untersucht. Als Vergleichskollektiv standen 57 Proben von 53 Patienten mit N-RE Veränderungen zur Verfügung. 
Tabelle 11: Auswertung der Kollagenfaserqualität und -quantität in der oberen und mittleren LP von RE-Patienten und N-RE-Patienten

\begin{tabular}{|c|c|c|c|}
\hline \multicolumn{4}{|c|}{ Obere Schicht der LP } \\
\hline & $\mathbf{R E}(\mathrm{n}=50)$ & Nicht RE $(n=53)$ & $\begin{array}{l}\text { Statistische } \\
\text { Signifikanz }\end{array}$ \\
\hline Anordnung & Parallel & Parallel & $\mathrm{p}=0,014$ \\
\hline Faserdichte & Physiologisch & Physiologisch-Stark & $\mathrm{p}=0,025$ \\
\hline Vernetzung & Mäßig & Gering & $\mathrm{p}=0,00000001$ \\
\hline Typ I & Viel & Viele Fasern & $p=0,13$ \\
\hline Typ III & Mäßig & Mäßig & $\mathrm{p}=0,40$ \\
\hline \multicolumn{4}{|c|}{ Mittlere Schicht der LP } \\
\hline & $\mathbf{R E}(\mathrm{n}=50)$ & Nicht RE $(n=53)$ & $\begin{array}{l}\text { Statistische } \\
\text { Signifikanz }\end{array}$ \\
\hline Anordnung & Netzartig & Netzartig & $\mathrm{p}=0,011$ \\
\hline Faserdichte & Mäßig & Physiologisch & $\mathrm{p}=0,0000001$ \\
\hline Vernetzung & Gering & Mäßig & $\mathrm{p}=0,0000086_{\mathrm{mp}}$ \\
\hline Typ I & Wenig-mäßig & Mäßig & $\mathrm{p}=0,00098$ \\
\hline Typ III & Wenig-mäßig & Viel & $\mathrm{p}=0,0000048$ \\
\hline
\end{tabular}

Sowohl bei den RE-Patienten als auch im Vergleichskollektiv zeigte sich ein bandartige Anordnung der Kollagenfasern in der oberen LP $(\mathrm{p}=0,014)$ (vgl. Tabelle 11). Die Dichte an Kollagenfasern in der oberen LP bei RE-Patienten war physiologisch $(p=0,025)$ (Abbildung 21).

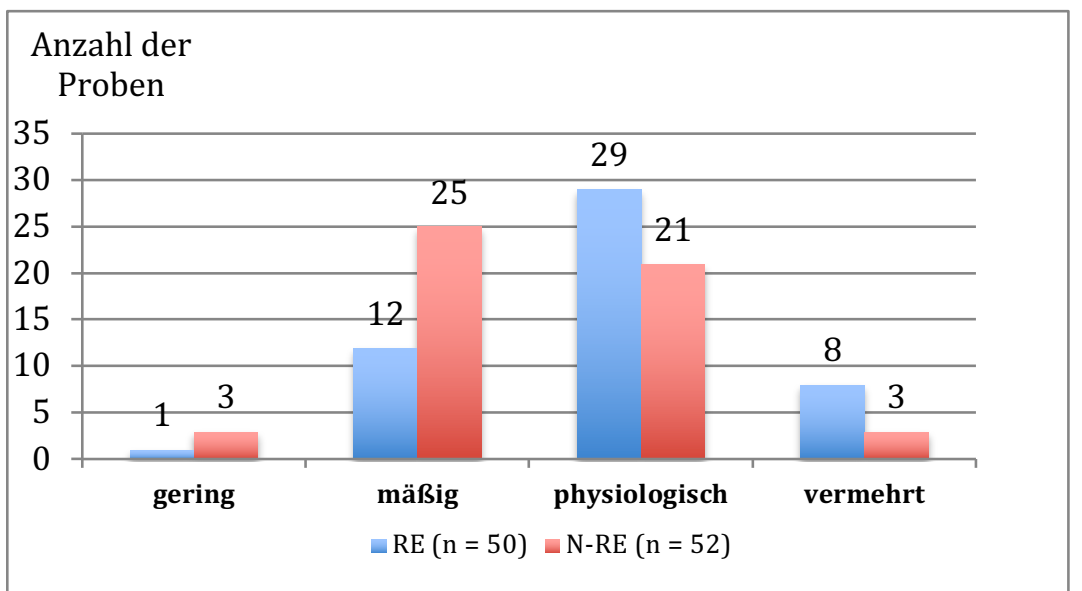

Abbildung 21 : Kollagenfaserdichte in der oberen LP bei RE- und N-RE-Patienten

In der mittleren LP zeigte sich eine geringere Dichte an Kollagenfasern bei den Patienten mit RE $(p=0,025)$, im Vergleich zum Vergleichskollektiv $(p=0,0000001)$ und zur oberen LP $(p=0,00000005)$ (Abbildung 22, 29). 


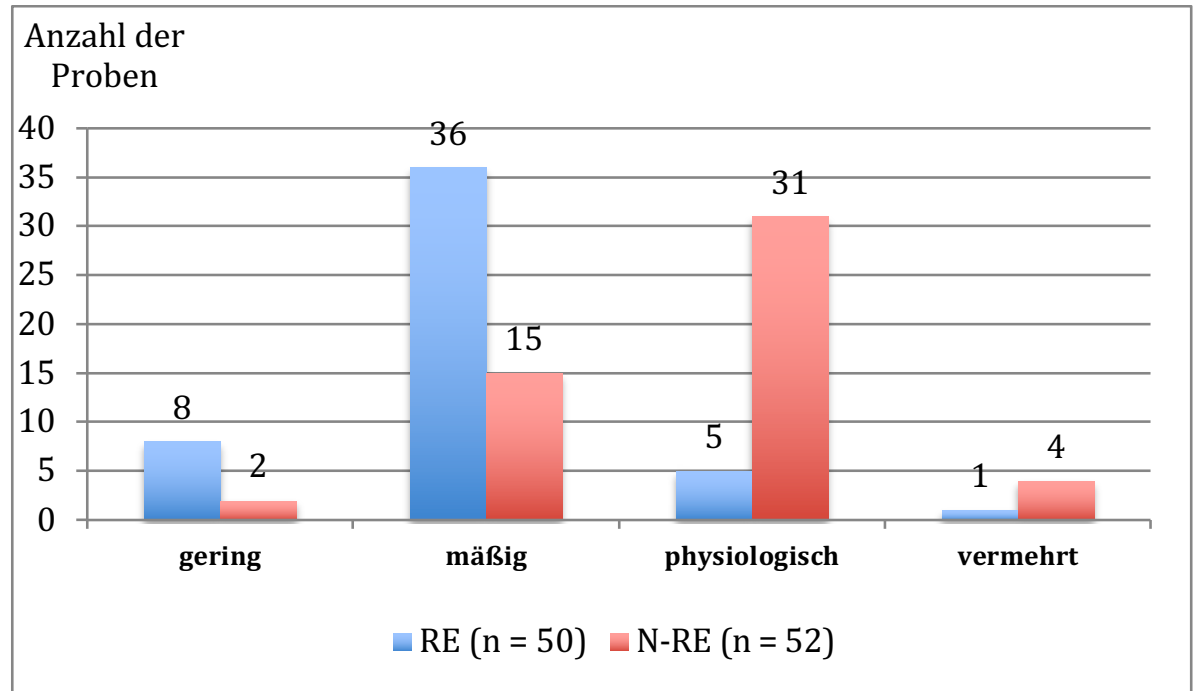

Abbildung 22: Kollagenfaserdichte in der mittleren LP bei RE- und N-RE-Patienten

Die Vernetzung der Kollagenfasern in der oberen LP zeigte sich mäßig bei den RE-Patienten und gering ausgeprägt bei dem Vergleichskollektiv ( $p=0,00000001)$ (Abbildung 23, 29).

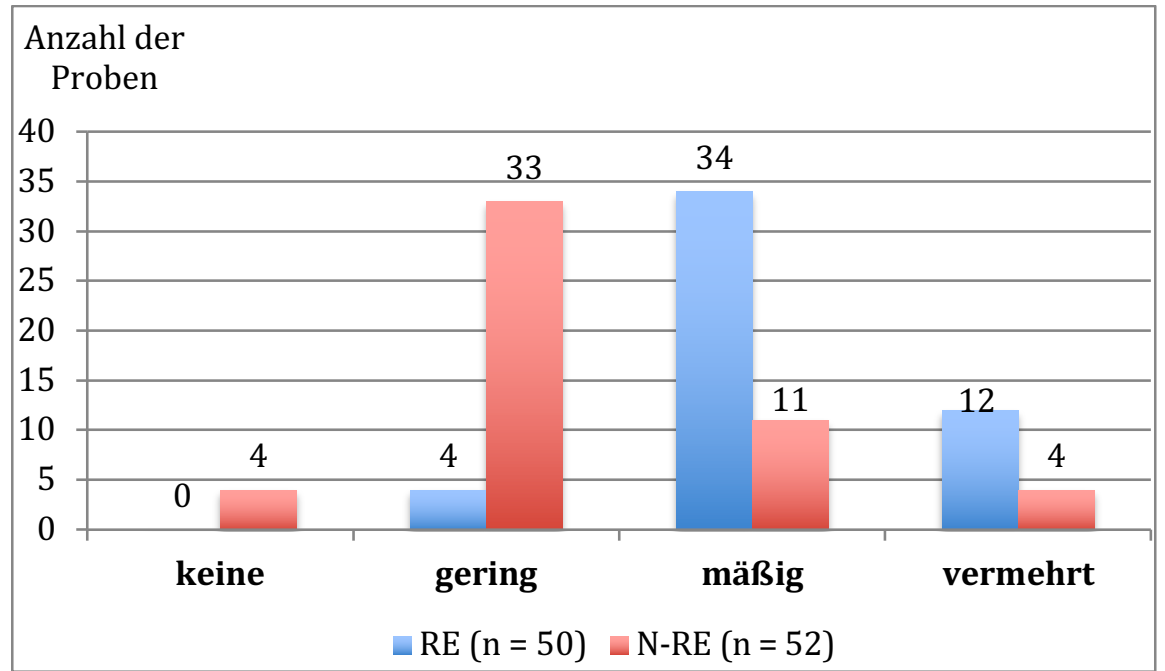

Abbildung 23: Vernetzung der Kollagenfasern in der oberen LP bei RE- und N-RE-Patienten

Die mittlere LP zeigte bei den RE-Proben im Verhältnis zur oberen LP eine geringere Vernetzung $(\mathrm{p}=0,00000005)$ und auch im Vergleich zum N-RE-Kollektiv $\left(\mathrm{p}=0,0000086_{\mathrm{mp}}\right)$ (Abbildung 24, 29). 


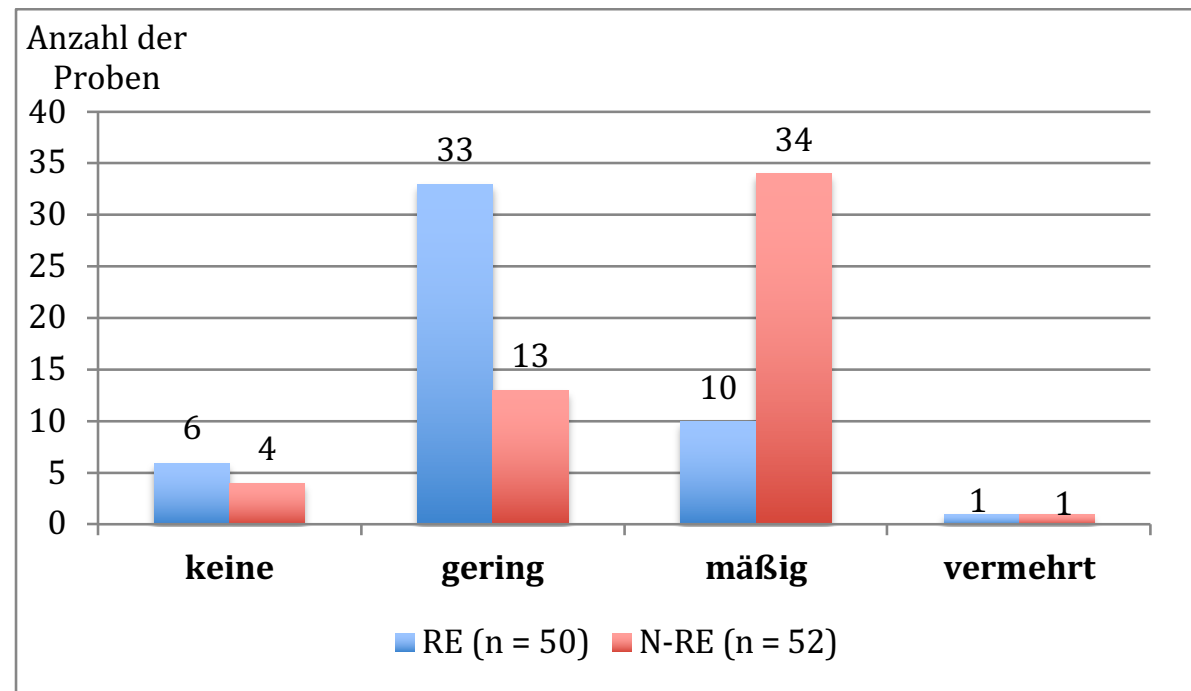

Abbildung 24: Vernetzung der Kollagenfasern in der mittleren LP bei RE und N-RE-Patienten

Die Verteilung von Kollagen Typ I war in der oberen LP bei Patienten mit einem RE ähnlich dem Vergleichskollektiv $(p=0,13)$ (Abbildung 25).

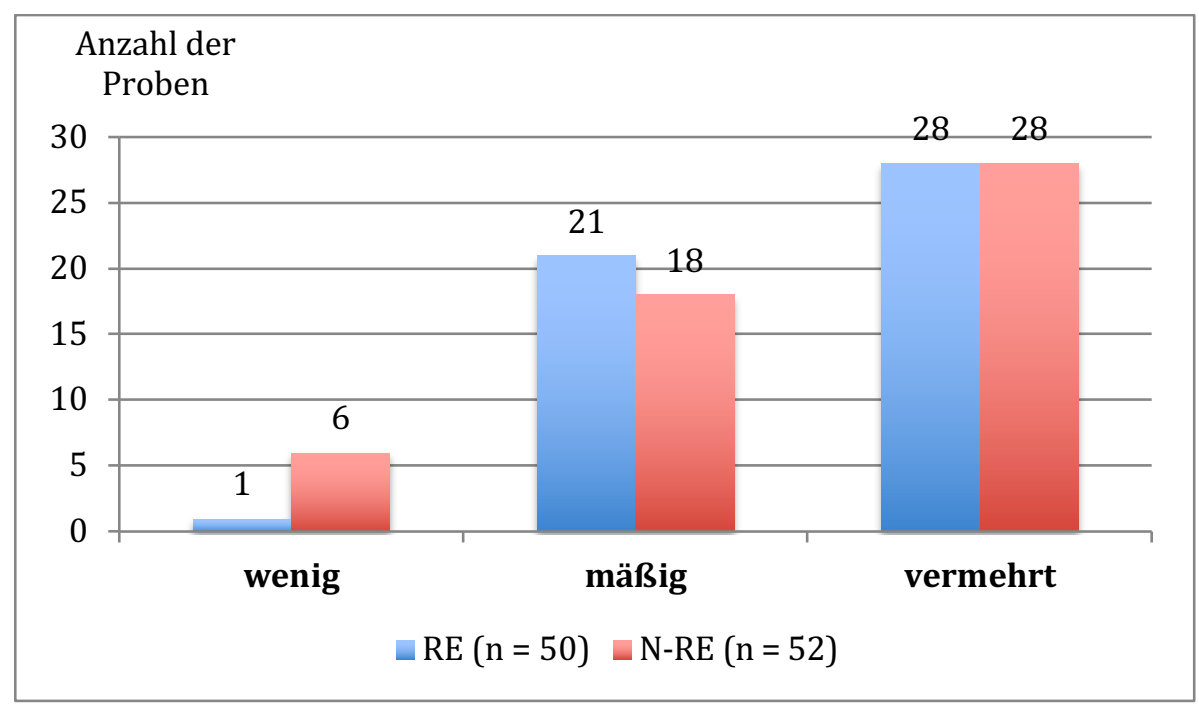

Abbildung 25: Verteilung der Kollagenfasern Typ I in der oberen LP bei RE und N-RE-Patienten

In der mittleren LP war im RE-Kollektiv weniger Kollagen von der Qualität Typ I zu finden im Vergleich zu der oberen LP ( $p=0,081)$ (Abbildung 26). Das Vergleichskollektiv zeigte auch mehr Kollagen Typ I in der mittleren LP $(p=0,00098)$ (Abbildung 26, 30). 


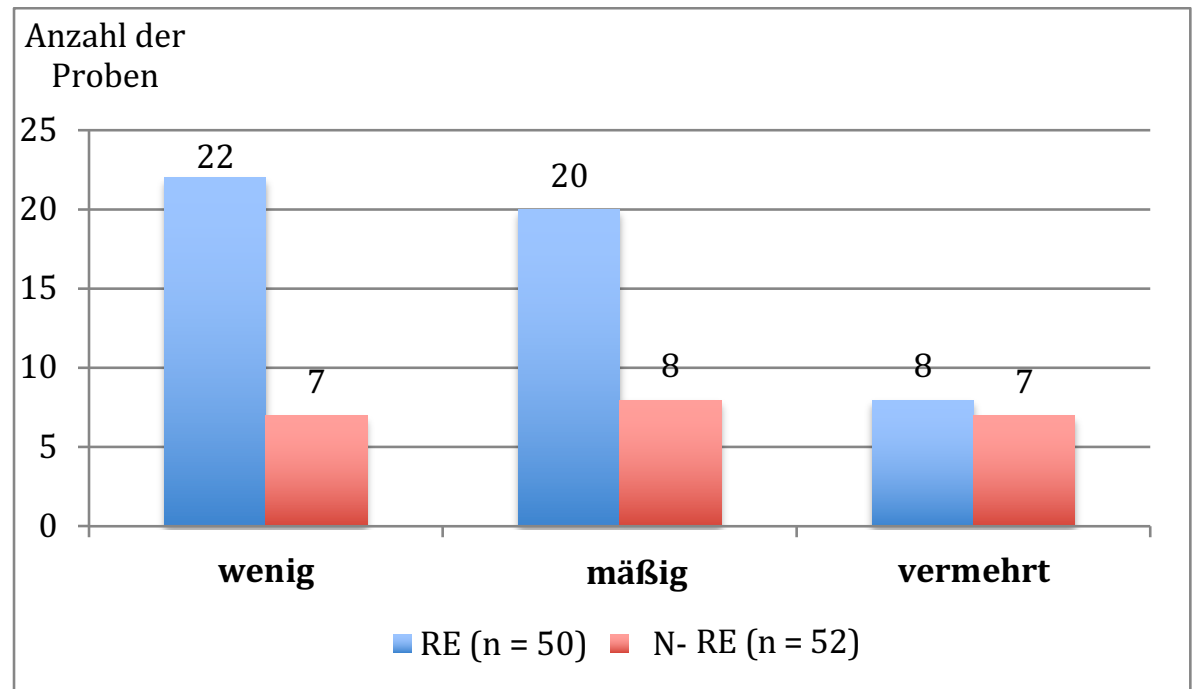

Abbildung 26: Verteilung der Kollagenfasern Typ I in der mittleren LP bei RE und N-RE-Patienten

Das Vorhandensein von Kollagen Typ III in der oberen LP war in bei dem N-RE Kollektiv vermehrt $(\mathrm{p}=0,40)($ Abbildung 27, 30).

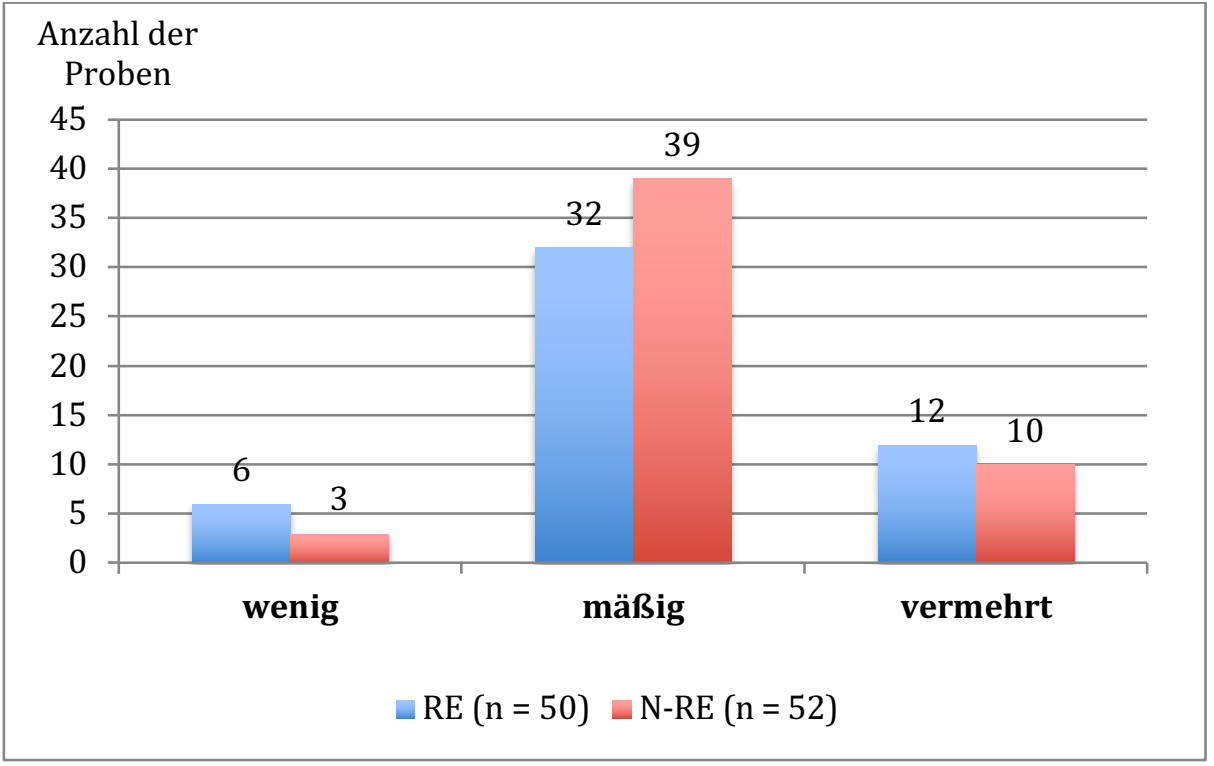

Abbildung 27: Verteilung der Kollagenfasern Typ III in der oberen LP bei RE und N-RE-Patienten

In der mittleren LP war bei den RE-Patienten weniger Kollagen Typ III vorhanden im Vergleich $\mathrm{zu}$ den anderen Pathologien $(\mathrm{p}=0,0000048)$ (Abbildung 28). Die Menge an Typ III im Verhältnis zur oberen LP war ähnlich $(\mathrm{p}=0,000016)$. 


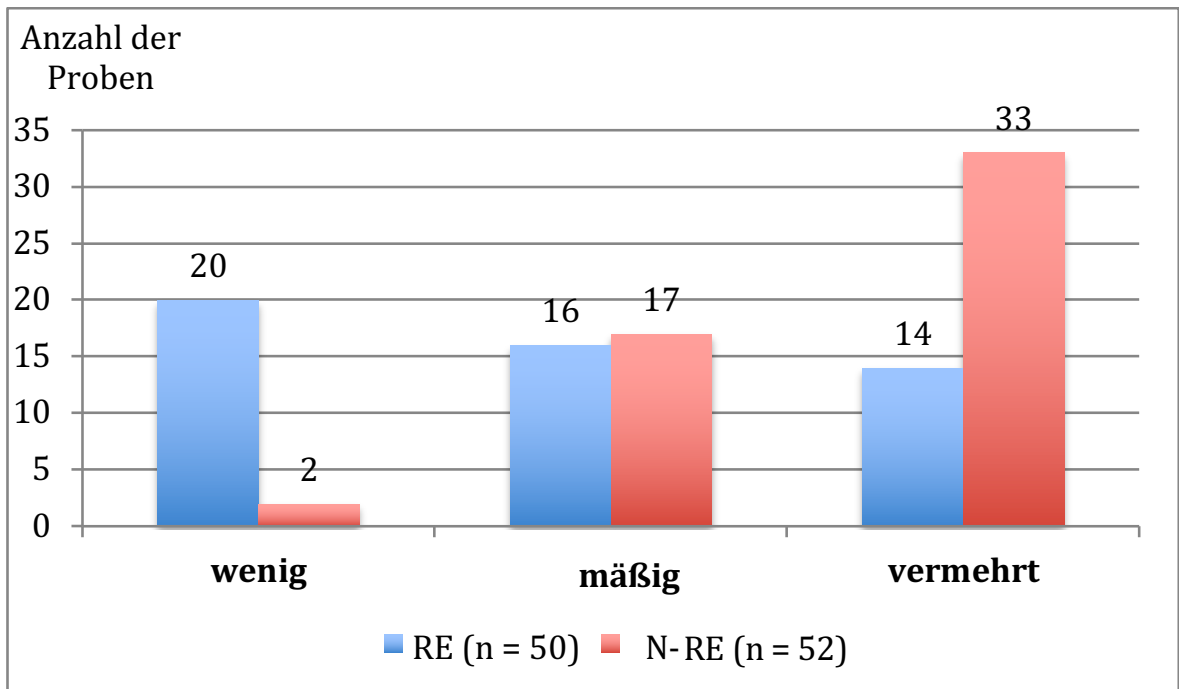

Abbildung 28: Verteilung der Kollagenfasern Typ III in der mittleren LP bei RE und N-RE-Patienten

Die Faserdichte und die Vernetzung der Kollagenfasern in der oberen LP korrelierten gut mit der klinischen Einteilung des RE $(\mathrm{p}=0,00001)$. Dagegen waren in der mittleren LP keine statistischen Zusammenhänge erkennbar für die Faserdichte $(\mathrm{p}=0,62)$ und die Vernetzung $(\mathrm{p}=0,77)$.
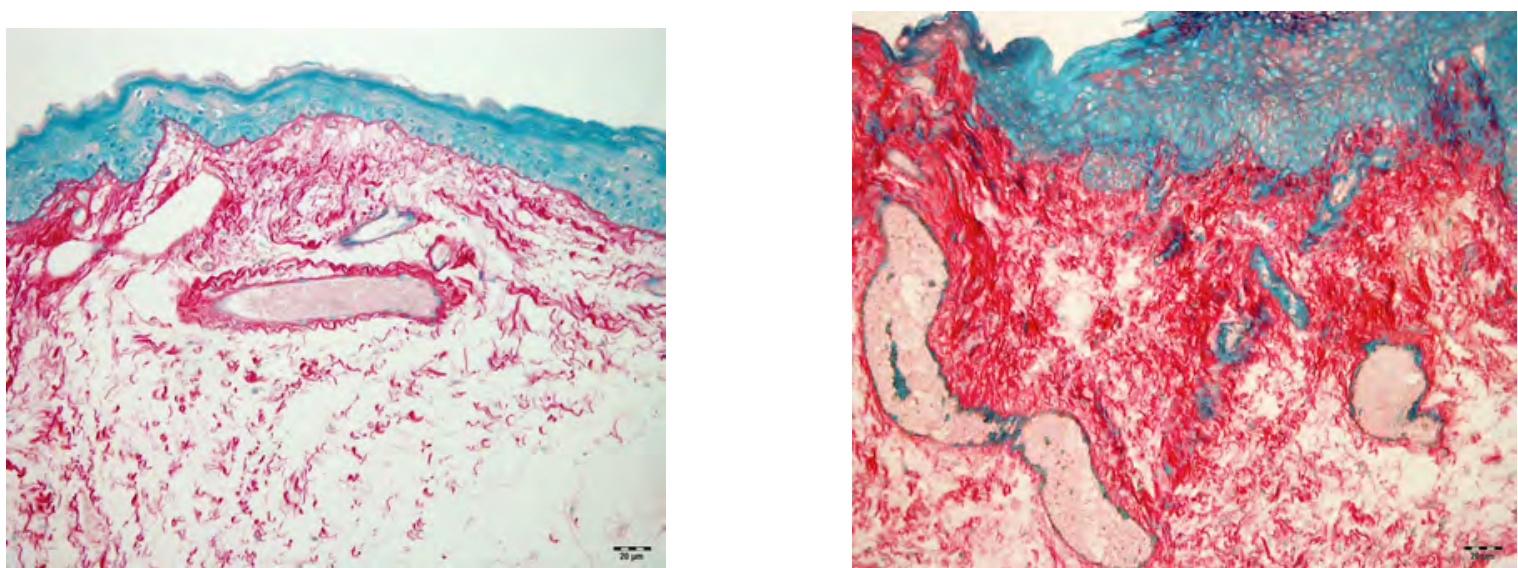

Abbildung 29 : Übersichtsaufnahme der Kollagenfasern eines RE (links) und einer Leukoplakie (rechts) in 10x Vergrößerung und Sirus-Red-Färbung 

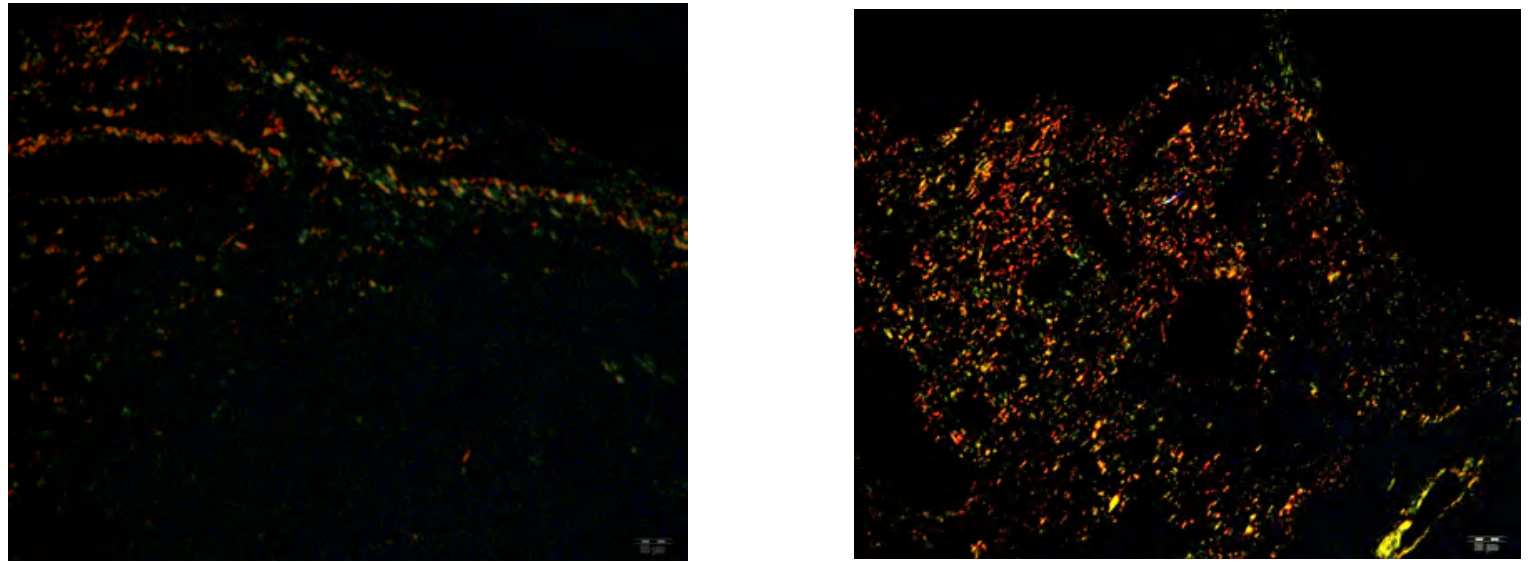

Abbildung 30: Kollagen Typ I (rot/gelb) und Kollagen Typ III (grün) beim RE (links) und bei einer Leukoplakie (rechts) in 10x Vergrößerung und Sirus-Red-Färbung

\subsection{Untersuchungen der elastischen Fasern in der Lamina propria}

Das RE Kollektiv besteht aus 57 Proben von 50 Patienten und das N-RE Kollektiv aus 58 Proben von 55 Patienten.

Tabelle 12: Ergebnisse der elastischen Fasern Auswertung in der oberen und mittleren LP bei RE und N-RE-Patienten
\begin{tabular}{|l|l|l|l|}
\hline Obere Schicht & RE $(\mathrm{n}=50)$ & N-RE $(\mathrm{n}=53)$ & $\begin{array}{l}\text { Statistische } \\
\text { Signifikanz }\end{array}$ \\
\hline & Strukturlos & Strukturlos & $\mathrm{p}=0,044$ \\
\hline Anordnung & Wenig & Wenig & $\mathrm{p}=0,076$ \\
\hline Faserdichte & Gering & Mäßig & $\mathrm{p}<0,00000005$ \\
\hline Destruktion & RE $(\mathrm{n}=50)$ & N-RE $(\mathrm{n}=53)$ & $\begin{array}{l}\text { Statistische } \\
\text { Signifikanz }\end{array}$ \\
\hline Mittlere Schicht & & Strukturlos & $\mathrm{p}=0,0019$ \\
\hline & Strukturlos & Wenig & $\mathrm{p}=0,011$ \\
\hline Anordnung & Physiologisch & Mäßig & $\mathrm{p}=0,13$ \\
\hline Faserdichte & Mäßig & & \\
\hline Destruktion & &
\end{tabular}

Sowohl in der oberen $(p=0,044)$ als auch in der mittleren LP $(p=0,0019)$ zeigte sich in beiden Vergleichsgruppen kein Unterschied. Die elastischen Fasern waren strukturlos angeordnet (vgl. Tabelle 12).

Die Dichte an elastischen Fasern zeigte sich in der oberen LP in beiden Gruppen unverändert ( $p=0,076$ für RE bzw. $p=0,011$ für die anderen Pathologien) (Abbildung 31, 35). 


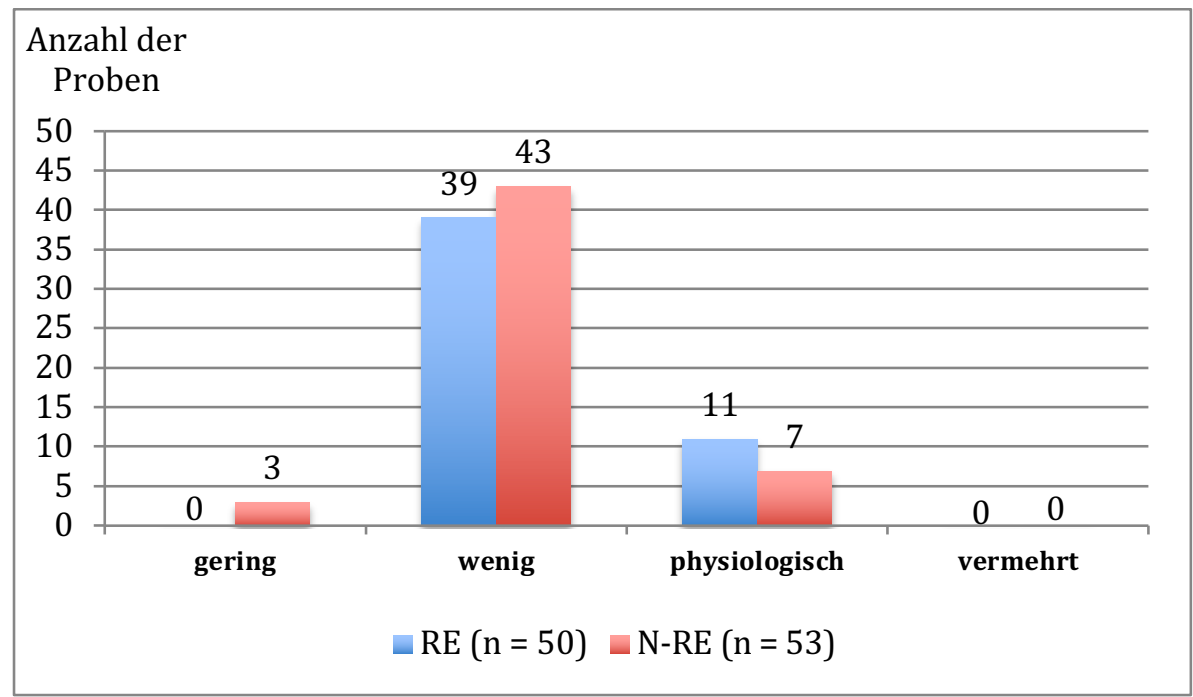

Abbildung 31: Faserdichte der elastischen Fasern in der oberen LP bei RE und N-RE-Patienten

Die Dichte an elastischen Fasern bei den RE-Patienten in der mittleren LP war physiologisch und höher als im Vergleichskollektiv $(\mathrm{p}=0,011)$ (Abbildung 32, 35).

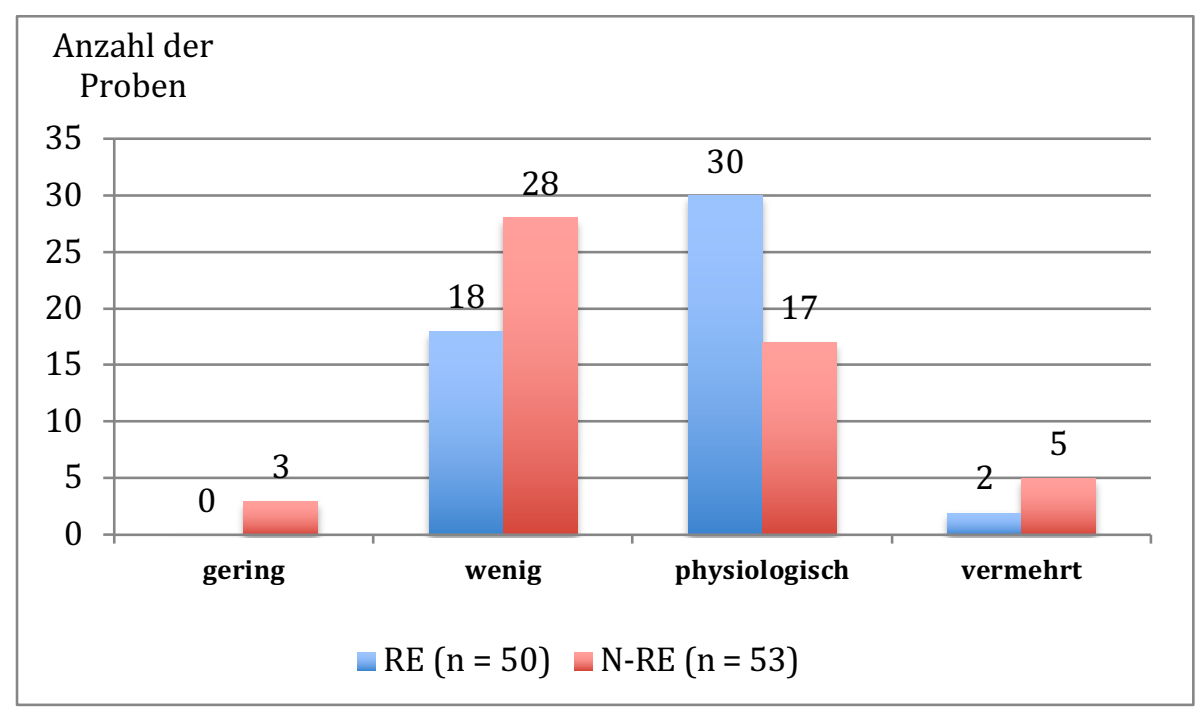

Abbildung 32: Faserdichte der elastischen Fasern in der mittleren LP bei RE und N-RE-Patienten

Die Destruktion der elastischen Fasern war in der oberen LP bei dem RE Kollektiv gering und höher bei den Vergleichsproben $(\mathrm{p}<0,00000005)$ (Abbildung 33, 35). 


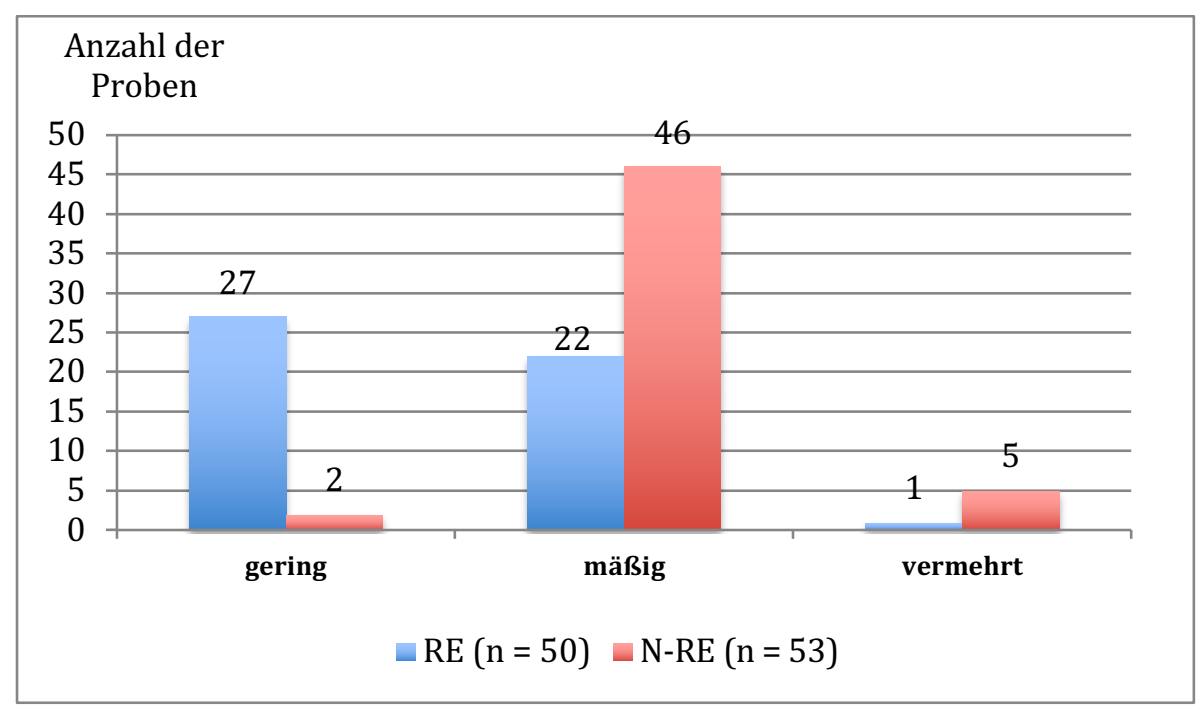

Abbildung 33: Faserdestruktion der elastischen Fasern in der oberen LP bei RE und N-RE-Patienten

In der mittleren LP zeigte sich eine mäßige Destruktion der elastischen Fasern in beiden Gruppen $(p=0,13)$ (Abbildung 34, 35).

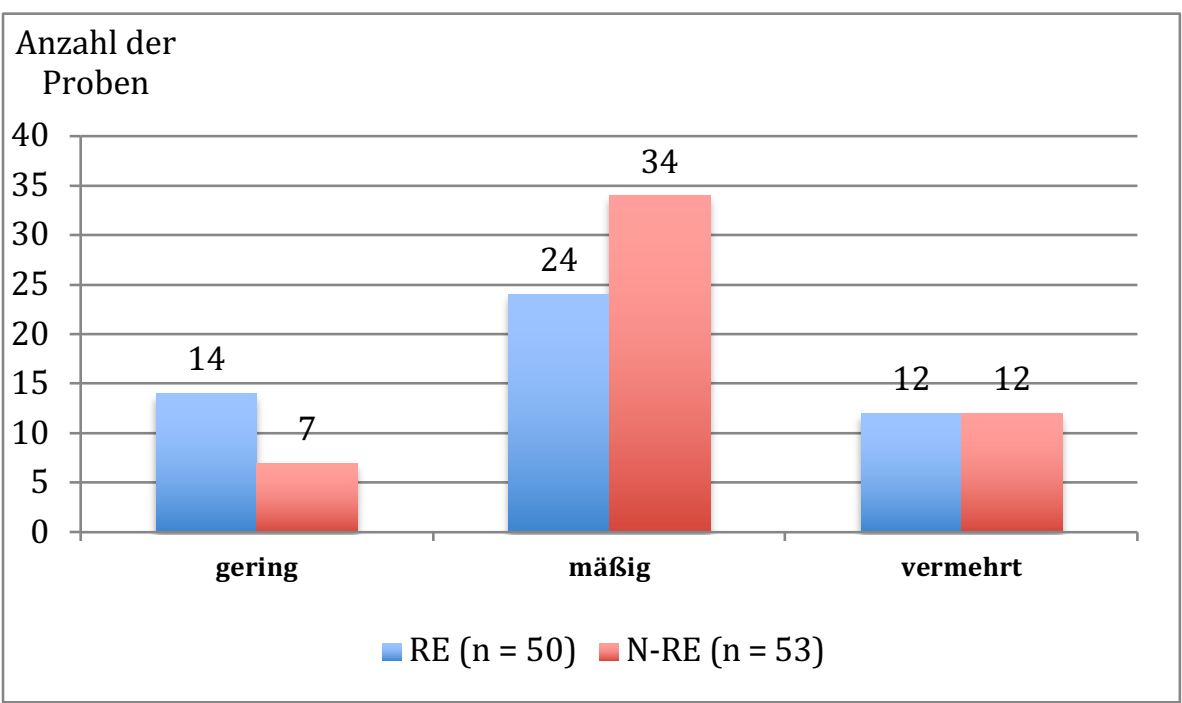

Abbildung 34: Faserdestruktion der elastischen Fasern in der mittleren LP bei RE und N-RE-Patienten 

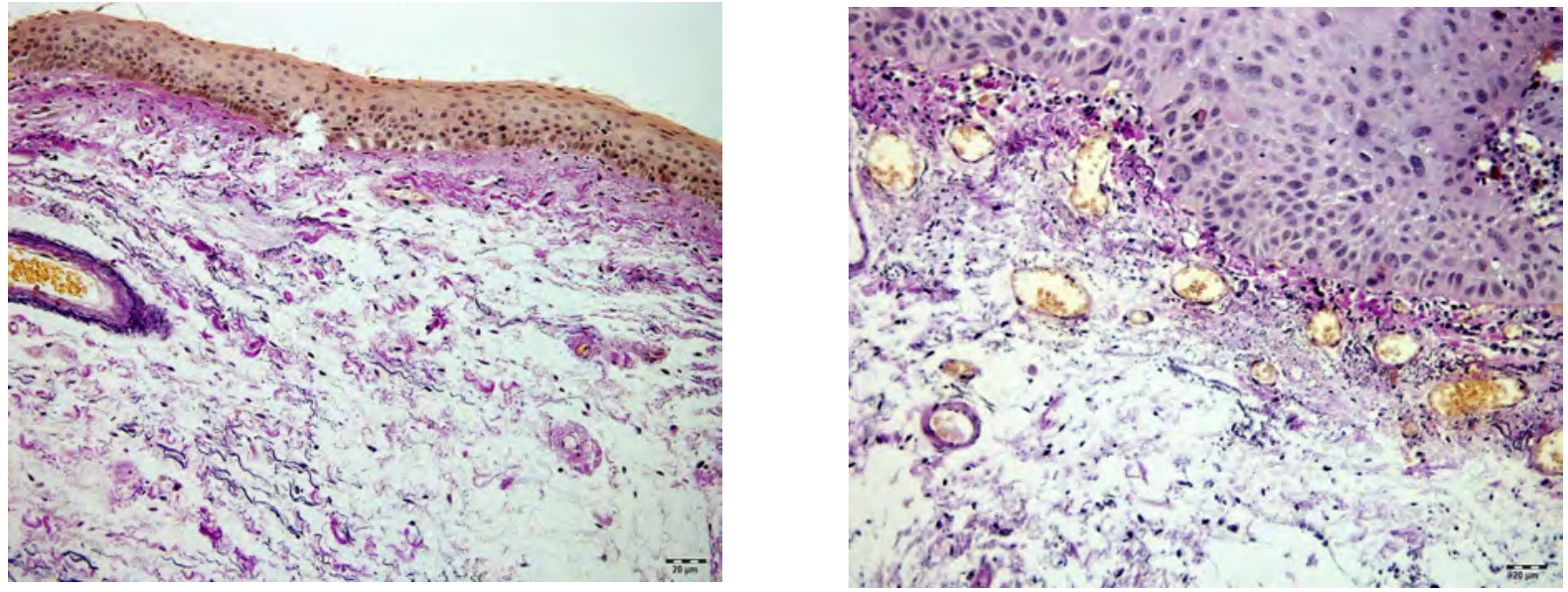

Abbildung 35: Elastische Fasern (schwarz) bei einem RE (links 10x Vergrößerung) und einer Leukoplakie (rechts 20x Vergrößerung), EvG-Färbung

\subsection{Untersuchungen der epithelialen Deckschicht der Lamina propria}

Untersucht wurden 57 Proben von 50 Patienten mit einem klinisch und histologisch nachgewiesenem RE sowie 59 Proben von 54 Patienten mit anderen pathologischen Veränderungen an der SL.

Die Anzahl an Epithelzellschichten war beim RE geringer (5 - 7 Zelllagen) als bei den anderen Pathologien, die eine deutliche Epithelzellhyperplasie von $>15$ Zelllagen zeigten $(\mathrm{p}=0,0000085)$ (Abbildung 36). Beim RE zeigte sich eine verdickte Basalmembran $>10 \mu \mathrm{m}$ im Vergleich zum Vergleichskollektiv $1-2 \mu \mathrm{m}(\mathrm{p}=0,019)$ (Abbildung 37).

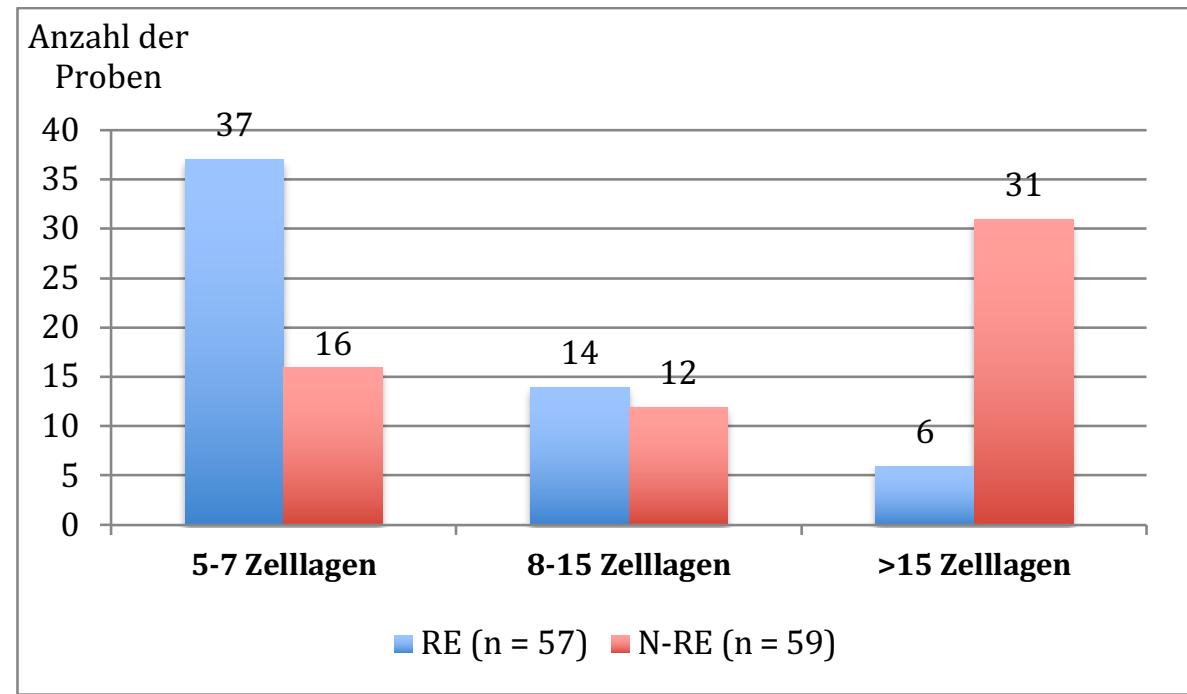

Abbildung 36: Zellhyperplasie der Epithelzellen bei RE- und N-RE-Patienten 


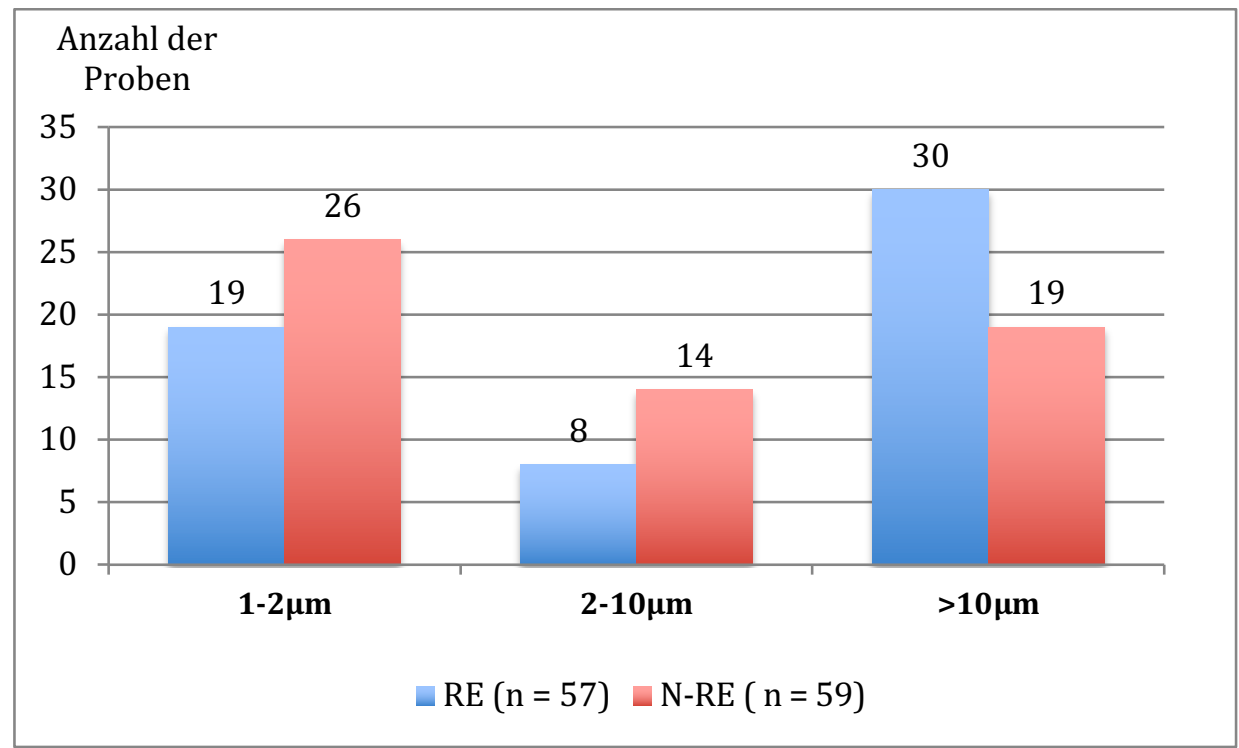

Abbildung 37: Dicke der Basalmembran bei RE- und N-RE-Patienten
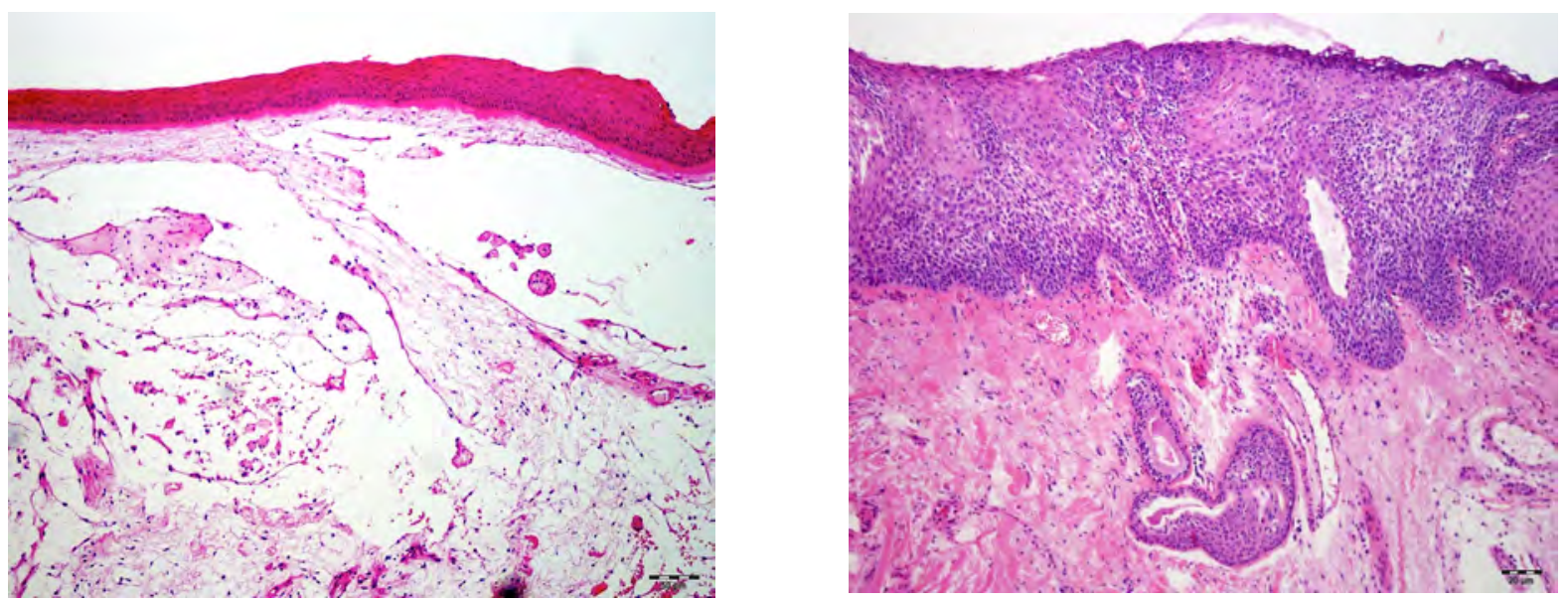

Abbildung 38: RE mit verbreiteter Basalmembran und physiologischer Epithelschichtstärke (links) und SL-Hyperplasie mit deutlicher Epithelzellschichthyperplasie und physiologischer Basalmembranstärke (rechts), 20x Vergrößerung und HE-Färbung

Eine vermehrte Zelldysplasie bzw. -atypie $(\mathrm{p}=0,0082)$, Keratinisierung der Epithelschicht $(\mathrm{p}=0,0018)$ und Entzündungsanzeichen $(\mathrm{p}=0,0085)$ traten häufiger im Vergleichskollektiv auf (Abbildung 38, 39, 40). 


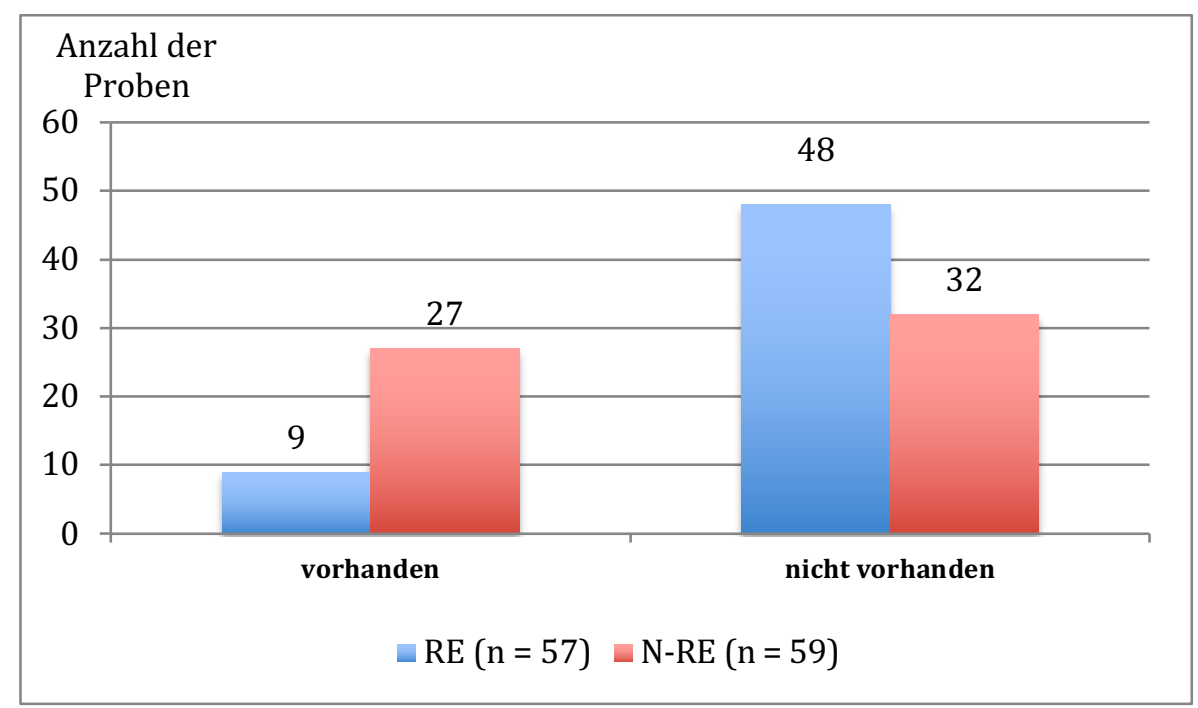

Abbildung 39: Deckschicht aus Keratin im Vergleich von RE- und N-RE-Patienten

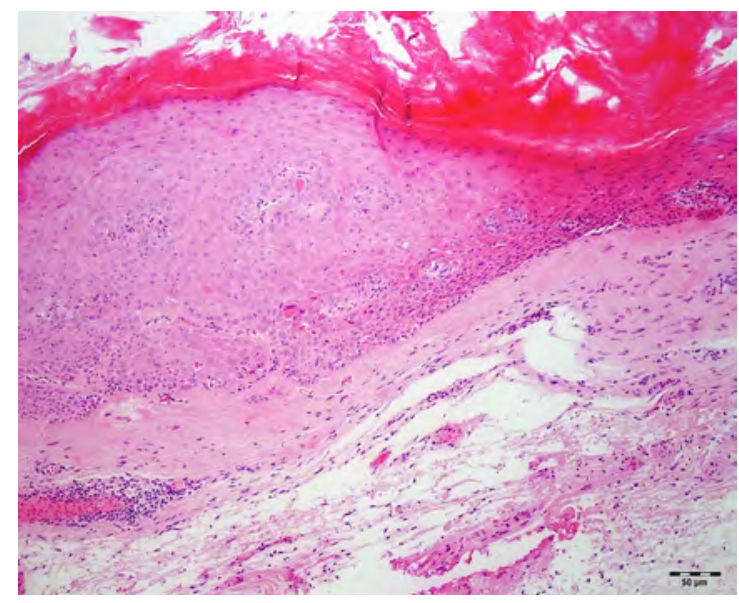

Abbildung 40: Leukoplakie mit Deckschicht aus Keratin und einer Zellhyperplasie, 10x Vergrößerung in HE-Färbung

\subsection{Untersuchungen der vaskulären Struktur}

Es wurden 50 Patienten mit einem RE und aus dem Vergleichskollektiv 55 Patienten mit anderen pathologischen Veränderungen untersucht. Hinsichtlich der Gefäßdichte zeigte sich kein großer Unterschied zwischen RE- und N-REPatienten. Bei den RE-Patienten waren im Median 14 Gefäße auf $100.000 \mu \mathrm{m}^{2}$ verteilt, bei den anderen Pathologien fallen ebenfalls 14 Gefäße auf $100.000 \mu \mathrm{m}^{2}(\mathrm{p}=0,97)$ (Abbildung 41). Der Gefäßdurchmesser war im Median höherer bei den RE-Patienten mit $18,05 \mu \mathrm{m}$ im Vergleich zu dem Vergleichskollektiv mit 14,59 $\mu \mathrm{m}(\mathrm{p}=0,00007)$ (Abbildung 41, 42). 


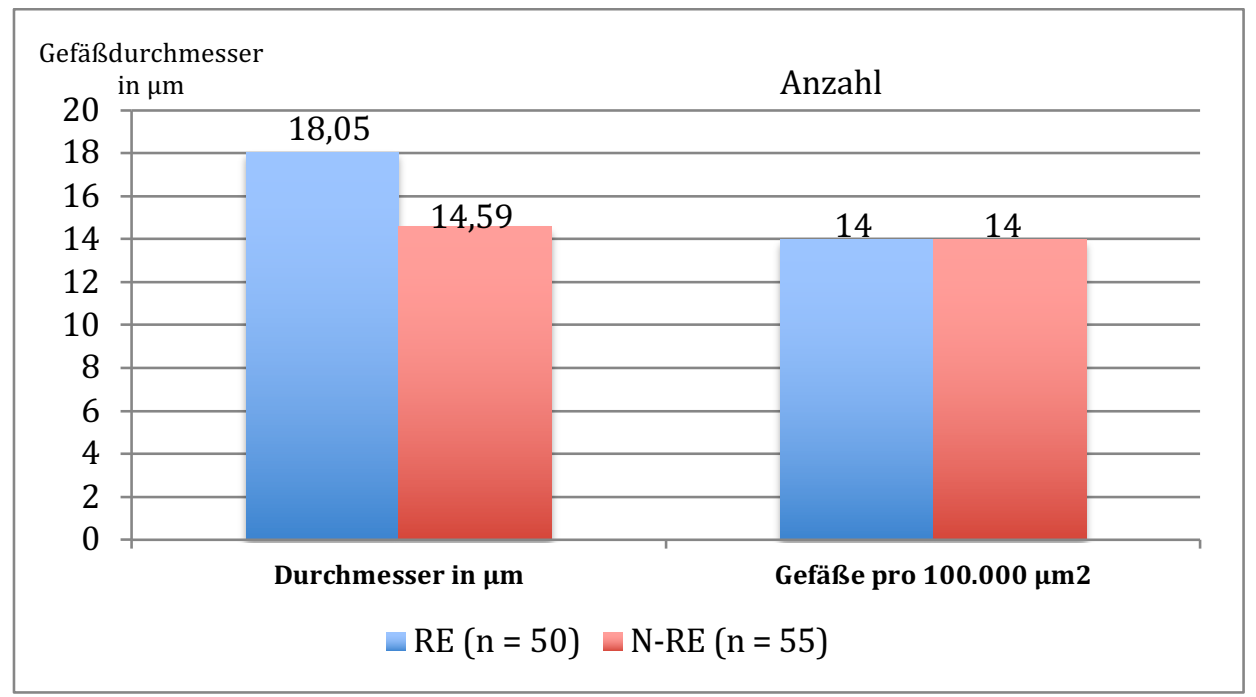

Abbildung 41: Durchmesser und Verteilung der Gefäße bei RE- und N-RE-Patienten im Median
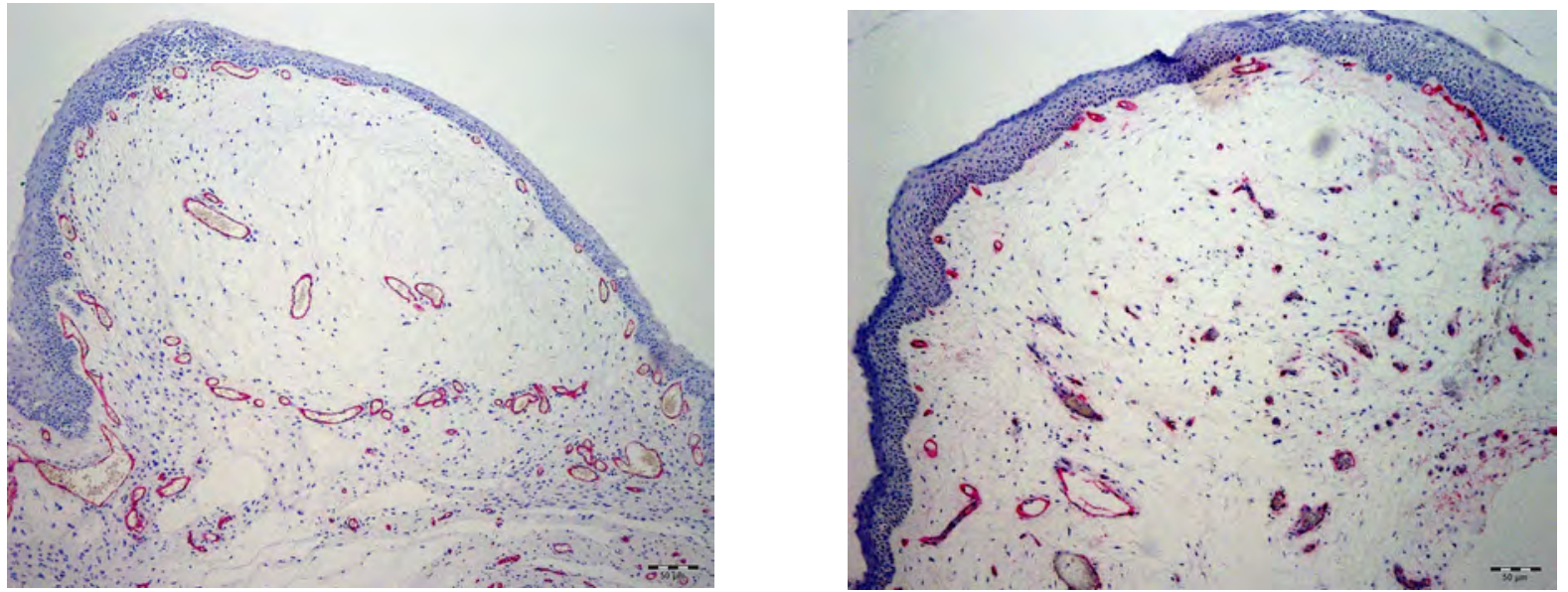

Abbildung 42: RE mit größeren Gefäßlumen (links) und Leukoplakie mit kleineren Gefäßlumen (rechts), 10x Vergrößerung, immunhistochemische Darstellung der Gefäße mit dem Antikörper CD 34

\subsection{Mikrotraumen in der Lamina propria}

Es wurde an 53 Patienten mit einem RE und an 55 Patienten mit anderen Pathologien die FE-Färbung durchgeführt. Frische Mikrotraumen und solche älterer Art mit Nachweis von Eisen waren sowohl in der oberen $(p=0,12)$ als auch in der mittleren LP $\left(p=0,028_{m p}\right)$ in beiden Kollektiven nicht zu beobachten.

\subsection{Ergebnisse der RT-PCR}

Es wurden 20 weibliche Patienten (Alter im Mittel 51,65 Jahre) mit einem klinisch und pathologisch nachgewiesenen RE und eine Vergleichsgruppe mit 46 Patienten davon 25 männlich und 21 weiblich (Alter im Mittel 56,46 Jahre) untersucht. 


\subsubsection{Hyaluronsynthasen HAS-1, HAS-2 und HAS-3}

Die Reinke Patienten zeigten eine vermehrte Expression der HAS im Vergleich zu der Vergleichsgruppe. Jedoch zeigte sich keine statistische Signifikanz für HAS-1 $(p(U)=0,15)$, HAS-2 $(\mathrm{p}(\mathrm{U})=0,14)$ und HAS-3 $(\mathrm{p}(\mathrm{U})=0,25)$ (Abbildung 43).

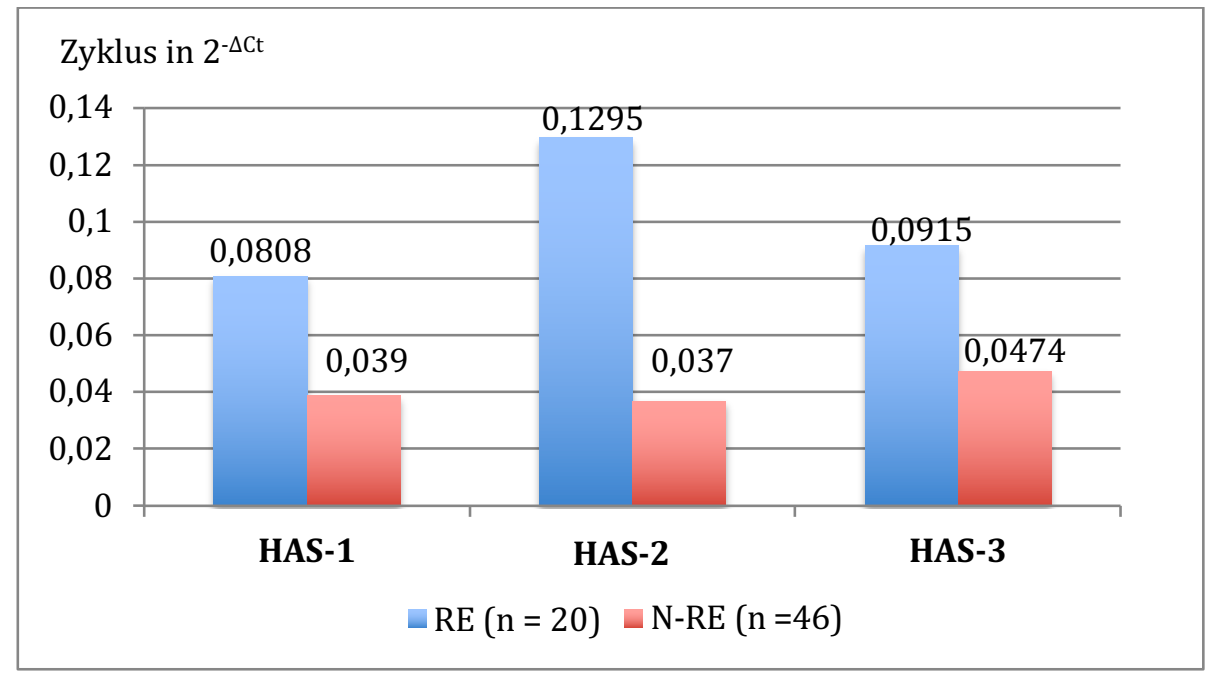

Abbildung 43: RT-PCR der Hyaluronsynthasen

\subsubsection{Hyaluronidasen Hyal-1 und Hyal-2}

Auch hier zeigte das Reinkekollektiv eine vermehrte Expression der Abbauenzyme Hyal-1 und Hyal-2 im Vergleich zu den anderen Pathologien. Aber es war keine statistische Signifikanz für Hyal-1 $(\mathrm{p}(\mathrm{U})=0,18)$ und Hyal-2 $(\mathrm{p}(\mathrm{U})=0,33)$ vorhanden (Abbildung 44).

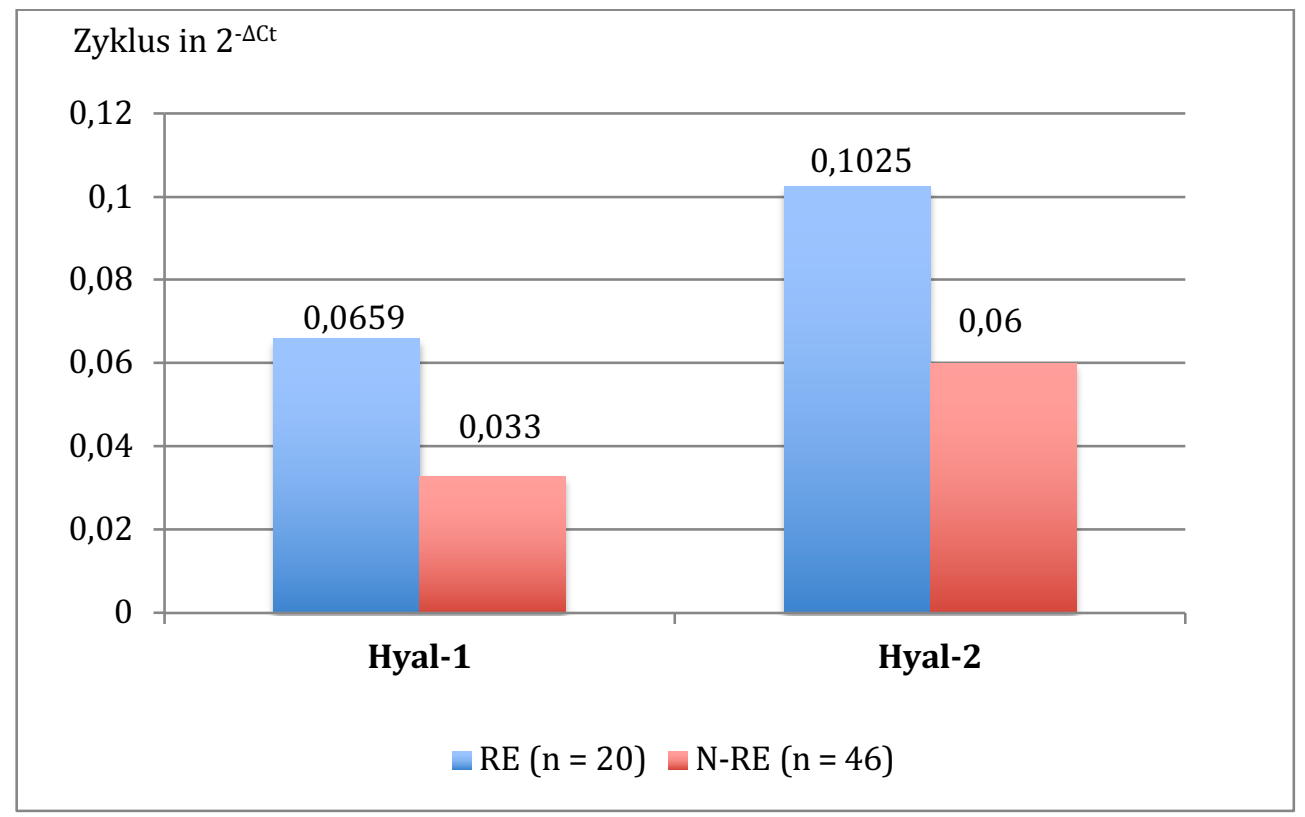




\section{Diskussion}

\subsection{Diskussion der Methodik}

Für die Auswertung der HA wurden jeweils zwei Serienschnitte angefertigt. Dadurch war es nicht immer gewährleistet, dass identische Areale der zu untersuchenden Gewebeveränderungen getroffen wurden. Ferner stammen die Ergebnisse aus einem zweidimensionalen Ausschnitt der jeweiligen LP-Schicht und beziehen sich nicht auf die gesamte obere oder mittlere LP. Da auch die Farbauswahl mit einer Erkennungsfunktion digital durch das Programm Axiovison getroffen wurde, wurde auch Gewebe mit bewertet, welches zwar im Farbspektrum der markierten Fläche lag, aber im Gewebeschnitt nicht als HA erschien. Ein weiterer Schwachpunkt war durch die Unspezifität der AlcianblauFärbung gegeben, die alle Glykosaminoglycane blau färbt. Die Spezifität der Hyaluronidasen war nicht immer zu 100 \% gegeben (Chan et al. 2001), auch andere Makromoleküle in der EZM können partiell degradiert werden (Chan et al. 2001). Schließlich wurden unterschiedliche Mengen Gewebe entnommenen: Bei manchen Gewebeproben war viel Material aus der mittleren LP vorhanden, bei anderen aber wiederum weniger, was Schwankungen vor allem in der quantitativen Analyse hervorrief. Es kann jedoch angenommen werden, dass die genannten Probleme aufgrund der Anzahl der untersuchten Proben die Ergebnisse nicht relevant beeinflussten.

\subsection{Diskussion der Ergebnisse}

Die LP ist die histoanatomische relevante Struktur für die Stimmproduktion. Deswegen gehen SL-Pathologien vor allem mit Veränderungen in der LP einher. Dazu gehören besonders das RE, SL-Polypen und auch SL-Knötchen (Ward et al. 2002).

\subsubsection{Der Hyaluronsäurehaushalt beim Reinke-Ödem}

Die HA ist eines der wichtigsten Moleküle der EZM der LP. Nicht bei allen pathologischen Veränderungen konnte gezeigt werden, dass in der mittleren LP mehr HA vorhanden war als in der oberen LP (vgl. Abbildung 18). Besonders viel HA war beim RE zu finden im Vergleich zu den N-RE-Veränderungen (vgl. Abbildung 18).

In der gesunden SL konnte eine geschlechtsspezifische Verteilung der HA innerhalb der Schichten der LP beobachtet werden (Butler et al. 2001): In der oberen LP besaßen Männer mehr HA als Frauen. Jedoch nahm die Menge an HA bei den Frauen zur Tiefe hin zu, bei den Männern zur Tiefe Richtung M. vocalis ab; diesen Befund konnten Butler et al. in einer Studie an 10 männlichen und 8 weiblichen Proben von Verstorbenen im Alter von 20-60 
Jahren mittels Immunhistochemie erheben (Butler et al 2001). Somit kann es naheliegend sein, dass Frauen eine geringere Möglichkeit haben, sich Vibrationstraumen am SL-Gewebe zu widersetzen, und dass verletztes Gewebe im Rahmen der Wundheilung HA verstärkt akkumuliert. Die geringe Widerstandskraft im weiblichen SL-Gewebe gegenüber den Mikrotraumen ist ein möglicher pathologischer Grund, dass das RE fast nur bei Frauen vorkommt. Entsprechend treten vermehrte SL-Veränderungen beim weiblichen Geschlecht bei hoher Stimmbelastung auf (Dikkers et al. 1999, Butler et al. 2001). Auch Lebl et al. konnten immunhistochemisch zeigen, dass Frauen mehr HA aufweisen als Männer (Lebl et al. 2007). In dieser Studie wurde auch der Ort der Probenentnahme aus der SL berücksichtigt: Frauen zeigten im anterioren Bereich der SL eine höhere Menge an HA, beim männlichen Geschlecht war keine Ortsabhängigkeit der HA erkennbar (Lebl et al. 2007). Betrachtet man die Verteilung der HA in den Schichten einer physiologisch unveränderten LP, so wurde beschrieben, dass in der oberen LP wenig HA zu finden war, in der mittleren am meisten und in der tiefen Schicht der LP weniger als in der mittleren (Hahn et al. 2006a, Korn et al. 2012). Hahn et al. untersuchten hierzu 6 menschliche Gewebeproben von Leichen 24 Stunden post mortem. Es wurden 2 Serienschnitte angefertigt und einer davon mit Hyaluronidase behandelt. Beide Serienschnitte wurden mit Alcianblau gefärbt und digital ausgewertet (Hahn et al. 2006a). Altersabhängig zeigten sich in dieser Studie erhöhte Konzentrationen von HA mit steigendem Alter bei Patienten mit einem RE, im Gegensatz zu den N-RE-Veränderungen, bei denen mit höherem Alter die Konzentration an HA abnahm. Dies konnte auch in dieser Studie bestätigt werden (vgl. Abbildung 20). In einem Tierversuch mit gesunden weiblichen Ratten, jeweils 8 jüngere und 8 ältere, wurde die Konzentration von HA mittels Fluoreszenzmethodik und ELISA bestimmt (Ramos et al. 2012). Es zeigte sich eine erhöhte Konzentration bei den jüngeren Ratten im Vergleich zu den älteren Ratten (Ramos et al. 2012). Jedoch sind die Ergebnisse von Tierversuchen nur eingeschränkt auf menschliches Gewebe übertragbar, da oft andere Bedingungen, z. B. bei der Entnahme, Gewebemenge und Fixation, herrschen. HA stellt ein Schlüsselmolekül in der EZM für den Prozess der Wundheilung dar. In der frühen Phase der Wundheilung stimuliert die HA Fibroblasten und sorgt somit für den Aufbau zellulärer Barrieren (Jacobson et al. 1984). Dabei hat die HA das Potential, die Vernarbung von Gewebe zu vermeiden (Chan und Titze 1999) und somit zu einer Regeneration von Gewebe zu führen (Thibeault et al. 2004). Man nimmt an, dass vermehrte Mengen an HA den Entzündungsprozess minimieren und dadurch in der frühen Phase der Wundheilung die Narbenbildung reduziert. Entsprechend konnten vermehrt 
Glycosaminoglycane und Proteoglycane während des Wundheilungsprozesses nachgewiesen werden (Kirsner und Eaglstein 1993). In einem Tierexperiment mit 28 Hasen wurde jeweils nach 3, 5, 10 und 15 Tagen eine Biopsie aus der SL entnommen. Die Konzentration der HA wurde im gesunden und im verletzten Gewebe bestimmt. Es zeigte sich ein signifikanter Anstieg an HA in den Gewebeproben aus dem verletzten Kollektiv an Tag 5, an den anderen Entnahmetagen war die Konzentration an HA im gesunden Gewebe höher (Thibeault et al. 2004). Das könnte eine Erklärung sein, warum in unserem Vergleichskollektiv eine deutlich geringere Menge an HA zu finden war, da die chirurgische Exzision erst ca. 3 - 5 Wochen nach klinischer Diagnosestellung vollzogen wurde. Darüber hinaus war im Vergleichskollektiv die begleitende inflammatorische Komponente stärker ausgeprägt als in den Geweben mit einem RE. Auch das RE wurde ca. 3 - 5 Wochen nach Diagnose chirurgisch entfernt, doch dort war die Menge an HA deutlich höher, was auf einen chronischen Wundheilungsprozess mit weitergehender, HA vermittelten Unterdrückung einer Begleitentzündung schließen lässt. Beim Neugeborenen liegt keine unterschiedliche Verteilung der HA in der LP vor, die LP zeigt somit keine Schichtung, sie ist uniform (Schweinfurth und Thibeault 2008). Dies konnte an einem Experiment mit 14 humanen Larynxproben mittels histochemischer Methoden nachgewiesen werden (Schweinfurth und Thibeault 2008). Durch die gleichmäßige Verteilung der HA in der LP baut sich kein osmotischer Gradient für Wasser auf, welcher sich in Form eines Ödems in der LP widerspiegeln und durch Ausbildung biochemischer Komplexe die Viskosität des SL-Gewebes erhöhen würde (Schweinfurth und Thibeault 2008). Diese unreife Struktur der LP bei Neugeborenen dient zum Abfangen und Eindämpfen von Kräften, die während des Schreiens wirken, und verhindert somit eine Aphonie (Schweinfurth und Thibeault 2008). Durch die ungleichmäßige Verteilung der HA in der LP beim RE dagegen kann es zum Aufbau eines osmotischen Gradienten kommen und sich Wasser in die Gewebestruktur einlagern. In der Laryngoskopie zeigte sich dann ein dickes, aufgesetztes, glasiges und gallertartiges Kissen auf den SL (Tillmann und Rudert 1982, Pastuzek et al. 2003), welches das gelegentliche Auftreten einer Aphonie beim RE erklärt. Hierbei ist die HA entscheidend für die Viskosität des SL-Gewebes (Gray et al. 1999, Chan et al 2001). Die Viskosität wird besonders beeinflusst durch die Molekülstruktur der HA, z B. durch die Anzahl und Größe der Saccharid- und Lipidseitenketten. Je größer das Molekül ist, desto größer ist die Viskosität des Gewebes (Gray et al. 1999). Ebenso führt eine gesteigerte Konzentration an HA im Gewebe zu einer erhöhten Viskosität, hervorgerufen durch Interaktionen mit der EZM und deren Wasserhaushalt (Gray et al. 1999). 
Thibeault et al. verglichen die Genexpression der HAS-2 und einer Hyaluronidase beim RE und einem SL-Polyp (Thibeault et al. 2002). Die Untersuchung erfolgte an vier humanen Proben mit RE und fünf Proben mit SL-Polypen. Für beide Veränderungen konnte eine vermehrte HA Produktion und ein vermehrter HA Abbau beschrieben werden. Somit zeigte sich ein erhöhter Gewebe-Turnover, also eine Umstrukturierung des Gewebes durch Abund Umbauvorgänge sowie Neubildung (Thibeault et al. 2002). In einem Tierversuch mit 15 SL von Ratten beschrieben Ohno et al. eine Abnahme der Genexpression der Hyaluronsynthasen HAS-1, -2 und -3 mit steigendem Alter (Ohno et al. 2009). Leider wurden die Hyal als Abbauenzyme nicht untersucht, um gegebenenfalls einen höheren HA-Turnover im Alter nachweisen zu können (Ohno et al. 2009).

Ein erhöhter Turnover der HA konnte auch in unseren Ergebnissen gezeigt werden, da sowohl die Hyaluronsynthasen HAS-1, -2 und -3 eine vermehrte Expression beim RE zeigten, als auch die Hyaluronidasen Hyal-1 und -2 (vgl. Abbildungen 43 und 44).

\subsubsection{Kollagenfaserqualität und -quantität beim Reinke-Ödem}

Neben der HA als großen Bestandteil der EZM (Ward et al. 2002), sind auch die Kollagenfasern bedeutend für die Anatomie und Physiologie der LP beziehungsweise der SL (Gray 2000).

In vielen Geweben finden Veränderungen in der Kollagenqualität und -quantität mit dem Prozess des Alterns oder durch pathologische Vorgänge statt (Culav et al. 1999). Eine pathologische Physiologie des Kollagenmetabolismus kann zu diversen Krankheiten wie Osteoartheritis oder Arteriosklerose führen (Visse und Nagase 2003). Die Kollagenfaserverteilung in der gesunden SL wurde als verknüpfendes Korbgeflecht beschrieben, das die Festigkeit der LP während deren Schwingungsvorgang bei der Phonation gewährleistet (Melo et al. 2003). Insbesondere soll das feine Fasernetzwerk die Gleichförmigkeit der LP während des Schwingungsvorgangs der SL aufrechterhalten (Melo et al. 2003). Ferner ist die dreidimensionale Struktur in der mittleren Schicht der LP für die Integrität der SL während der Phonation verantwortlich (Sato 1998). Sake et al. beschrieb bei 20 Patienten mit einem RE eine ungeordnete Konfiguration und Zerstörung der Kollagenfasern in der LP im Gegensatz zu der physiologischen geflechtartigen Anordnung (Sake et al. 2008), die in den mittleren Schichten der LP im Vergleich zu den oberen stärker ausgeprägt waren. Somit zeigte sich auch hier, dass die mittlere Schicht der LP bevorzugt pathologische Veränderungen beim RE aufweisen. Die Zerstörung des klassischen Aufbaus der SL-Histologie in der mittleren LP mit Destruktion und geringer Kollagenfaserdichte 
beim RE konnten wir auch in unserer Arbeit zeigen (vgl. Abbildungen 21, 22 und 23, 24). Vermutlich werden die Kollagenfasern durch das Ödem verdrängt und die LP verliert ihre netzartige Struktur, was die SL-Dysfunktion bedingt.

Das fibrilläre Kollagennetzwerk der menschlichen LP wird von Kollagen Typ I und III gebildet (Tateya et al. 2007). In der mittleren Schicht liegt hauptsächlich Kollagenfaser Typ III vor (Melo et al. 2003, Prades et al. 2010). Bei unseren Untersuchungen zeigte sich eine verringerte Menge an Kollagen Typ III in der mittleren Schicht der LP (vgl. Abbildung 28), wiederum durch das Ödem bedingt, das für eine Verdrängung der Fasern sorgt und so das Bild einer verringerten Anzahl an Fasern im Vergleich zu anderen SL-Pathologien erzeugt. Auch Tateya et al. konnten an pathologisch unverändertem, menschlichem SL-Gewebe zeigen, dass Kollagen Typ I und Typ III essentiell für die Morphologie und Funktion sind (Tateya et al. 2006). Typ I sorgt in der oberflächlichen Schicht mit seiner bandartigen, dichten Anordnung für Zugfestigkeit. Außerdem sorgen diese Fasern dafür, dass die SL ihre Form auch unter Vibrationskräften während der Phonation beibehält. Typ III ist gleichmäßig in der LP verteilt und verleiht dem Gewebe Elastizität und Flexibilität (Tateya et al. 2006). Die Struktur in der oberen Schicht der LP geht beim RE nicht verloren. Dort bleibt das dichte Kollagenband, hauptsächlich aus Typ I, erhalten. Das wird auch durch unsere Ergebnisse bestätigt (vgl. Abbildung 25).

\subsubsection{Veränderung der elastischen Fasern beim Reinke-Ödem}

Die polymere Elastin-Struktur verleiht den elastischen Fasern die Funktion der Elastizität. Die Elastizität ist abhängig von dem Elastinanteil (Gray et al. 2000). Reife elastische Fasern mit einem hohen Elastinanteil sind vor allem in der mittleren Schicht der LP zu finden und sind dort wichtig für die viskoelastischen Eigenschaften des Gewebes (Gray et al. 2000). In der oberen Schicht der LP zeigte sich bei den RE-Gewebeproben und bei dem Vergleichskollektiv generell eine geringe Dichte an elastischen Fasern (vgl. Abbildung 31). In der mittleren Schicht der LP war eine physiologische Dichte bei den RE-Patienten, im Vergleichskollektiv war dagegen eine geringere Dichte an elastischen Fasern zu beobachten (vgl. Abbildung 32). Ein dem Vergleichskollektiv ähnliches Bild wurde bei SLGewebeproben von älteren Menschen beschrieben, die aufgrund der Stimmbelastung und Schwingungsveränderungen eine sehr geringe Anzahl an elastischen Fasern in den oberen Schichten der LP, einzelne elastische Fasern in den mittleren Schichten der LP und die meisten in den tiefen Schichten der LP aufwiesen (Roberts et al. 2011). 
In der oberen Schicht der LP zeigt sich normalerweise ein Netzwerk aus dünnen, wellenförmig angeordneten elastischen Fasern, welches parallel zur Basalmembran verläuft (Sake et al. 2010). Sowohl in der oberen als auch in der mittleren Schicht der LP konnten wir in beiden Kollektiven eine strukturlose Anordnung der elastischen Fasern beobachten. Ein hoher Grad einer Faserdestruktion konnte jedoch nicht gezeigt werden. Gleiches beschrieb Sake et al. in ihren Untersuchungen über die elastischen Fasern beim RE und sprachen von einem ,verworrenen Charakter“ der elastischen Fasern. Die Fasern seien nicht mehr wellenförmig angeordnet, teilweise fragmentiert und nicht mehr parallel zur Basalmembran ausgerichtet (Sake AS et al. 2010).

\subsubsection{Veränderungen an der Epithelschicht und Basalmembran beim Reinke-Ödem}

Eine mehrschichtige Epithelzellschicht und die Basalmembran bedecken die LP-Anteile kehlkopflumenwärts (Rosen und Simpson 2008). Die Aufgaben der Basalmembran sind die Anheftung der Epithelzellen an das Stroma, die Konstanthaltung der Polarität des Epithels sowie damit verbundene Barriere- und Transportfunktionen (Knöbber 1994). In elektronenmikroskopischen Untersuchungen von Knöbber zeigten sich ungleichmäßig verbreiterte Areale in der Lamina densa, vermehrt Ankerfilamente und eine lückenhafte Basalmembran bei 9 Patienten mit einem RE (Knöbber 1994). Verdickungen der Basalmembran konnten auch bei anderen gutartigen SL-Pathologien beobachtet werden (Dikkers et al. 1993). Eine generell verdickte oder lokal verbreiterte Basalmembran beim RE und eine physiologische Breite der Basalmembran bei SL-Polypen und Pseudozysten konnten auch in einer weiteren Studie bestätigt werden (Hantzakos et al. 2009). Diese Ergebnisse konnten auch in unseren Untersuchungen erzielt werden (vgl. Abbildung 37). Die Epithelzellen sind im normalen histologischen SL-Gewebe mehrschichtig und unverhornt. Die Basalzellschicht ist mit Desmosomen an der Basalmembran verankert (Gray 1997). Ein Vermehrung der Epithelzellschicht war bei Patienten mit einem RE nicht zu erkennen, jedoch zeigten die anderen pathologischen Veränderungen der SL des Vergleichskollektivs eine Vermehrung der Zelllagen der Epithelzellen (vgl. Abbildung 36). Auch trat eine Keratinisierung der Epitheldeckschicht bei RE- im Gegensatz zu N-REVeränderungen äußerst selten auf (vgl. Abbildung 40). Eine gelegentliche und somit seltene Keratinisierung der Epitheldeckschicht beim RE im Vergleich zu SL-Polypen, -Knötchen und Pseudozysten wurde auch in einer anderen Studie nachgewiesen (Hantzakos et al. 2009). Das Auftreten einer Verhornung der Deckzellschicht wird besonders bei stark ausgeprägten Ödemen beobachtet, hierbei kommt es zum Kontakt mit der kontralateralen 
SL und somit zur stetigen Traumatisierung der obersten Zellschichten, die dann eine Keratinisierung als Schutz aufweisen.

Ein vermehrter Tabak- bzw. Nikotinkonsum führten zu einer Hyperplasie und Keratinisierung des Epithels (Marcotullio et al. 2002). Bei unseren Untersuchungen waren die RE-Patienten zwar alle Raucher, man konnte jedoch keine verbreiterte Epithelzellschicht erkennen.

\subsubsection{Vaskuläre Strukturen im Stimmlippengewebe}

Im nicht pathologisch veränderten SL-Gewebe sind vor allem sehr kleine Arteriolen und Venolen vorhanden, welche parallel zum frei beweglichen Randsaum der SL verlaufen. In einer Studie an acht menschlichen Gewebeproben von Verstorbenen im höheren Alter, zeigten sich Blutgefäße in allen Schichten der LP, ebenfalls parallel zur Oberfläche der SL verlaufend (Roberts et al. 2011). In einem Versuch mit 80 Gewebeproben von Patienten mit einem RE, zeigten sich im subepithelialen Gewebe viele kleine Gefäße, die über Anastomosen verbunden waren. Ebenso zeigten die Blutgefäße eine deutlichen Weitung der Gefäßlichtung und eine dünne Gefäßwand (Jovanovic et al. 2007). Ein erweitertes Gefäßlumen bei Patienten mit einem RE konnte in unseren Untersuchungen ebenfalls bestätigt werden (vgl. Abbildung 41). Diese subepitheliale Mikrovascularisierung könnte ein Indikator für die Entstehung eines Ödems in der SL sein. Durch das Sprechen und die Schwingung der SL baut sich ein stetiger Druck im Gewebe und auch in den dort verlaufenden Gefäßen auf, was schließlich zu einer erhöhten Permeabilität führt. Eine gesteigerte Permeabilität wiederum führt zur einer Gefäßdilatation und Ausbildung des Ödems in der SL (Sato et al. 1999). 


\section{Zusammenfassung}

Das RE ist eine gutartige, pathologische Veränderung der SL. Die Krankheit äußert sich durch Funktionsverlust der SL-Mechanik, einhergehend mit Verschlechterung der Stimmqualität bis hin zum Stimmverlust oder Dyspnoe. Fast ausschließlich tritt die Erkrankung bei Frauen mittleren Alters auf. Prädisponierende Faktoren sind vor allem langjähriger Tabakkonsum, eine hohe Belastung der Stimme sowie ösophagler Reflux. Laryngoskopisch ist eine breite, wulstartige, ödematöse Schwellung der SL-Schleimhaut zu beobachten, deren histologische Charakterisierung Ziel dieser Arbeit war. Histologisch kommt es zu diversen Veränderungen in der EZM des SL-Gewebes im Vergleich zu anderen Pathologien der SL, was in der vorliegenden Arbeit aufgezeigt wird. Im Gegensatz zu anderen Erkrankungen der SL zeigt sich beim RE eine deutliche Akkumulation an HA in der LP. Jedoch konnte weder eine isolierte vermehrte Genexpression der synthetisierenden HAS-1, -2 und -3 noch eine isolierte verminderte Genexpression der abbauenden Hyal-1 und -2 beim RE festgestellt werden, sondern nur ein erhöhter Turnover der HA. Die Kollagenund elastischen Fasern verloren beim RE deutlich an Struktur. Es kam durch die Entstehung des Ödems in der LP zu einer Destruktion der feinen Netzwerke der jeweiligen Fasern. Eine erhöhte Anzahl an Gefäßen in der LP beim RE konnte nicht gezeigt werden, jedoch besaßen die Gefäße ein deutlich erweitertes Lumen im Vergleich zu den N-RE assoziierten gutartigen Veränderung der SL. Neben der EZM wurde auch die epitheliale Deckschicht inklusive der Basalmembran der LP lichtmikroskopisch untersucht. Es war eine wesentlich breitere Basalmembran beim RE zu erkennen. Die epitheliale Deckschicht war dagegen eher gering verändert und zeigte gegenüber den anderen Pathologien eine verminderte Anzahl an Zelllagen. Die Genese von gutartigen SL-Erkrankungen ist aufgrund von bekannten Risikofaktoren so gut wie aufgeklärt. Mittels der vorliegenden Untersuchungen ließen sich histologische Unterschiede vor allem in der EZM zwischen dem RE und anderen Erkrankungen der SL erkennen. Jedoch war kein eindeutiger Kausalzusammenhang hinsichtlich möglicher Risikofaktoren und den Veränderungen der EZM, insbesondere der HA, beim RE zu erkennen. Dies sollte in weiterführenden Studien erforscht und geklärt werden; hier sind vor allem die MMP's zu nennen, von denen vermutet wird, dass sie über aktive Reparatur- und Umbaumechanismen die physiologische Struktur der SL erhalten beziehungsweise wiederherstellen können. 


\section{$6 \quad$ Literaturverzeichnis}

Berbohm H, Kaschke O, Nawka T: Kurzlehrbuch Hals- Nasen- Ohrenheilkunde, Thieme Verlag, Stuttgart 2009

Boenninghaus HG, Lenarz T: HNO. 13. Auflage; Springer Verlag, Berlin/Heidelberg 2007

Bornstein P (1974): The Biosynthesis of Collagen. Annu Rev Biochem $\underline{43}$, 567-603

Bosman FT, Stamenkovic I (2003): Preface to extracellular matrix and disease. J Pathol $\underline{200}$, $421-422$

Buhler RB, Sennes LU, Mauad T, Melo ECM, Silva LFF, Saldiva PHN (2008): Collagen Fiber and Versican Distribution Within the Lamina Propria of Fetal Vocal Folds. Laryngoscope $\underline{118}, 371-374$

Butler JE, Hammond TH, Gray SD (2001): Gender-Related Differences of Hyaluronic Acid Distribution in the Human Vocal Fold. Laryngoscope 111, 907-911

Chan RW, Gray SD, Titze IR (2001): The importance of hyaluronic acid in vocal fold biomechanics. Otolaryngol. Head Neck Surg 124, 607-614

Chan RW, Titze IR (1999): Hyaluronic Acid (With Fibronectin) As a Bioimplant for the Vocal Fold Mucosa. Laryngoscope 109, 1142-1149

Cohen E, Kolbus A, van Trostenburg M, Rudas M, Horvat R, Schneider B (2009): Immunhistochemical Examinations of Sex Hormone Receptors in Benign Vocal Fold Lesions. Folia Phoniatr Logop 61, 259-262

Culav EM, Clark CH, Merrilees MJ (1999): Connective Tissues: Matrix Composition and Its Relevance to Physical Therapy. Phys Ther 79, 308-319

Debelle L, Tamburro AM (1999): Elastin: molecular description and function. Int J Biochem Cell Biol 31, 261-272 
Deutzmann R, Brückner-Tudermann L, Brückner P: Binde- und Stützgewebe; In: Löffler G, Petrides PE, Heinrich PC (Hrsg.): Biochemie und Pathochemie; 8. Auflage; SpringerVerlag, Heidelberg 2007, 715-754

Dikkers F, Nikkels P (1995): Benign lesions oft he vocal folds: histopathology and phonotrauma. Ann Otol Rhinol Laryngol 104, 698-703

Dikkers FG, Nikkels PGJ (1999): Lamina propria of the mucosa of benign lesions of the vocal folds. Laryngoscope 109, 1684-1689

Dikkers FG, Hulstaert CE, Oosterbaan JA, Cervera-Paz FJ (1993): Ultrastructural Changes oft he Basement Membrane Zone in Benign Lesions oft he Vocal Folds. Acta Otolaryngol $113,98-101$

Fränkel B (1889): Zur Histologie der Stimmbänder. Virchows Arch. path. Anat. 118, 370375

Gray SD (2000): Cellular physiology of the vocal fold. Otolaryngol Clin North Am $\underline{33}, 679$ 697

Gray SD (1997): Benign pathologic responses oft he larynx. Curr Opin Otolaryngol Head Neck Surg 5, 129-132

Gray SD, Titze IR, Alipour F, Hammond TH (2000): Biomechanical and histologic observations of vocal fold fibrous proteins. Ann Otol Rhinol Laryngol 109, 77-85

Gray SD, Titze IR, Chan R, Hammond TH (1999): Vocal Fold Proteoglycans and Their Influence on Biomechanics. Laryngoscope $\underline{109}, 845-854$

Hahn MS, Kobler JB, Starcher BC, Zeitels SM, Langer R (2006a): Quantitative and Comparative Studies of the Vocal Fold Extracellular Matrix I: Elastic Fibers and Hyaluronic Acid. Ann Otol Rhinol Laryngol 115, 156-164 
Hahn MS, Kobler JB, Zeitels MD, Langer R (2006b): Quantitative and Comparative Studies oft he Vocal Fold Extracellular Matrix II: Collagen. Ann Otol Rhinol Laryngol 115, 225232

Hajek M (1925): Beiträge zur Anatomie der Stimmlippen. Hals-, Nasen- Ohrenheilk 13, $161-172$

Hamacher S, Matern S, Roeb E (2004): Extrazelluläre Matrix - von der Grundlagenforschung zur klinischen Bedeutung. Dtsch Med Wochenschr 124, 1976-1980

Hammer SS (Hrsg.): Stimmtherapie mit Erwachsenen, 3. Auflage; Springer Verlag, Heidelberg 2007

Hammond TH, Zhou R, Hammond EH, Pawlak A, Gray SD (1997): The intermediate Layer: A Morphologic Study oft he Elastin an Hyaluronic Acid Constituents of Normal Human Vocal Folds. J voice 11 , 59-66

Hammond TH, Gray SD, Butler J, Zhou R, Hammond E (1998): Age- and gender-related elastin distribution changes in human vocal folds. Otolaryngol. Head Neck Surg $\underline{119}, 314$ 322

Hantzakos A, Remacle M, Dikkers FG, Degols JC, Delos M, Friedrich G, Giovanni A, Rasmussen N (2009): Exudative lesions of Reinke's space: a terminology proposal. Eur Arch Otorhinolaryngol 266, 869-878

Hirano M: Clinical examination of voice, Springer Verlag, Wien, New York 1981, 100

Hubmacher D, Apte SS (2013): The biology of the extracellular matrix: novel insights. Curr Opin Rheumatol 25, 65-70

Jacobson K, O’Dell D, Holifeld B, Murphy TL, August JT (1984): Redistribution of a Major Cell Surface Glycoprotein during Cell Movement. J Cell Biol 99, 1613-1623 
Jovanovic MB, Mulutinovic Z, Perovic J, Grubor A, Milenkovic S, Malobabic S (2007): Contact Telescopy Reveals Blood Vessel Alterations of Vocal Fold Mucosa in Reinke's Edema. J Voice 21, 355-360

Kahane JC (1987): Connective Tissue Changes in the Larynx and Their Effects on Voice. J Voice 1, 27-30

Kielty CM, Sherratt MJ, Shuttleworth CA (2002): Elastic fibres. J Cell Sci 115, 2817-2828

Kirsner RS, EaglsteinWH (1993): The wound healing process. Dermatologic Clin 11, 629_640

Kleinsasser O (1974): Mikrolaryngoskopie und endolaryngeale Mikrochirurgie. Teil II Rückblick auf 2500 Fälle. HNO 22, 69-83

Kleinsasser O: Mikrolaryngoskopie und endolaryngeale Mikrochirurgie. 3. Auflage; Schattauer-Verlag, Stuttgart 1991

Knöbber D (1994): Die Basalmembran bei Erkrankungen der Stimmlippen: Elektronenmikroskopische und immunmorphologische Befunde. Laryngo-Rhino-Otologie $\underline{73}, 642-646$

Korn GP, Martins JRM, Park SW, Mendes A, Kobayashi EY, Nader HB, Biase NGD (2012): Concentration of Hyaluronic Acid in Human Vocal Folds in Young and Old Subjects. Otolaryngology-Head and Neck Surgery $\underline{145}, 981-986$

Kreil G (1995): Hyaluronidases - A group of neglected enzymes. Protein Sci $\underline{4}$, 1666-1669

Lebl MDA, Martins JRM, Nader HB, Simões MJ, Biase ND (2007): Concentration and Distribution of Hyaluronic Acid in Human Vocal Folds. Laryngoscope 117, 595-599

Lee JY, Spicer AP (2000): Hyaluronan: a multifunctional, megaDalton, stealth molecule. Curr Opin Cell Biol 12, 581-586 
Lehmann W, Pampurik J, Guyot J-P (1989): Laryngeal Pathologies Observed in Microlaryngoscopy. Oto-Rhino-Laryngol 51, 206-215

Lemaître V, D’Armiento J (2006): Matrix Metalloproteinases in Development and Disease. Birth Defects Res C Embryo Today $\underline{78}, 1-10$

Marcotullio D, Magliulo G, Pezone T (2002): Reinke's Edema and Risk Factors: Clinical and Histopathologic Aspects. Am J Otolaryngol 23, 81-84

Mayet A (1955): Zur funktionellen Anatomie der menschlichen Stimmlippe, Z. Anat. $\underline{119}$, $87-115$

Mayet A (1961): Die morphologischen Grundlagen des Reinke`schen Stimmbandödems, Archiv für Ohren-Nasen-Kehlkopfheilkunde 177, 160-173

McKee CM, Lowenstein CJ, Horton MR, Wu J, Bao C, Chin BY, Choi AMK, Noble PW (1997): Hyaluronan Fragments Induce Nitric-oxide Synthase in Murine Macrophages

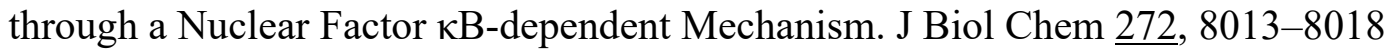

Melo ECM, Lemos M, Filho JAX, Sennes LU, Saldiva PHN, Tsuji DH (2003): Distribution of Collagen in the Lamina Propria oft the Human Vocal Fold. Laryngoscope $\underline{113}$, 21872191

Meyer K, Palmer JW (1934): The polysaccharide of the vitreous humor. J Biol Chem 107, $629-634$

Nawaka T, Hosemann W (2005): Gestörte Stimme, chirurgische Verfahren. Laryngo Rhino - Otol 84, Suppl 1, 201-212

Necas J, Bartosikova L, Brauner P, Kolar J (2008): Hyaluronic acid (hyaluronan): a review. Vet Med $\underline{53}, 397-411$ 
Neumann A, Schinzel R, Palm D Riederer P, Munch G (1999): High molecular weight hyaluronic acid inhibits advanced glycationendproduct-induced NF- $\mathrm{kB}$ activation and cytokine expression. FEBS Lett $\underline{453}$, 283-287

Ohkawara Y, Tamura G, Iwasaki T, Tanaka A, Kikuchi T, Shirato K (2000): Activation and Transforming Growth Factor- + Production in Eosinophils by Hyaluronan. Am J Respir Cell Mol Biol $\underline{23}, 444-451$

Ohno T, Hirano S, Rousseau B (2009): Age-Associated Changes in the Expression and Deposition of Vocal Fold Collagen and Hyaluronan. Otol Rhinol Laryngol 118, 735-741

Pastuzek P, Krecicki T, Zalesska-Krecicka M, Jelen M, Rak J, Krajewska B (2003): Histological and Electron Microscopic Investigation of Reinke's Edema. Pol J Pathol $\underline{54}$, 61-64

Prades JM, Dumollard JM, Duband S, Timoshenko A, Richard C, Dubois MD, Martin C, Peoc'h M (2010): Lamina propria oft he human vocal fold: histomorphometic study of collagen fibers. Surg Radiol Anat $\underline{32}, 377-382$

Probst R, Greves G, Iro H (Hrsg.): Hals-Nasen-Ohrenheilkunde. 3. Auflage; Thieme Verlag, Stuttgart 2008

Ramos HVL, Neves LR, Martins JRM, Nader HB, Pontes P (2012): Influence of aging on hyaluronic acid concentration in the vocal folds of female rats. Braz J Otorhinolaryngol $\underline{78}$, 14-18

Raabe J, Pascher W (1999): Das Reinke-Odem: Eine Untersuchung zu Fragender Atiologie, der Prognoseund der Wirksamkeittherapeutischer Interventionen. Laryngo-Rhino-Otol $\underline{78}$, 97-102

Reinke F (1895): Untersuchungen über das menschliche Stimmband, Fortschr Med $\underline{13}$, 469478 
Reinke F (1897): Über die funktionelle Struktur der menschlichen Stimmlippe mit besonderer Berücksichtigung des elastischen Gewebes, Anat Hefte 9, 103-115

Roberts T, Morton R, Al-Ali S (2011): Microstructure of the Vocal Fold in Elderly Humans. Clin Anat 24, 544-551

Rosen C, Simpson C: (Hrsg.) Operative Techniques in Laryngology. 1. Auflage; Springer Verlag, Berlin/Heidelberg 2008

Sake AS, Imamura R, Sennes LU, Tsuji DH, Mauad T, Saldiva PHN (2010): Elastic Fibers in Reinke's Edema. Ann Otol Rhinol Laryngol 119, 609-614

Sake F, Imamura R, Sennes L, Maud T, Saldiva P, Tsuji D (2008): Disarrangement of Collagen Fibers in Reinke`s Edema. Laryngoscope 118, 1500-1503

Sato K (1998): Reticular Fibers in the Vocal Fold Mucosa. Ann Otol Rhinol Laryngol 107, $1023-1028$

Sato K, Hirano M, Nakashima T (1999): Electron microscopic and immunohistochemical investigation of Reinkes`edema. Ann Otol Rhinol Laryngol 108, 1068-1072

Sato K, Hirano M, Nakashima T (2001): Fine Structure of the Human Newborn and infant Vocal Fold. Ann Otol Rhinol Laryngol 110, 417-424

Schade G, Hess M (2001): Flexible versus starre Laryngoskopie und Stroboskopie, unterschiedliche Befunde bei Stimmstörungen. HNO $\underline{49}, 562-568$

Schiebler TH, Korf HW (Hrsg): Anatomie: Histologie, Entwicklungsgeschichte, makroskopische und mikroskopische Anatomie, Topographie. 10. Auflage; Steinkopff Verlag, Heidelberg 2007

Schünke M, Schulte E, Schumacher U, Voll M, Wesker K (Hrsg.): Prometheus Lernatlas der Anatomie - Hals und Innere Organe. 1. Auflage; Thieme Verlag, Stuttgart 2005 
Schweinfurth JM, Thibeault SL (2008): Does Hyaluronic Acid Distribution in the Larynx Relate to the Newborn's Capacity for Crying? Laryngoscope 118, 1692-1699

Snoek van Beurden P A.M., Von den Hoff J W. (2005): Zymographic techniques for the analysis of matrix metalloproteinases and their inhibitors. Biotechniques $\underline{38}, 73-83$

Stern R, Jedrzejas MJ (2006): Hyaluronidases: Their Genomics, Structures, and Mechanisms of Action. Chem Rev 106, 818-839

Tateya T, Tateya I, Bless DM (2006): Collagen Subtypes in Human Vocal Folds. Ann Otol Rhinol Laryngol $\underline{115}, 469-476$

Tateya T, Tateya I, Bless DM (2007): Immuno-Scanning Electron Microscopy of Collagen Types I and III in human Vocal Fold Lamina Propria. Ann Otol Rhinol Laryngol 116, 156159

Thibeault SL (2005): Our understanding of the Reinke space. Curr Opin Otolaryngol Head Neck Surg $\underline{13}, 148-151$

Thibeault SL, Gray SD, Li W, Ford CN, Smith ME, Davis RK (2002): Genotypic and phenotypic expression of Vocal Fold Polyps and Reinke`s Edema: A preliminary study. Ann Otol Rhinol Laryngol 111, 302-309

Thibeault SL, Rousseau B, Welham NV, Hirano S Bless DM (2004): Hyaluronan Levels in Acute Vocal Fold Scar. Laryngoscope 114, 760-764

Tillmann B, Rudert H (1982): Licht- und elektronenmikroskopische Untersuchungen zum Reinke-Ödem, HNO 30, 280-284

Tillmann B, Rudert H, Schünke M, Werner J (1995): Morphological studies on the pathogenesis of Reinke's edema. Eur Arch Otorhinolaryngol 252, 469-474

Visse R, Nagase H (2003): Matrix Metalloproteinases and Tissue Inhibitors of Metalloproteinases: Structure, Function, and Biochemistry. Circ Res 92, 827-839 
Voelter C, Kleinsasser N, Joa P, Nowack I, Martinez R, Hagen R, Voelker HU (2008): Detection of hormone receptors in the human vocal fold. Eur Arch Otorhinolaryngol 265, 1239 1244

Volić SV, Klapan I, Seiwerth S, Ibrahimpašić T(2004) Extracellular matrix of reinke space in some pathological conditions. Acta Otolaryngol 124, 505-508

Ward PD, Thibeault SL, Gray SD (2002): Hyaluronic Acid: Ist Role in Voice. J Voice 16, 303-309

Woessner JF (1994): The family of Matrix Metalloprotinases. Ann N Y Acad Sci $\underline{732}$, 1121 


\section{Danksagung}

Mein besonderer Dank gilt meinen Betreuerinnen, Frau Dr. med. Perske und Frau PD Dr. med. Völter, die mir das Thema bereitstellten und mich während meiner Promotionsarbeit betreuten und anleiteten.

Weiterhin bedanke ich mich bei Herrn Professor Dr. med. Heinz-Joachim Radzun, der mir die Möglichkeit einräumte, meine Promotionsarbeit in seinem Institut zu absolvieren.

Weiterer Dank gebührt dem gesamten Laborteam, insbesondere Herrn Rolf Kleinhans und Herrn Axel Stange, die mir bei der experimentellen Durchführung mit Rat und Tat zur Seite standen, sowie Frau Anke Klages und Nicole Putzer für die aufgebrachte Zeit und stetige Geduld, mich in die molekularbiologischen Methoden einzuarbeiten.

Zudem gilt mein Dank der Klinik für Hals-Nasen-Ohrenheilkunde der Georg-August-Universität Göttingen, besonders Herrn Prof. Dr. Olthoff, für die Bereitstellung von Patientendaten und -gewebe aus dem entsprechenden Krankengut.

Danken möchte ich auch noch Frau Dr. Imme Haubitz für die Unterstützung bei der Durch-führung der statistischen Analysen. 